\title{
3 Konjunkturen der Entwicklungspolitik: Tansania und die beiden deutschen Staaten
}

Als Tanganjika im Dezember 1961 die Unabhängigkeit von Großbritannien erlangte, waren die Beziehungen zur DDR und der BRD, den beiden Nachfolgestaaten der ehemaligen deutschen Kolonialmacht, lose und punktuell. Nur zehn Jahre später hatte Tansania einen Status als Schwerpunktland der BRD-,,Entwicklungshilfe“ sowie der DDR-Außenpolitik und blickte bereits auf zahlreiche geplante, initiierte, durchgeführte und gescheiterte Projekte zurück. ${ }^{1}$ Bis zum Ende der DDR 1990 waren die beiden deutschen Staaten entwicklungspolitisch in Tansania aktiv. Über den Zeitraum von 1961 bis 1985 gerechnet lag Tansania in der Rangliste afrikanischer Empfängerstaaten von BRD-Entwicklungshilfe auf Platz 3 (Finanzhilfe) bzw. Platz 2 (Technische Hilfe). ${ }^{2}$ In Relation zur Größe der Bevölkerung hatte die BRD nur für Israel mehr Mittel aufgewendet. ${ }^{3}$ Die DDR hielt sich ab 1970 mit materiellem Engagement zwar zurück, zählte Tansania aber weiterhin zur Riege der strategisch wichtigen Staaten. Tansania stellt damit einen Ausnahmefall dar, sowohl was den zeitweiligen Schwerpunktstatus in beiden deutschen Staaten als auch was die Kontinuität der Beziehungen bis 1990 angeht. Dieses Kapitel zeichnet die Dynamik der entwicklungspolitischen Beziehungen und der Personalentsendung im breiteren Kontext nach und zeigt anhand von Beispielen die strukturellen Charakteristika und Grenzen der Transfers auf.

Die „Entwicklungshilfe“ der BRD und die „sozialistische Hilfe“ der DDR gingen aus verschiedenen Systemen hervor, sie entstanden aber im selben Zeitraum und bildeten ähnliche Transfermodi aus, um auf dem globalen entwicklungspolitischen Feld handlungs- und konkurrenzfähig zu sein. Vier Phasen lassen sich in der Konjunktur der Entwicklungspolitik unterscheiden. ${ }^{4}$ Die erste Phase von 1958 bis 1964 stand im Zeichen der Dekolonisierung weiter Teile Afrikas und war geprägt von der Emergenz entwicklungspolitischer Strukturen und Netzwerke. Tansanische und deutsche AkteurInnen streckten auf dem globalen Feld der Entwicklungspolitik ihre Fühler aus, um eigene Interessen zu verfolgen

1 Dietrich Kebschull, FRG and GDR in the Third World, in: Intereconomics 5 (1971), S. 158-160, hier: S. 160. BRD und DDR konzentrierten ihre entwicklungspolitischen Aktivitäten 1971 auf 12 bzw. 13 Länder.

2 Schulz, Development Policy in the Cold War Era, S. 117-118.

3 Köhler, Zum Stellenwert Tanzanias, S. 21-22.

4 Diese Periodisierung stützt sich, mit einigen Anpassungen für den spezifischen Fall Tansanias, auf die Einteilung der Afrikapolitik der BRD und DDR in Engel/Schleicher, Die beiden deutschen Staaten.

Ә OpenAccess. (C) 2021 Eric Burton, publiziert von De Gruyter. (cc) BY Dieses Werk ist lizenziert unter der Creative Commons Attribution 4.0 International Lizenz. https://doi.org/10.1515/9783110705621-006 
und neue Allianzen zu schließen. Zwischen 1964 und 1970 führte die deutschlandpolitische Konkurrenz zu einer Phase der hyperpolitisierten „Entwicklungshilfe“. Während die DDR in Sansibar mit Personalentsendungen und Großprojekten eine Präsenz wie wohl in keinem Land zuvor oder danach erlangte, versetzte eine diplomatische Krise den Beziehungen zwischen der BRD und Tansania einen Dämpfer. Der Hintergrund war hier der Widerstand Nyereres gegen eine politische Instrumentalisierung von „Hilfe“. Unter Willy Brandts Ostpolitik und im Kontext des globalen Tauwetters zwischen USA und Sowjetunion gelang die beidseitige Wiederannäherung. In der Phase der friedlichen Koexistenz von 1970 bis 1977 unterstützte die BRD eine Vielzahl von Großprojekten in Tansania, um Ujamaa zum Erfolg zu verhelfen. Die Unterstützung führte jedoch gleichzeitig zu einer höheren Abhängigkeit und Verschuldung. Die DDR verfolgte ihre politischen Interessen, vor allem den Zugang zu den in Tansania ansässigen Befreiungsbewegungen, weitgehend durch Personalentsendung. In der Phase der Konvergenz von 1977 bis 1990 wurden sowohl in den deutschen Staaten als auch in Tansania Debatten zwischen zwei Gruppen ausgetragen, von denen die erste makroökonomischen und die zweite sozio- und entwicklungspolitischen Motiven Vorrang einräumte. Während die DDR zunehmend wirtschaftliche Interessen verfolgte (ohne dabei politische Kriterien aufzugeben), verlegte sich die Bonner Regierung schließlich auf die Wiederbelebung antikommunistischer Rhetorik und eine politische Konditionalisierung der „Entwicklungshilfe“.

\subsection{Emergenz: Kontaktarbeit und die Institutionalisierung der Entwicklungspolitik in BRD und DDR, 1958-1964}

Während die DDR Beziehungen zu Ländern wie Tanganjika und Sansibar genauso wie spezialisierte Organisations- und Wissensformen fast vom Nullpunkt aufbauen musste, konnte die BRD auf bereits bestehende Kontakte und Institutionen zurückgreifen. Ostafrikanische Akteure, insbesondere die Führungsfiguren von Gewerkschaften, Parteien und Befreiungsbewegungen, waren seit der spätkolonialen Zeit aktiv auf der Suche nach Ressourcenquellen und Bündnispartnern, sodass es sich hier um gegenseitige Annäherungen handelte. Während die DDR dabei durch eine antiimperialistische Haltung zu punkten versuchte, wagten bundesdeutsche Diplomaten einen Balanceakt zwischen dem Mythos kolonialer Unbeflecktheit einerseits und dem Eingehen auf afrikanische Strategien, aus der geteilten kolonialen Vergangenheit Verantwortung und Ressourcentransfers abzuleiten, andererseits. Obwohl das Bündnis mit den anderen Westmächten bzw. mit der Sowjetunion immer einen wichtigen Handlungsrahmen darstellte, waren die beiden deutschen Staaten keinesfalls nur Surrogate der Supermächte, son- 
dern verfolgten eigene Strategien und setzten eigene Schwerpunkte. Im Falle beider Staaten wurden die ersten Beziehungen unterhalb der diplomatischen Ebene geknüpft; insbesondere die Etablierung von Ausbildungskanälen schien den beteiligten Parteien dabei zentral, um ihre jeweiligen Interessen zu verfolgen.

\section{Von Deutsch-Ostafrika zur Entwicklungshilfe}

Mehrere Wurzeln der staatlichen Entwicklungspolitik der BRD liegen in nichtstaatlichen Bereichen. In den ersten vier Jahren nach 1945, als Innen- und Außenpolitik noch von den Besatzungsmächten bestimmt wurden, lag es vor allem an nicht-staatlichen Akteuren, Verbindungen in die außereuropäische Welt aufzubauen. Der BRD gelang es dank weitgehend intakter Industriekapazitäten und mithilfe des Marshallplans, sich schon im Nachkriegsjahrzehnt wieder als Wirtschaftsmacht und Exportnation zu etablieren. So konnten Export- und Handelsfirmen, kirchliche Missionswerke und wissenschaftliche Institute an bereits vorhandene Überseekontakte anknüpfen und die außenpolitische Präsenz der BRD direkt oder indirekt vorbereiten. ${ }^{5}$ Auch einige kolonialrevisionistische Gruppen bestanden fort oder erneuerten sich, darunter etwa die Gesellschaft der Freunde Afrikas, die 1952/53 gegründet wurde und 1958 in der offiziösen Deutschen AfrikaGesellschaft aufging. Diese Gruppierungen zeigen exemplarisch den Übergang von völkisch-rassistisch geprägten Kolonialforderungen zur Einpassung in den Entwicklungsdiskurs der Nachkriegszeit, gerade die Afrika-Gesellschaft „etablierte sich rasch als der rührigste und öffentlichkeitswirksamste Lobbyist für eine deutsche Anteilnahme an der weiteren Entwicklung Afrikas““. ${ }^{6}$ Viele der kolonialen Kontinuitätslinien brachen allerdings, was personelle und institutionelle Verflechtungen anging, ab. In innenpolitischer Hinsicht resultierte die Institutionalisierung der staatlichen Entwicklungspolitik eher aus dem Druck der westdeutschen Exportwirtschaft und der Kirchen, dem Engagement des Bun-

5 Dieter Danckwortt, Die Anfänge der Entwicklungspolitik in der Bundesrepublik Deutschland in den fünfziger Jahren und die Weichenstellungen für die folgenden Jahrzehnte - Ursache und Wirkung, in: Manfred Glagow, Hg., Deutsche und internationale Entwicklungspolitik: Zur Rolle staatlicher, supranationaler und nicht-regierungsabhängiger Organisationen im Entwicklungsprozeß der Dritten Welt, Opladen 1990, S. 13-17, hier: S. 13

6 Dirk van Laak, Imperiale Infrastruktur. Deutsche Planungen für eine Erschliessung Afrikas 1880 bis 1960, Paderborn 2004, S. 357, 367. Viele der kolonialen Biographien führten jedoch nicht in den Entwicklungshilfesektor sondern „liefen aus“; ebd., S. 371, 376. 
destags sowie koalitionspolitischen Motiven. ${ }^{7}$ Der Marshallplan war ebenfalls ein wichtiger Vorläufer. ${ }^{8}$

Das entwicklungspolitische Feld der BRD bildete sich innerhalb etwas eines Jahrzehnts als „spezialisiertes Subsystem“ mit „eigenen Handlungslogiken“, spezifischen Akteurs- und Zielgruppen und fachlichen Standards heraus. ${ }^{9}$ Die Etablierung der staatlichen Entwicklungshilfe in den 1950er Jahren verlief jedoch vorerst nur stockend. Ab 1952 nahm die BRD am technischen Hilfsprogramm der Vereinten Nationen teil, widmete Haushaltsmittel 1956 erstmals spezifisch für Hilfe und beauftragte 1957 die Garantie-Abwicklungs-Gesellschaft (GAWI) mit der Expertenentsendung. Erste Zielländer der westdeutschen „Technischen Hilfe“ waren Ägypten und Indien. Ab Beginn der 1950er Jahre beteiligte sich die BRD, meist unter Federführung des Auswärtigen Amts und des Bundesministeriums für Wirtschaft, sporadisch an entwicklungspolitischen Interventionen und Transfers. Erst 1961 wurde ein eigenes Ministerium mit entwicklungspolitischem Auftrag gegründet: das Bundesministerium für wirtschaftliche Zusammenarbeit (BMZ). Das bedeutete eine Kristallisierung der Entwicklungspolitik, wie sie sich in diesen Jahren auch in der Gründung staatlicher Entwicklungsagenturen und -ministerien bzw. der Umwidmung von Kolonialministerien anderer westlicher Länder zeigte. ${ }^{10}$ In personeller und institutioneller Hinsicht jedoch war das BMZ ein Erbe des Marshallplan-Ministeriums; Beamte wandten bereits vertraute „Techniken der internationalen Zusammenarbeit“ wie Kredit- und Gegenwertprogramme an nur dass sich die BRD vom Empfänger zum Geber wandelte. ${ }^{11}$ Die Kreditanstalt für Wiederaufbau (KfW) wurde ebenfalls von einer Institution des Marshallplans zur Abwicklung von Entwicklungshilfe umfunktioniert. Dementsprechend ist auch

7 Aram Ziai, Globale Strukturpolitik? Die Nord-Süd-Politik der BRD und das Dispositiv der Entwicklung im Zeitalter von neoliberaler Globalisierung und neuer Weltordnung, Münster 2007, S. 95-96.

8 Heide-Irene Schmidt, Pushed to the Front: The Foreign Assistance Policy of the Federal Republic of Germany, 1958 - 1971, in: Contemporary European History 12/4 (2003), S. 473 - 507, hier: S. $474-476,478-480$.

9 Ziai, Globale Strukturpolitik, S. 103-104.

10 Die hagiographische Perspektive zeigt Markus Porsche-Ludwig, 50 Jahre BMZ: Von Entwicklungshilfe über Entwicklungspolitik bis zur Entwicklungszusammenarbeit, in: Wolfgang Gieler, Hg., 50 Jahre deutsche Entwicklungszusammenarbeit: Das BMZ von Walter Scheel bis Dirk Niebel, Bonn 2011, S. 247-263.

11 Interview mit Heinz Esche (ehemaliger BMZ-Beamter), 13.9.2014, Seeheim-Jugenheim. Unter den Leitungen befanden sich auch ehemalige NSDAP-Mitglieder; siehe Michael Bohnet, Geschichte der deutschen Entwicklungspolitik. Strategien, Inhalte, Zeitzeugen, Herausforderungen, Konstanz 2015, S. 37-40; Schmidt, Pushed to the Front, S. 485-487; van Laak, Imperiale Infrastruktur, S. 361. 
die Entwicklungshilfe für Tanganjika, ungeachtet der anderen ökonomischen Voraussetzungen und im Vergleich verschwindend geringen Transfers, bisweilen als „Marshallplan“ bezeichnet worden. ${ }^{12}$ Finanzhilfe ${ }^{13}$, Technische Hilfe (in Verschränkung mit Bildungshilfe ${ }^{14}$ ) und Humanitäre Hilfe wurden zu den wichtigsten und institutionell weitgehend separat stehenden Eckpfeilern der westlichen Entwicklungshilfe. Der Technischen Hilfe wurde dabei, wie die Formel „Keine Mark ohne deutschen Mann“ verdeutlichte, konzeptuell die Priorität vor Finanzhilfe eingeräumt. Es galt die Annahme, dass erst der Transfer von Wissen die Bedingungen schaffen würde, in denen Kapitalhilfe wirksam sein könnte. ${ }^{15}$ Außerdem hatte die Entsendung von ExpertInnen immer auch die Funktion, die „sachgerechte“ Verwendung zugesagter Mittel zu kontrollieren. ${ }^{16}$ Auf Tanganjika (und später Tansania), wo die „Manpower-Lücke“ noch vor Kapital- und Devisenknappheit als entscheidendes „Entwicklungshemmnis“ gesehen wurde, traf diese Sichtweise für mindestens zwei Jahrzehnte $\mathrm{zu}^{17}$

Die Kontakte zwischen der BRD und Tanganjika intensivierten sich Ende der 1950er-Jahre und ganz besonders 1960/61, als TANU-PolitikerInnen bereits das self-government auf innenpolitischer Ebene übernommen hatten. Diese Kontakte entstanden jedoch kaum mit der Bundesregierung, sondern mit gesellschaftlichen Gruppen und Institutionen, die sich allesamt darum bemühten, entwicklungspolitische Maßnahmen auch zu ihren Gunsten zu beeinflussen. Deutsche „Pflanzer“ und Siedler, die sich nach dem Zweiten Weltkrieg (z.T. wieder) in Tanganjika niedergelassen hatten, traten ebenso wie Privatfirmen an staatliche

12 Hessisches Hauptstaatsarchiv Wiesbaden (HHStAW), 507, 10498, Bd. 1, Lückel (Geschäftsführendes Vorstandsmitglied der Gesellschaft für Berufsförderung in Afrika e.V.), Bericht über eine Informationsreise zum Studium der Förderungsmaßnahmen auf dem Gebiet der gewerblichen Berufsausbildung in Tanganyika, 26.-28.2.1961, S. 7.

13 Die Kreditbedingungen der Finanzhilfe waren variabel, wobei aber günstiger als Kredite auf dem Kapitalmarkt. Schmidt, Pushed to the Front, S. 498-499.

14 Die Bildungshilfe wird mitunter als Teil der Technischen Hilfe verstanden, funktionierte aber auch oft als eigenständiger Teil ohne Anbindung an spezifische Projekte. So wurden z.B. in Abkommen über die „Technische Zusammenarbeit“ auch allgemeine Festlegungen zur Aus- und Fortbildung sowie Studien gemacht.

15 BArch Koblenz, B 102/212635, Bericht über eine internationale DSE-Tagung 1965 über Entwicklungshilfe in Großbritannien und in Deutschland 18.-20.10.1965, Bonn, 15.11.1965, S. 4.

16 Hansjörg Elshorst, Organisation und Entwicklung - Zum System der deutschen Entwicklungspolitik, in: Manfred Glagow, Hg., Deutsche und internationale Entwicklungspolitik: Zur Rolle staatlicher, supranationaler und nicht-regierungsabhängiger Organisationen im Entwicklungsprozeß der Dritten Welt, Opladen 1990, S. 19-34, hier: S. 26; Theo Rauch, Entwicklungspolitik. Theorien, Strategien, Instrumente, Braunschweig 2009, S. 40 - 41.

17 Heinz Wirth, Aspekte des Zusammenhangs von Entwicklungshilfe und Entwicklungsplanung in Tansania, Dissertation, Bonn 1985, S. 138-139. 
Stellen in Tanganjika und der BRD heran, um Exportgeschäfte, Ausbildungsprogramme oder politische Kontakte einzufädeln. ${ }^{18}$ Sozialdemokratische Politiker und Beamte in Hessen versuchten ebenfalls, Kontakte zu Nyerere herzustellen, betonten allerdings - wohl, um weder das Auswärtige Amt noch Großbritannien zu verärgern oder zu hohe Ansprüche auf der Gegenseite auszulösen - dass sie als Privatpersonen handeln würden. Schon 1958 knüpften sozialdemokratische Führungsfiguren wie Ministerpräsident Helmut Zinn persönliche und wirtschaftliche Bindungen gen Ghana und Nigeria. Der Staatssekretär des Hessischen Ministeriums für Wirtschaft und Verkehr, Friedrich Wilhelm Reuss, lernte Nyerere bei dessen Besuch in Wiesbaden im Jahr 1958 kennen. Im Februar 1960 knüpfte er an dieses Treffen an, offerierte Nyerere hessische Ausbildungshilfe für Tanganjika und drängte, diese schon vor der Unabhängigkeit und der offiziellen Aufnahme diplomatischer Beziehungen anzunehmen, um „Rückschläge“ wie in Guinea,dass sich nach dem Unabhängigkeitsreferendum und dem folgenden Bruch durch Frankreich 1958 dem sowjetischen Lager zugewendet hatte, zu vermeiden. Schließlich fügte er hinzu: „I am not acting in any official capacity, but I am interested in these matters solely as a friend of Africa“. ${ }^{19}$ Im Juni 1961 antwortete Reuss auf das Ansuchen eines deutschen Siedlers (der seit 1926 als Pflanzer in Tanganjika tätig war und laut eigener Aussage gute Kontakte zu Nyereres Bruder Joseph Nyerere und dem Außenminister Oscar Kambona unterhielt), Hessen möge zehn Stipendien für Krankenschwester-Ausbildungen bereitstellen, wobei man „keine Privataktionen machen“ dürfe, sondern dem Bildungsminister Kambona die Auswahl der Stipendiatinnen überlassen müsse. ${ }^{20}$ Getragen von den Motiven, Exportmärkte für hessische Unternehmen zu erschließen und Tanganjika vom sowjetischen Lager fernzuhalten, träumte der hessische Landtagsabgeordnete Olaf Radke davon, das System bundesdeutscher Verwaltung auf das unabhängige Tanganjika oder gar ganz Afrika zu übertragen. ${ }^{21}$

In missionarischen Kontexten bildeten sich neue Vereine unter Stichworten wie Berufsausbildung und Entwicklungshilfe, womit bereits länger etablierte Tätigkeiten in einen neuen Kontext gestellt und von staatlicher Seite subventioniert werden sollten. So legte etwa die Gesellschaft für Berufsförderung in Afrika

18 HHStAW, 507, 10497, Bd. 1, Reuss (StS Hess. Ministerium für Wirtschaft und Verkehr) an Voigt, o.O., 3.6.1961; ebd., Bildungsminister Kambona an StS Reuss, Dar es Salaam, 2.5.1961.

19 HHStAW, 507, 10497, Bd. 1, Reuss an Nyerere, 10.2.1960.

20 Ebd., Reuss an Voigt, 3.6.1961; Kambona an Reuss, Dar es Salaam, 2.5.1961. Kambona hatte sich bereits im Mai bei Reuss gemeldet, um diese Stipendien in Anspruch nehmen zu können. 21 Ebd., Hess. Landtagsabgeordneter Radke an Hess. Ministerpräsident Zinn, Frankfurt/Main, 25.7.1961; ebd., Holzer (Frankfurter Rundschau) an Barth (Hess. Ministerium für Wirtschaft und Verkehr), Frankfurt/Main, 24.2.1960. 
e. V., die mit der seit 1886 tätigen Evangelischen Missionsgesellschaft für DeutschOstafrika (Bethel Mission) zusammenhing, im Februar 1961 einen Bericht vor, in dem als erstes „Projekt“ eine Handwerkerschule im Norden Lushotos vorgestellt wurde. Dieses sei geleitet von Heinrich Waltenberg, der sich seit dreißig Jahren in Tanganjika befinde und „als erster Weißer durch die selbstständige afrikanische lutherische Kirche von Usambara-Digo zum Präsidenten gewählt wurde“.22 So erhielten Referenzen auf afrikanische Selbstständigkeit selbst auf persönlicher Ebene neue Bedeutung. Gleichzeitig wurden Netzwerke zwischen Deutschen in Tanganjika und verschiedenen Stellen in Deutschland - jedoch ausschließlich in der BRD, nicht in der DDR - erneuert.

Tanganjika ist mit dieser Melange aus staatlichen, privatwirtschaftlichen und kirchlichen Interessen kein unübliches Beispiel für die Beziehungen zwischen der BRD und Afrika in den Jahren um 1960, die bei allen Divergenzen durch einen antikommunistischen und entwicklungspolitischen Konsens untereinander oft anschlussfähig waren. Dazu gehörten selbst Kooperationsvorschläge aus Kreisen von Kolonialveteranen, die Afrika in eine „kontinentale Großraumwirtschaft“ einzubinden gedachten. ${ }^{23}$ Zur tatsächlichen Etablierung und Expansion des entwicklungspolitischen Instrumentariums der BRD trugen jedoch wie erwähnt in erster Linie kirchlich geprägte Lobbygruppen in der BRD sowie der Druck der USA und anderer Bündnispartner, mehr Entwicklungshilfe $\mathrm{zu}$ leisten, bei. ${ }^{24}$ Die außenpolitischen Leitlinien aus Bonn, die den Spielraum entwicklungspolitischer Maßnahmen in diesen Jahren absteckten, waren vom Blockdenken und deutschlandpolitischer Rivalität geprägt: Die Position des Westens sollte gestärkt, „östliche Infiltration“ abgewehrt und die diplomatische Anerkennung der DDR verhindert werden. ${ }^{25}$ Die wirtschaftliche Potenz der BRD führte in Verbindung mit dem Ziel, die Anerkennung der DDR und die Ausbreitung des Kommunismus zu verhindern, zur viel zitierten „Gießkannenpolitik“. Mit der breiten Streuung von Ressourcen auf möglichst viele Länder - bis Mitte der 1960er-Jahre waren es bereits 72 - sollte ein möglichst flächendeckender außenpolitischer Loyalitäts-

22 HHStAW, 507, 10498, Bd. 1, Lückel, Bericht über eine Informationsreise zum Studium der Förderungsmaßnahmen auf dem Gebiet der gewerblichen Berufsausbildung in Tanganyika, 26.28.2.1961, S. 32.

23 Van Laak, Imperiale Infrastruktur, 401. Entsprechende Vorstellungen über europäisch-afrikanische Wirtschaftsräume oder sogar politische Verbände waren bis Mitte der 1960er Jahre noch weit verbreitet in Westeuropa; zumal auch manche afrikanische Eliten auf diese ungleichen Allianzen setzten, um Ressourcenflüsse und Stabilität zu gewährleisten. Siehe Cooper, Africa since 1940, Kap. 3.

24 Schmidt, Pushed to the Front.

25 Ulf Engel/Hans-Georg Schleicher, Die beiden deutschen Staaten in Afrika. Zwischen Konkurrenz und Koexistenz, 1949-1990, Hamburg 1998, S. 155. 
effekt erzielt werden, der zur weiteren diplomatischen Isolation der DDR beitragen sollte. ${ }^{26}$

Da 1961 alle anderen ostafrikanischen Länder noch Kolonial- und Protektoratsstatus besaßen, kam Tanganjika zum Zeitpunkt der Unabhängigkeit eine wegweisende Bedeutung in der Region zu. Die ersten Verhandlungen über Entwicklungshilfe waren noch vor der Unabhängigkeit im September 1961 geführt worden; im Zeitraum bis 1964 war die BRD die drittgrößte Gebernation. Zur Unabhängigkeitsfeier am 9. Dezember 1961 verkündete CDU-Politiker Kai-Uwe von Hassel (1913-1997, zu diesem Zeitpunkt Ministerpräsident von Schleswig-Holstein) die Vergabe bundesdeutscher Kredite und Technischer Hilfe für Projekte an Tanganjika. ${ }^{27}$ Von Hassels Biografie zeigt exemplarisch die Kontinuitäten von der Kolonialherrschaft des Deutschen Reiches zur bundesdeutschen Entwicklungshilfe der 1960er-Jahre sowie den Übergang von kolonialrevisionistischen Positionen $\mathrm{zu}$ entwicklungspolitischen und wirtschaftszentrierten Diskursen. ${ }^{28}$ KaiUwe von Hassels Vater, Theodor von Hassel (1868-1935), war Pflanzer, Hauptmann der Schutztruppen in Deutsch-Ostafrika und Befehlshaber während der größten Schlacht des Maji-Maji-Kriegs Ende August 1905 gewesen. Sein Sohn KaiUwe von Hassel wurde 1913 noch in Deutsch-Ostafrika geboren, absolvierte in der Zwischenkriegszeit eine Ausbildung für Überseeaktivitäten und war von 1935 bis zu seiner Ausweisung durch die Briten 1940 als Pflanzungskaufmann in Tanganjika tätig. Als Vertreter der deutsch-ostafrikanischen „Landsmannschaft“ und der „Deutsch-Ostafrikanischen Gesellschaft“ war er auch nach dem Zweiten Weltkrieg hervorragend vernetzt und stellte eine Brücke zwischen der Politik und der kolonialnostalgisch-entwicklungspolitischen Lobby dar. Er sprach fließend Swahili und konnte ein exzellentes Verhältnis zu Julius Nyerere aufbauen, das beiden Seiten Einflussmöglichkeiten gab. Nyerere sollte von Hassel in den kommenden Jahren nutzen, um diplomatische Spannungen abzubauen (siehe unten). In der BRD trieb von Hassel die entwicklungspolitische Institutionalisierung voran. Als zentrale Figur für die 1963 erfolgte Gründung der Deutschen Entwicklungsgesellschaft (DEG) versuchte er, die losen Entwicklungshilfestrukturen zu bündeln und mit wirtschaftlichen Interessen zu verschmelzen. Die DEG förderte

26 Bohnet, Geschichte, 39-40.

27 Von Hassels Inszenierung von Zusagen glich dabei der üblichen Praxis in dieser Zeit. Hochrangige westdeutsche Politiker reisten „,vor Ort“ und verkündeten die Übergabe ganzer Pakete von Krediten, Technischer Hilfe und Hermes-Garantien (staatliche Garantien für Exportkredite). Ein besonders eifriger Hilfsreisender war Bundespräsident Heinrich Lübke, „during his state visits he liked to give away aid almost like candy“ schreibt William Glenn Gray, Germany's Cold War. The global campaign to isolate East Germany, 1949-1969, Chapel Hill 2003, S. 121.

28 Biografische Informationen aus: van Laak, Imperiale Infrastruktur, S. 367. 
bundesdeutsche Privatinvestitionen in allen als „Entwicklungsländern“ klassifizierten Staaten und beteiligte sich in folgenden Jahren auch an Firmen in Tanganjika bzw. Tansania wie etwa der halbstaatlichen Tanganyika Development Finance Company (TDFC), die in fast allen Wirtschaftssektoren des Landes Anteile hielt.

Von Hassel schwieg über die Gräuel des Maji Maji-Krieges, die sein Vater mit zu verantworten hatte. Das war durchaus symptomatisch für die zwischenstaatlichen Beziehungen. Die heiklen Aspekte der Kolonialvergangenheit wurden in der gegenseitigen Annäherung ausgeblendet und infrastrukturelle Investitionen der Kolonialzeit auch von tansanischer Seite als neutrale technologische Errungenschaften hervorgehoben. Anfang der 1960er Jahre wusste man im Auswärtigen Amt durchaus um die Gräuel der deutschen Kolonialherrschaft in Tanganjika und kam daher zum Schluss, dass ein Anknüpfen an das koloniale Erbe nicht angebracht sei; das Afrikareferat des Auswärtigen Amtes sah die BRD 1959 widersprüchlicherweise aber auch als „kolonial unbelastete[s]“ Land, dem eine „natürliche Vermittlerrolle“ zwischen (aktuellen) Kolonialmächten und Afrika zukomme. ${ }^{29}$ Anlassweise wurde die geteilte koloniale Vergangenheit dennoch als verbindendes Element hervorgehoben. In der BRD wie in Tanganjika wurde das gemeinsame historische Erbe als Legitimationsgrund zur Intensivierung der Beziehungen herangezogen. Laut einer internen Expertise der BRD aus dem Jahr 1961 habe Nyereres Regierung besondere Unterstützung vonseiten der BRD erwartet, da Tanganjika ein deutsches Schutzgebiet gewesen war und zudem die deutsche Kolonialverwaltung von „Afrikanern“ in der Gegenwart höher bewertet werde als die britische. ${ }^{30}$ Das Umschiffen kontroverser Themen und die Kultivierung eines geteilten Geschichtsbildes mit blinden Flecken waren im beidseitigen Interesse, die staatlichen und wirtschaftlichen Beziehungen auszubauen.

In der BRD selbst herrschte während der Wirtschaftswunderjahre eine Zukunftsorientierung, in der eine kritische Aufarbeitung der Kolonialvergangenheit keinen Platz hatte. Vereinzelt deuteten tansanische Diplomaten, etwa der Botschafter in Bonn, die Kolonialherrschaft für ein westdeutsches Publikum Mitte der 1960er Jahre gar in „freundschaftliche Bande“ um, an die es anzuknüpfen gelte, da die „Wurzeln der Wertschätzung“ für die BRD „bis in die Zeit deutscher Ko-

29 Zit. nach Ulf Engel, Die Afrikapolitik der Bundesrepublik Deutschland 1949-1999. Rollen und Identitäten, Hamburg 2000, S. 40, 118-120. Zu Versuchen, von der „kolonialen Unbelastetheit“ politischen und wirtschaftlich zu profitieren, siehe auch Christian Kleinschmidt/Dieter Ziegler, Hg., Dekolonisierungsgewinner: Deutsche Außenpolitik und Außenwirtschaftsbeziehungen im Zeitalter des Kalten Krieges, Berlin 2018.

30 Röhnelt, Die bundesdeutsche Entwicklungshilfe, S. 39. 
lonialherrschaft in Ostafrika“ zurückreichten. ${ }^{31}$ Auch tansanische InterviewpartnerInnen, die in GTZ-Projekten gearbeitet hatten, zogen 2014 Kontinuitätslinien von der Kolonialzeit in die Gegenwart. Besonders häufig tauchte die entpolitisierende und verharmlosende Umdeutung vom Kolonialismus zur „Kooperation“ bei der Frage auf, warum die BRD ab den 1970er-Jahren ihre Maßnahmen auf die Tanga-Region konzentrierte. Mehrere InterviewpartnerInnen vermuteten, dass kolonialnostalgische Gefühle eine wichtige Rolle gespielt hatten: Tanga sei sentimentale Heimat der Deutschen, Wilhelmstal (das heutige Lushoto) in den Usambarabergen hatte einst Deutsch-Ostafrikas Hauptstadt werden sollen, und auch in den 1970er Jahren lebten noch bzw. wieder einige deutsche SiedlerInnen und Missionare dort. ${ }^{32}$ Es gibt auch Anhaltspunkte, dass Nyerere es verstand, in vertraulichen Gesprächen mit Bundesdeutschen deren Nostalgie und rühriges Verantwortungsgefühl in entwicklungspolitische Ressourcentransfers umzumünzen. ${ }^{33}$ Während positive Bezugnahmen auf die Kolonialzeit in den bilateralen Beziehungen eine erstaunliche Beständigkeit aufweisen, waren sie in der Ära der Dekolonisierung auf internationaler Ebene inopportun.

Die Bekundung von Solidarität für die nach Unabhängigkeit strebenden Länder war infolge der afro-asiatischen Bandung-Konferenz 1955 wichtiges symbolisches Kapital auf dem Feld der globalen Politik. ${ }^{34}$ Beide deutsche Staaten bemühten sich daher ab Ende der 1950er-Jahre verstärkt um eine Abgrenzung vom kolonialen Diskurs und stilisierten sich selbst zu Verbündeten der gerade unabhängig gewordenen Staaten. Auf BRD-Seite betonte man, im Gegensatz zu Frankreich oder Großbritannien keine unmittelbare Vergangenheit als Kolonialmacht zu haben. Andererseits hoben Vertreter beider deutscher Staaten hervor, dass sie den USA bzw. der UdSSR „zu Dank verpflichtet“ waren und aufgrund der erfahrenen Unterstützung nun auch anderen Ländern Unterstützung zuteilwerden lassen wollten. ${ }^{35}$ BRD-Politiker nutzten den Kolonialbegriff antikommunistisch gewendet für außen- und deutschlandpolitische Zwecke und stellten die

31 So der tansanische Botschafter Kahama in der BRD, zit n. HHStAW, 507/11328, Wiesbadener Tagesblatt, „Hessen - ein Freund in der Not“, 5.11.1965. Siehe auch BArch Koblenz, B 213/7672, BRD-Botschaft an AA, Dar es Salaam, 9.8.1969, S.11.

32 Diese Vermutung findet sich bei Lizz Lyle Kleemeier, Integrated Rural Development in Tanzania: The Role of Foreign Assistance, 1972-1982, PhD Thesis, Berkeley 1984, S. 31.

33 Interview \#80, Tansanischer Landwirtschaftsexperte. Vgl. auch Interview \#27, GTZ-Projektleiter, der einen BfE-Mitarbeiter zitiert, der die Aussage wiederum von Eppler persönlich gehört habe: „Der Nyerere meinte die Deutschen müssten uns doch eigentlich mal wieder zeigen, wie man Entwicklung macht und so, und Tanga ist doch eine traditionell deutsche Provinz, sollen doch die Deutschen Tanga machen.“

34 Go, Global Fields, 216-218.

35 Schulz, Development Policy, 8-9. 
Analogie zu einem neuen „kommunistischen Kolonialismus“ her, der „seit zehn Jahren auch die Mittelzone Deutschlands“ sowie Osteuropa unterdrücke und nunmehr die „farbigen Völker der Welt“ bedrohe. ${ }^{36}$

Gleichzeitig stand die BRD - worauf die DDR immer wieder hinwies - in einem NATO-Bündnis mit den Kolonialmächten Portugal, Großbritannien und Frankreich und unterhielt enge Wirtschaftsbeziehungen mit Südafrika. Tatsächlich positionierte sich die Bundesregierung durch ihre Einbindung in das westliche Bündnis in Konfliktfällen eher auf der Seite der Metropolen als auf Seite der (Ex-)Kolonien. In Verhandlungen mit Ländern wie Tanganjika hatten die Interessen der Bündnispartner Vorrang vor den Interessen der „Entwicklungsländer“. Bisweilen sprachen sich westdeutsche Diplomaten vor Verhandlungen mit Tanganjika sogar mit ihren „Verbündeten“ aus Großbritannien oder Frankreich ab, um die Einflusssphären abzustecken. ${ }^{37}$ So sicherten hochrangige Vertreter aus Außenpolitik und Wirtschaftsministerium dem Central African Office in London zu, „in ehemals britischen Gebieten“ nicht tätig zu werden, „ohne die britische Auffassung zu den jeweiligen Problemen zu kennen“. ${ }^{38}$ Damit wurde die Verhandlungsmacht der Metropole erhöht und die Manövrierfähigkeit Tanganjikas verringert. Als Großbritannien und Tanganjika 1963 etwa über die Modalitäten des Abzugs der Kolonialbeamten verhandelten, ging die BRD nicht auf Gesuche von Nyereres Regierung für Personalentsendungen ein. ${ }^{39}$ Gleichzeitig konkurrierten die westlichen Länder jedoch auch um politischen Einfluss und den Zugang zu Märkten, sodass derartige Absprachen selten blieben und noch seltener völlig eingehalten wurden. ${ }^{40} \mathrm{Im}$ Gegensatz zur DDR war die BRD aber bereits in den

36 FDP-Abgeordneter Becker, Rede über Leitfragen Außenpolitik, Dekolonialisierung und Kolonialisierung durch den Kommunismus, Beratung des Antrags der Fraktion der SPD betrf. Genfer Außenministerkonferenz der Vier Mächte (Drucksache 1723), 2. Deutscher Bundestag-115. Sitzung. Bonn, Freitag, den 2. Dezember 1955, 6178. http://dip21.bundestag.de/dip21/btp/02/02115. pdf (Zugriff: 13.3.2017). Ich danke Clemens Pfeffer für den Hinweis auf dieses Zitat.

37 Siehe hierzu z.B. die Aufzeichnungen über Konsultationen mit Großbritannien in BArch Koblenz, B 102/212635. Die USA sprachen sich mit Kolonialmächten ebenfalls ab und bezogen noch abhängige Gebiete nicht in die Vergabe von Entwicklungshilfe ein. Siehe hierzu Corinna R. Unger, The United States, Decolonization, and the Education of Third World Elites, in: Jost Dülffer/ Marc Frey, Hg., Elites and Decolonization in the Twentieth Century, Houndmills 2011, S. 241-261, hier: S. 244.

38 BArch Koblenz, B 102/212635, Besprechung im Central African Office über Fragen der wirtschaftlichen und politischen Entwicklung in den noch abhängigen Gebieten Zentralafrikas am 19.11.1963, Bonn, 25.11.1963.

39 Ebd.

40 So zeigen Fallstudien über Algerien und die Côte d'Ivoire die Konkurrenz zwischen Frankreich und den USA und Erfolge der afrikanischen Regierungen, aus der Konkurrenz entstehende Manövrierräume zu nutzen: Bamba, African Miracle; Byrne, Mecca of Revolution. 
1960er-Jahren in multilaterale Organisationen mit entwicklungspolitischen Funktionen eingebunden, allen voran die Bretton Woods-Institutionen, aber auch Vorläuferorganisationen der Europäischen Union und die OECD mit ihrem 1960 einberufenen entwicklungspolitischen Koordinationsorgan, dem Development Assistance Committee (DAC).

Die DDR denunzierte die Entwicklungshilfe des Westens als Instrument neokolonialer Einflussnahme und wies auf die Inkohärenz zwischen Entwicklungshilfe einerseits und vermeintlich ausbeuterischen Wirtschaftsbeziehungen andererseits hin. ${ }^{41}$ Die Kritik musste sich schon deswegen auf wirtschaftliche Expansionsstrategien richten, weil die Bundesregierung außenpolitisch behutsam agierte und offen kolonialrevisionistischen Kreisen kein Forum bot. ${ }^{42}$ Die wirtschaftlichen Intentionen in der Vergabe von Entwicklungshilfe wurden jedoch nicht verschwiegen. Der erste Minister des BMZ Walter Scheel (1961-1966, FDP) wünschte sich Entwicklungshilfe als „Pre-Investment für privatwirtschaftliche Investitionen“, während sein Nachfolger Hans-Jürgen Wischnewski (1966-1968, SPD) „Märkte für morgen schaffen“ wollte. Als „Rose ohne Dornen“, wie Kanzler Adenauer die Entwicklungshilfe bezeichnete, hatte das BMZ auch in späteren Jahrzehnten einen schwachen Stand gegenüber anderen Ressorts, insbesondere dem Auswärtigen Amt und dem Wirtschaftsministerium, und musste sich nach seiner Gründung eine eigene Handlungslogik erst erarbeiten. ${ }^{43} 1967$ waren 50\% der gesamten westdeutschen Entwicklungshilfekredite daran gebunden, die zugesagten Mittel an BRD-Firmen zurückfließen zu lassen; viele Kredite wurden auch ohne vertragliche Bindung zum Kauf in der BRD genutzt. ${ }^{44}$ Schon 1960 hatten SPD- und FDP-Politiker kritisiert, dass bundesdeutsche Unternehmen oft die einzigen Profiteure von Instrumenten waren, die unter dem Begriff der Entwicklungshilfe ins Leben gerufen worden waren. ${ }^{45}$ Zwischen den verschiedenen entwicklungspolitischen Instrumenten und anderen Sektoren gab es immer wieder Verflechtungen; so konnten Entwicklungshilfemaßnahmen etwa privatwirtschaftliche Investitionen flankieren, was auch in Tanganjika bzw. Tansania häufiger der Fall war. ${ }^{46}$ Eine eindeutige Trennung von „Wirtschaft“ und „Hilfe“ war zu keinem Zeitpunkt gegeben; in den 1970er Jahren wurde dann zunehmend

41 Reinhard Stockmann u.a., Entwicklungspolitik. Theorien-Probleme-Strategien. Lehr- und Handbücher der Politikwissenschaft, München 2010, S. 351-353.

42 Van Laak, Imperiale Infrastruktur, S. 355; Anselm Doering-Manteuffel, Die Bundesrepublik Deutschland in der Ära Adenauer, Darmstadt 1988.

43 Konrad Adenauer, zit. nach Ziai, Globale Strukturpolitik, S. 96.

44 Köhler, Mittler zwischen den Welten, S. 131-133.

45 Schmidt, Pushed to the Front, S. 501-503; Gray, Germany's Cold War, S. 118.

46 Wirth, Aspekte, S. 131-132. 
auch aus akademischen Kreisen die Kritik vorgebracht, die Entwicklungspolitik sei nicht mehr als Exportförderung und ein Instrument des „D-Mark-Imperialismus".47

\section{Die Bundesrepublik im unabhängigen Tanganjika}

Tanganjika bzw. Tansania war jedoch weder „als Rohstofflieferant noch als Absatzmarkt für deutsche Erzeugnisse von vorrangiger Bedeutung“.48 Mit Ausnahme weniger Schlüsselländer wie Südafrika, Ägypten und Nigeria war das für den afrikanischen Kontinent insgesamt der Fall, insbesondere wenn makroökonomische Import- und Exportstatistiken als Gradmesser herangezogen werden. ${ }^{49}$ Quantitative Indikatoren allein sind allerdings ungenügend und teils irreführend, da sie die damaligen akteursspezifischen Erwartungshorizonte und Argumentationsmuster ausblenden. ${ }^{50}$ Die Erwartungshaltungen angesichts des prognostizierten Wachstumspotenzials in afrikanischen Ländern übertrafen regelmäßig die reelle Bedeutung. Außerdem war das Handelsvolumen aus Sicht Tanganjikas höchst signifikant. Die BRD als wirtschaftsstärkstes Land Europas spielte für Nyereres Regierung eine zentrale Rolle, um die Außenhandelsbeziehungen zu diversifizieren und so die Abhängigkeit von Großbritannien zu verringern. Bis in die Mitte der 1960er-Jahre wurde die BRD, wenngleich mit immer noch deutlichem Abstand zu Großbritannien, Tansanias zweitwichtigster Außenhandelspartner. ${ }^{51}$

47 Dirk Messner, Entwicklungspolitik als globale Strukturpolitik, in: Thomas Jäger u.a., Hg., Deutsche Außenpolitik: Sicherheit, Wohlfahrt, Institutionen und Normen, 2., aktualisierte und erw. Aufl., Wiesbaden 2011, S. 414-442, hier: S. 421; Siehe auch Schulz/Hansen, Aid sowie Klaus Bodemer, Entwicklungshilfe - Politik für wen? Ideologie und Vergabepraxis der deutschen Entwicklungshilfe in der 1. Dekade, München 1974; Klaus Bodemer, Programmentwicklung in der Entwicklungspolitik der Bundesrepublik Deutschland, in: Franz Nuscheler, Hg., Dritte-Welt-Forschung, Opladen 1985, S. 277-309.

48 Wirth, Aspekte, S. 109.

49 Rolf Hofmeier, Aid from the Federal Republic of Germany to Africa, in: The Journal of Modern African Studies 24/4 (1986), S. 577-601, hier: S. 577.

50 So heißt es in einem dependenztheoretischen Text über die Kontinuität imperialer Beziehungen bei einem Wechsel von kolonialen zu neokolonialen Beziehungen zwischen der BRD und Afrika: „The African continent is enormously important to the West German economy, despite the fact that this is not necessarily reflected by official statistics for trade and investment." Brigitte Schulz/William Hansen, Aid or Imperialism? West Germany in Sub-Saharan Africa, in: The Journal of Modern African Studies 22/2 (1984), S. 287-313, hier: S. 311.

51 7,6\% (Großbritannien: 30,2\%) der Exporte Tansanias gingen in die BRD, 8,2\% (GB: 32,3\%) der Importe stammten von dort. Wirth, Aspekte, S. 37. 
Westdeutsche Regierungsvertreter nutzten dieses ökonomische Gewicht, um die entwicklungspolitischen Transfers von den wirtschaftlichen Beziehungen abhängig zu machen und Vereinbarungen nach eigenen (d.h. einerseits national und andererseits westlich orientierten) ordnungspolitischen Vorstellungen durchzusetzen. Die Klärung wirtschaftspolitischer Fragen ging Entwicklungshilfeverhandlungen üblicherweise voraus, d.h. erst wenn die wirtschaftspolitischen Streitpunkte ausgeräumt waren, kamen entwicklungspolitische Angebote auf den Tisch. $^{52}$ Die 1962 geschlossenen Abkommen über Technische Hilfe und Kapitalhilfe ${ }^{53}$ wurden von der BRD erst unterzeichnet, nachdem eine Vereinbarung über Handel und Wirtschaft,in der beide Regierungen versicherten, von Diskriminierung im Waren-, Dienstleistungs-, Kapital- und Zahlungsverkehr abzusehen, zustande gekommen war. ${ }^{54}$ Außerdem machte die BRD (wie auch im Fall anderer ostafrikanischer Länder) die Entwicklungshilfevergabe von der Gewährung der Landerechte an die Lufthansa abhängig. ${ }^{55}$ Ein Investitionsschutzabkommen folgte 1965. Dies weist auf formelle und informelle Konditionalitäten hin, die durch das Machtgefälle zwischen den verhandelnden Parteien festgeschrieben wurden; gleichzeitig zeigt die Abfolge, dass das BMZ dem Wirtschaftsministerium in der Ressorthierarchie nach- und untergeordnet war. Der BRD ging es in wirtschaftlicher Hinsicht in erster Linie um Einflusssicherung und die Durchsetzung marktwirtschaftlicher Ordnungsprinzipien im globalen Maßstab. Hinzu kamen weitere Motive, u.a. Tanganjika als „Ausbildungsstätte und Erfahrungsquelle für Wissenschaftler aus der Bundesrepublik“ sowie zur Entwicklung neuer Pharmazeutika zu nutzen. ${ }^{56}$

Bis 1964 hatte die Präsenz der BRD in Tanganjika unübersehbare Ausmaße angenommen. Militär-, Finanz- und Technische Hilfe sicherten der BRD politi-

52 Am intensivsten natürlich während drei spezifischer Phasen: Nach der Unabhängigkeit Tanganjikas zum Aufbau wirtschaftlicher Beziehungen (hier hatte das BMZ aber ohnehin noch eine sehr eingeschränkte Verhandlungsautonomie gegenüber den anderen Ministerien), nach der Deklaration von Arusha und der folgenden Verstaatlichung von Betrieben, Banken und Versicherungen sowie ab Mitte der 1980er Jahre im neoliberalen Reformdiskurs. Siehe u.a. die Dokumente in BArch Koblenz, B 102/86572; ebd., B 213/48193, Technical College Arusha, Summary Record of the Tanzanian-German Government Negotiations on Economic Cooperation from 20 to 22 January 1987.

53 Röhnelt, Die bundesdeutsche Entwicklungshilfe, S. 41

54 Ebd., S. 43.

55 Die ostafrikanischen Länder Uganda, Tanganjika und Kenia waren zu dieser Zeit noch in einer gemeinsamen Luftfahrtbehörde zusammengeschlossen. BArch Koblenz, B 213/7661, Berater der Regierung in Finanzfragen 1964-1970, Ministerialrat Dr. Karl Erdmann (BMWi) an Dr. Liebig (GAWI), Bonn, 13.4.1964.

56 BArch Koblenz, B 213/33011, Geuting an GAWI, Dar es Salaam, 18.5.1964, S. 10. 
schen und wirtschaftlichen Einfluss. Die wichtigsten Projekte mit westdeutscher Beteiligung waren im Agrar- und Bildungsbereich angesiedelt: Eine landwirtschaftliche Versuchs- und Lehranstalt in Ifakara (Zentraltansania), eine Landwirtschaftsschule in Nyegezi (Nordwesttansania), ein Veterinärforschungslabor in Dar es Salaam und das College of Business Education in Arusha (Nordtansania) waren die personell wie finanziell aufwändigsten Vorhaben. Der Deutsche Entwicklungsdienst, gegründet 1963, schickte seine allerersten EntwicklungshelferInnen nach absolvierter Vorbereitung nach Tanganjika. Einige von ihnen arbeiteten in einem Wohnbauprogramm (Slum Clearing) in Dar es Salaam, das ein direktes Konkurrenzprojekt zum Wohnungsbau der DDR in Sansibar wurde. 46 Experten, 36 EntwicklungshelferInnen, 9 Marineberater und eine 15 Mann starke Luftwaffenberatergruppe befanden sich Anfang 1965 im Rahmen von Militär- und Technischer Hilfe in Tansania. ${ }^{57}$

Hinzu kamen hochrangige Regierungsberater. Mitte 1962 bat Nyerere die Regierungen vier westlicher Länder sowie des blockfreien Jugoslawiens um die Entsendung von „Chefberatern“ für ihn als Premierminister - ein weiterer Schritt, um den britischen Einfluss zu verringern und die internationalen Beziehungen zu diversifizieren. ${ }^{58}$ Die BRD entsandte als Antwort auf dieses Ansuchen den auf Landwirtschaft spezialisierten Volkswirt Horst Geuting, der schnell ein Vertrauensverhältnis zu Nyerere aufbauen konnte. ${ }^{59}$ Zwei weitere Regierungsberater entsandte die BRD, nachdem Finanzminister Paul Bomani um Ersatz für zwei ausgeschiedene englische Staatssekretäre gebeten hatte; schließlich bekam auch der Industrieminister einen bundesdeutschen Berater. ${ }^{60}$ Die Regierungsberater wurden im Rahmen des Technische Hilfe-Abkommens entsandt und zeichneten sich dadurch aus, dass sie - was vonseiten der politischen Elite Tanganjikas zu dieser Zeit auch gewünscht war - offensiv für eine „freiheitliche Wirtschaftspolitik und zielstrebige wirtschaftliche Entwicklung des Landes“ eintraten. ${ }^{61}$

\section{DDR und Dekolonisierung}

Während die DDR-Beziehungen zu den bereits unabhängigen westafrikanischen Ländern Guinea und Ghana in den späten 1950er-Jahren an Fahrt aufnahmen, entwickelten sich die Kontakte mit dem spätkolonialen Tanganjika nur punktuell.

57 BArch Koblenz, B 102/68167, Liste deutscher Experten in Tansania, o.O., o.D. [1965].

58 BArch Koblenz, B 213/33011, Schoeller (BRD-Botschaft) an AA, Dar es Salaam, 28.7.1962.

59 BArch Koblenz, B 213/33011, Geuting, Bericht Nr. 1, Dar es Salaam, 25.6.1963.

60 BArch Koblenz, B 102/121668, Schroeder (BRD-Botschaft) an AA, Dar es Salaam, 24.1.1964. 61 BArch Koblenz, B 213/33011, Geuting, Bericht Nr. 1, Dar es Salaam, 25.6.1963, S. 4. 
Vor 1960 hatte die DDR keinerlei Verbindung zu Julius Nyerere aufbauen können und wollen. Die TANU galt aufgrund ihrer westlichen Kontakte in der ČSSR als Partei von „Kollaborateuren“; in der Sowjetunion kritisierte man den Reformismus der „bourgeoisen“ TANU-Führung, die in einem Missverhältnis zum revolutionären Willen des Volkes stehe. ${ }^{62}$ Diese Einschätzung war noch an der stalinistischen Zwei-Lager-Theorie orientiert, die auch die DDR-Führung bis Mitte der 1950er-Jahre davon abgehalten hatte, Beziehungen gen Asien und Afrika aufzubauen. Der Zwei-Lager-Theorie zufolge waren die Anführer nationalistischer Befreiungsbewegungen und postkolonialer Staaten nur Anhängsel des Imperialismus. Dieser Blick war nach Stalins Tod 1953 und dem zunehmenden Bedeutungsgewinn postkolonialer Staaten in diplomatischen Foren wie der UN aber einer Einschätzung gewichen, die Befreiungsbewegungen und den neu entstehenden Staaten eine potenziell progressive, wenn auch nicht gänzlich eigenständige Rolle im Geschichtsprozess zugestand. ${ }^{63}$ Der Antiimperialismus der Dritten Welt galt nun als Verbündeter, auch wenn er von nicht-kommunistischen Organisationen getragen wurde. ${ }^{64}$ Die antikolonialen Befreiungsbewegungen galten in dieser Perspektive neben den Staaten des „sozialistischen Weltsystems“ und der internationalen Arbeiterbewegung unter Führung der kommunistischen Parteien als einer der drei „revolutionären Hauptströme“, die das globale Kräfteverhältnis zugunsten des Sozialismus verschieben würden.

Nyereres konziliante Haltung gegenüber der Kolonialmacht Großbritannien schien selbst mit dieser Theorie jedoch schwer vereinbar. Der Kontakt zu Nyerere war zudem bis in die letzten Jahre der Fremdherrschaft durch die britische Abschirmung erschwert worden, so wurde z.B. einem sowjetischen Diplomaten ein Einreisevisum verweigert. ${ }^{65}$ Hofierte die DDR in den späten 1950er-Jahren noch vor allem die Bandung-Staaten wie Ägypten, Indien und Indonesien, so lag der Fokus ab 1960 zunehmend auf afrikanischen Ländern, derer siebzehn in diesem Jahr die Unabhängigkeit erlangten. 1960 gab das Politbüro des SED-Zentralkomitees Weisung, mit möglichst vielen der gerade unabhängig gewordenen oder

62 Jan Dvorácek u. a., A History of Czechoslovak Involvement in Africa. Studies from the Colonial Through the Soviet Eras, Lewiston 2014, S. 91; Klaus Lüders, Tansania in der Sicht der Sowjetunion. Eine Studie zur sowjetischen Schwarzafrika-Politik, Hamburg 1978, S. 33-35.

63 Müller, Bildungshilfe, 15-17.

64 Bastian Hein, Die Westdeutschen und die Dritte Welt. Entwicklungspolitik und Entwicklungsdienste zwischen Reform und Revolte 1959-1974, München 2006, S. 19.

65 Kilian, Die Hallstein-Doktrin, S. 188-189. 
werdenden afrikanischen Länder zwischenstaatliche Beziehungen herzustellen. ${ }^{66}$ Hauptziel der „Anerkennungsdiplomatie“67 war jedoch - und gerade in dieser Hinsicht hatte die DDR ein spezifisches nationales Eigeninteresse - aus der politischen Isolation auszubrechen. Vielversprechende Annäherungsversuche wie 1958 in Guinea und 1960 in Kongo-Léopoldville waren vorerst daran gescheitert, dass die afrikanischen Länder die Entwicklungshilfe der finanzstarken BRD bevorzugten, selbst wenn sie die Ressourcentransfers mit Einbußen in der außenpolitischen Entscheidungsfreiheit begleichen mussten. ${ }^{68}$ So wirkten Erwartungen und Transfers auf dem Feld der Entwicklungspolitik auch auf die Außenpolitik zurück.

Wirtschaftlich kalkulierende DDR-Planer äußerten jedoch selbst in dieser Phase der außenpolitischen Offensive Bedenken, den Systemwettstreit auf dem globalen Feld der Entwicklungspolitik auszutragen und Mittel dafür bereitzustellen. Sie gaben schließlich nur unter dem Druck der Sowjetunion und politischer Eigeninteressen nach. ${ }^{69}$ Die Wirtschaftskraft der DDR, ohnehin beschränkt angesichts der schmalen Rohstoffbasis, war durch die Demontage von Industrieanlagen und Reparationszahlungen für die Sowjetunion im ersten Nachkriegsjahrzehnt strapaziert worden. ${ }^{70}$ An einen umfassenden Schuldenerlass, wie ihn die BRD 1953 aushandeln konnte, war nicht zu denken. Der Ausbau der Schwerindustrie führte $\mathrm{zu}$ erheblichen Produktionssteigerungen und etablierte die DDR als zweite Wirtschaftsmacht im RGW, ging jedoch auf Kosten der Konsumgüterindustrie und des Dienstleistungssektors. ${ }^{71}$ Die wirtschaftliche Lage der

\footnotetext{
66 Hans-Georg Schleicher, Afrika in der Außenpolitik der DDR, in: Ulrich van der Heyden u.a., Hg., Die DDR und Afrika: Zwischen Klassenkampf und neuem Denken, Münster 1993, S. 10 - 30, hier: S. 11.

$67 \mathrm{Zu}$ Anerkennungsdiplomatie siehe Werner Kilian, Die Hallstein-Doktrin. Der diplomatische Krieg zwischen der BRD und der DDR 1955-1973. Aus den Akten der beiden deutschen Außenministerien, Berlin 2001, S. 171-214; Ulrich van der Heyden, „I Will Not Recognise East Germany Just Because Bonn Is Stupid“: Anerkennungsdiplomatie in Tansania, 1964 bis 1965, in: Ulrich van der Heyden/Franziska Benger, Hg., Kalter Krieg in Ostafrika: Die Beziehungen der DDR zu Sansibar und Tansania, Berlin 2009, 9-30.

68 Gray, Germany's Cold War, S. 110; Winrow, The Foreign Policy of the GDR in Africa, 62-65; Schleicher, Afrika in der Außenpolitik der DDR, S. 10.

69 Lorenzini, Dilemmas, S. $70-71$.

70 Hermann Weber, Die DDR 1945-1990, 5., aktualisierte Auflage, München 2012, S. 38; André Steiner, Von Plan zu Plan. Eine Wirtschaftsgeschichte der DDR, München 2004, 19-34. Auch „intellektuelle Reparationen“ hatte die DDR zu leisten, etwa mit der Entsendung von Fachkräften wie Flugzeugingenieuren in die Sowjetunion. Siehe Rainer Karlsch, „Weltniveau“. Spitzenleistungen in Technik und Produktion?, in: Thomas Großbölting, Hg., Friedensstaat, Leseland, Sportnation? DDR-Legenden auf dem Prüfstand, Berlin 2009, S. 22-49, hier: S. 32.
}

71 Weber, Die DDR, S. 38. 
DDR verbesserte sich bis zum Anfang der 1960er-Jahre zwar, aber gerade die Devisennot blieb ein Faktor, der das außenpolitische Austeilen von „Geschenken“ analog zur westlichen Entwicklungshilfe einschränkte. ${ }^{72}$ So erklärt sich zu einem guten Teil die anfängliche Konzentration auf die Vergabe von Stipendien einerseits und die Personalentsendung, die in den 1950er-Jahren zuerst nach China, Nordkorea und Albanien führte, andererseits. ${ }^{73}$

Chancenlos, mit der Exportmacht BRD in materieller Hinsicht zu konkurrieren, argumentierten DDR-VertreterInnen, dass die westliche Entwicklungshilfe Abhängigkeiten konsolidiere und zur politischen Beeinflussung diene, während die eigenen Praktiken auf genuiner Partnerschaft beruhen und tatsächlichen Fortschritt erlauben würden. ${ }^{74}$ In Abgrenzung zur „Inkohärenz“ der westlichen Entwicklungshilfe, die nur die Ausbeutung durch den Imperialismus alimentieren und stabilisieren würde, beanspruchte die DDR für sich, dass die verschiedenen Ressorts unter Parteiführung nach gleichen Zielvorstellungen handelten und ihre Praktiken sich demnach nicht widersprachen. ${ }^{75}$ Die DDR-Entwicklungspolitik basierte auf der Annahme, dass die Herstellung einer gerechteren Gesellschaftsordnung und die Befreiung vom (Neo-)Kolonialismus - also Sozialismus und Dekolonisierung - zwei Seiten derselben Medaille darstellten. ${ }^{76}$ In historischer Hinsicht exterritorialisierte die DDR das koloniale Erbe des Deutschen Reiches in die BRD und stellte sich in eine Kontinuitätslinie mit dem Antikolonialismus der Arbeiterbewegung im Deutschen Reich bzw. der Weimarer Republik, deren Initiativen zu Vorläufern der nationalen Befreiungskämpfe nach dem Zweiten Weltkrieg stilisiert wurden. ${ }^{77}$

\section{Wege in die kommunistische Welt}

Konkrete Bezüge und biografische Verflechtungen entstanden insbesondere durch die Nachfrage der Unabhängigkeitsbewegungen für Bildungsangebote. Die

72 Gray, Germany's Cold War, S. 124.

73 Elidor Mëhilli, Socialist Encounters: Albania and the Transnational Eastern Bloc in the 1950s, in: Patryk Babiracki/Kenyon Zimmer, Hg., Cold War Crossings: International Travel and Exchange across the Soviet Bloc, 1940s-1960s, Arlington 2014, S. 107-133.

74 Hans-Georg Schleicher, Entwicklungszusammenarbeit und Außenpolitik der DDR, in: HansJörg Bücking, Hg., Entwicklungspolitische Zusammenarbeit in der Bundesrepublik Deutschland und der DDR, Berlin 1998, S. 95-110.

75 Spanger/ Brock, Die beiden deutschen Staaten, S. 84.

76 Schleicher, Entwicklungszusammenarbeit.

77 Gareth M. Winrow, The Foreign Policy of the GDR in Africa, Cambridge 2009, S. 34-35. 
DDR war gemeinsam mit anderen kommunistischen Ländern und Finnland eines der Stiftungsländer für den Mitte der 1950er eingerichteten Stipendienfonds des Internationalen Studentenbundes, der die Ausbildung junger Menschen finanzierte, „die auf Grund kolonialer und neokolonialistischer Praktiken keinerlei Zugang zu einer Hochschulbildung hatten bzw. haben“. ${ }^{78}$ Hinzu kamen direkte Kontakte zwischen Vertretern von DDR-Organisationen und antikolonialen Aktivisten in Drittstaaten. So kamen ab den späten 1950er-Jahren vereinzelt Personen aus Sansibar und Tanganjika für Studienaufenthalte in die DDR, oft über Kairo, das zu dieser Zeit (wie wenig später Dar es Salaam) Refugium und Schaltstelle für zahlreiche afrikanische Unabhängigkeitsbewegungen wie die Zanzibar Nationalist Party (ZNP) war und als Drehkreuz zwischen „Ost“, „West“ und „Süd“ fungierte. $^{79}$

Anstelle von Nyerere oder anderen TANU-PolitikerInnen empfing die DDR noch vor der Unabhängigkeit Nyereres größten innenpolitischen Gegenspieler Zuberi Mtemvu, der seine eigene Partei gegründet hatte und international um Unterstützung warb. Das Beispiel Mtemvus zeigt deutlich, dass die Verbindungen in diesen Jahren keinesfalls nur auf das Interesse der DDR zurückgingen; sie waren gleichermaßen Ausdruck der Globalisierungs- und Diversifizierungsstrategien von Akteuren aus Tanganjika und Sansibar. Mtemvu war bereits Jahre vor der Unabhängigkeit aus der TANU ausgetreten und hatte 1958 den African National Congress (in keiner direkten Verbindung zum südafrikanischen ANC stehend) in Tanganjika gegründet. Im Gegensatz zu Nyerere vertrat Mtemvu mit der Unterstützung gewerkschaftlicher Kreise Positionen wie die sofortige völlige „Afrikanisierung“ aller wichtigen Posten und den Ausschluss aller nicht-afrikanischen Gruppen von politischen Aktivitäten. In einem Brief an den Freien Deutschen Gewerkschaftsbund (FDGB) der DDR belegte Mtemvu, dass er gut über die außenpolitischen Interessen der DDR informiert war und gelobte, diese bei einem Erfolg seinerseits zu unterstützen. ${ }^{80}$ Als Mtemvu im Frühjahr 1961 durch Osteuropa tourte, warnte er in einer Rede an der Karl-Marx-Universität Leipzig vor

78 „Was sind ISB-Stipendien?“, in: Forum 19 (1981), zit. nach Roland Wiedmann, Probleme der Studienfinanzierung in der Deutschen Demokratischen Republik, in: Hans F. Illy/Wolfgang Schmidt-Streckenbach, Hg., Studenten aus der Dritten Welt in beiden deutschen Staaten, Berlin 1987, S. 149-157, hier: S. 153.

79 Matthes, Zur Entwicklung, S. 57. Siehe auch detaillierter Kap. 4 sowie Eric Burton, Hubs of Decolonization. African Liberation Movements and Eastern Connections in Cairo, Accra and Dar es Salaam, in: Lena Dallywater/Helder A. Fonseca/Chris Saunders, Hg., Southern African Liberation Movements and the Global Cold War „East“: Transnational Activism 1960-1990, Berlin 2019, S. 25-56.

80 SAPMO BArch Berlin, DY 34/2504, Mtemvu an Fischer, o.O., 10.11.1961. 
Nyerere: „When so many praises are sung about a nationalist in the capitalist metropoles then you know that in the leader you may have another TSHOMBE!“*81 Moïse Tshombé, der mit westlicher Unterstützung die Sezession des rohstoffreichen Katanga vom Kongo verfolgt hatte und an der Ermordung Patrice Lumumbas beteiligt gewesen war, fungierte als personifizierter Verrat im Dienste des Imperialismus (im Übrigen auch für Nyerere selbst, der Tshombé wiederholt scharf verurteilte). Funktionäre des FDGB und der SED, ebenso wie Stimmen aus der Sowjetunion, sahen jedoch die TANU im Gegensatz zum ANC immer noch die „Einheitsfront“, die in dieser historischen Phase notwendig wäre, und enthielten sich jeglicher Unterstützung für Mtemvu und seinen ANC, dem jegliche Massenbasis fehle. ${ }^{82}$

DDR-Akteuren ging es in den Bemühungen um die Gunst der TANU und die Regierung Tanganjikas letztlich nicht um bilaterale Beziehungen, sondern um Tanganjika als Tor zur Region und den Befreiungsbewegungen im Exil. Im September 1961, zwei Monate vor der Unabhängigkeit Tanganjikas, gab die SEDFührung den Aufbau von Beziehungen mit Tanganjika als Ziel aus, „damit die Kontakte zu den Befreiungsbewegungen Ostafrikas von Dar es Salaam aus verbessert werden können“.83 Wenn die DDR ihre proklamierten außenpolitischen Positionen - Antiimperialismus und Antirassismus - glaubhaft und effektiv vertreten und Beziehungen zu Befreiungsbewegungen aufbauen wollte (um sozialistische Kräfte zu stärken, aber auch um die eigene diplomatische Anerkennung zu erreichen), war eine Präsenz in Dar es Salaam unerlässlich. ${ }^{84}$ Ähnlich war man in der Tschechoslowakei an TANU und Nyerere vor allem interessiert, um Kontakte zu kongolesischen und mosambikanischen Befreiungsbewegungen $\mathrm{zu}$ knüpfen, sodass kurz darauf ein Konsulat in Dar es Salaam eröffnet wurde. ${ }^{85} \mathrm{Da}$ Tanganjika seine Rolle im Befreiungskampf und in regionalen politischen Fragen wie auch der Blockfreienbewegung in den folgenden Jahren noch weiter ausbauen konnte, blieb das DDR-Interesse bestehen.

Weitere institutionelle, aber in der Regel nach wie vor nicht-staatliche Kontakte zwischen Tanganjika und der DDR entwickelten sich auf Geheiß des SEDZentralkomitees Anfang der 1960er-Jahre über transnationale Organisationen wie den sowjetisch dominierten Weltgewerkschaftsbund, den Internationalen Studen-

81 Zit. nach Brennan, Julius Rex, S. 467-479; Bjerk, Julius Nyerere, S. 95.

82 SAPMO BArch Berlin, DY 34/2504, Anmerkung [über den ANC], o.D. [1961]; Lüders, Tansania, S. $33-35$.

83 SAPMO BArch Berlin, DY 30 / IV 2/20/53, Plan für die Entwicklung der Beziehungen der DDR zu afrikanischen Ländern südlich der Sahara für 1962, 13.9.1961, Fol. 194.

84 Engel/Schleicher, Die beiden deutschen Staaten, S. 178.

85 Philip Muehlenbeck, Czechoslovakia in Africa, 1945-1968, New York 2016, S. 41. 
tenbund und die Internationale Demokratische Frauenförderation. ${ }^{86}$ Einige der Gewerkschafter, Studenten und Sprachlehrer, die in dieser Zeit die DDR besuchten, bekleideten in späteren Jahren Regierungsämter oder wichtige Posten in der Verwaltung und wurden zu wichtigen Anlaufstellen und Fürsprechern der DDR. Dazu zählte etwa der sansibarische Gewerkschafter Ahmed Badawi Quallatein, der einen Lehrgang beim FDGB absolvierte und die DDR später mit Informationen über die politische Lage im postrevolutionären Sansibar versorgte. Auf dem Festland wurde Stephen Mhando, der während seines Aufenthalts als SwahiliLehrer an der Karl-Marx-Universität Leipzig eine DDR-Bürgerin geheiratet hatte, zu einem wichtigen Kontakt. Als Journalist und Herausgeber der Parteizeitungen Uhuru und The Nationalist sowie der Gewerkschaftszeitung Mfanyakazi verantwortete er zahlreiche Artikel im Geiste der DDR-Außenpolitik und bemühte sich nach seiner Ernennung zum Außenminister 1968 durch Nyerere um bessere Beziehungen $\mathrm{zu}$ den Staaten des sowjetischen Lagers. ${ }^{87}$ In der ersten Hälfte der 1960er-Jahre blieb der Einfluss dieser personellen Verschränkungen jedoch gering; insbesondere was das Festland anging. Im April 1962 machte Tanganjikas Außenminister und TANU-Generalsekretär Oscar Kambona während seiner Reise durch die sozialistischen Länder Osteuropas auch in der DDR halt, um Beziehungsmöglichkeiten auszuloten und - wie schon Mtemvu 1961 - über die Bereitstellung von Ausbildungs- und Studienplätzen zu diskutieren. ${ }^{88} 1963$ und 1964 intensivierte sich der Delegationsaustausch, die Gewerkschaftsorganisationen näherten sich einander weiter an und vereinbarten die Vergabe weiterer Stipendien. Vorerst blieb der Einfluss dieser Zirkulationen jedoch sehr beschränkt.

Dazu trug nicht zuletzt der Antikommunismus bei, der in vielen Köpfen der gebildeten Elite Tanganjikas fest verankert war. Maßgeblich waren hier womöglich der Einfluss von Missionsbildung und der oft an westlichen Idealen ausgerichtete Habitus der Beamtenschaft. Der Antikommunismus spiegelte sich deutlich in publizierten Erfahrungsberichten von Studierenden, Seminaristen und kirchlichen Abgesandten, die im Rahmen von BRD- oder Österreich-Aufenthalten

86 SAPMO BArch Berlin, DY 30/IV 2/20/53, Information an das Sekretariat des Zentralrates der FDJ über „Die Entwicklung der Beziehungen der FDJ zu den Jugend- und Studentenorganisationen Afrikas“, Juli 1962, Bl. 356-358.

87 Roberts, Politics, S. 103; ders., Press, Propaganda, and the German Democratic Republic's Search for Recognition in Tanzania, 1964-1972, in: Philip E. Muehlenbeck/Natalia Telepneva, Warsaw Pact Intervention in the Third World: Aid and Influence in the Cold War, London 2018, S. $148-172$.

88 Matthes, Zur Entwicklung, S. 56 - 57; Schleicher, Afrika in der Außenpolitik der DDR, S. 14-15; Ilona Schleicher, FDGB-Offensive in Westafrika. Der Gewerkschaftsbund im Jahr Afrikas, in: Heyden, Ulrich van der u.a., Hg., Engagiert für Afrika: Die DDR und Afrika II, Münster 1994, S. 82-93. 
auch den Eisernen Vorhang vorgeführt bekamen. In ihren Schilderungen bezeugten die Gäste aus einer Außensicht das kommunistische Unrechtsregime, das sich im Stacheldraht und den Überwachungstürmen ebenso ausdrücke wie in der Unterdrückung der Religion; zusammen mit anderen Kommentatoren warnten sie vor den Verlockungen des Kommunismus, der die Versprechungen des Wohlstands nicht einlösen werde. ${ }^{89}$ In Sansibar waren antikommunistische Diskurse weit weniger wirksam; hier hatten Gruppen mit Affinität und konkreten Verbindungen zu kommunistischen Parteien sowie Kuba, China und der Sowjetunion zudem deutlich mehr Einfluss in der politischen Szene. Sansibar war wenig später auch das erste postkoloniale Land, das die DDR - zumindest kurzzeitig - diplomatisch anerkannte. Zudem waren auch in anderen postkolonialen Staaten halboffizielle Stellen der DDR eröffnet worden.

\subsection{Konkurrenz: „Hallsteinzeit" ${ }^{\text {(900 }}$ in Ostafrika. Entwicklungspolitik und der deutsch-deutsche Wettlauf um Afrika, 1964-1970}

In der BRD blieb die „Unterwanderung“ der Hallstein-Doktrin durch DDR-Handelsmissionen, die Vergabe von Stipendien und die Aktivitäten „gesellschaftlicher Organisationen“ nicht unbemerkt. 1964 gab das Auswärtige Amt die Richtlinie aus, Kontaktaufnahmen (es blieb ungeklärt, welcher Art) mit „Pankow“ künftig mit der Kürzung von Wirtschaftshilfe zu beantworten. Empfängerstaaten sollten die westdeutsche „Großzügigkeit“ mit Unterstützung in der Isolationskampagne gegen die DDR entgelten oder anderenfalls abgestraft werden. ${ }^{91}$ Das bedeutete eine explizite Ausweitung der Hallstein-Doktrin vom politischen auf das wirtschaftliche und entwicklungspolitische Feld. ${ }^{92}$ In den Jahren 1964 bis 1970 wirkte die Außenpolitik daher unmittelbar auf die Entwicklungshilfe ein und machte sie zu einer Rose mit Dornen. Für geschickt taktierende Regierungen im globalen Süden blieb die Hallstein-Doktrin jedoch auch ein „Pfeil im Köcher“, mit dem sie die beiden deutschen Staaten zu einem entwicklungspolitischen Wett-

89 Siehe etwa Stanislaus Mutahyabarwa, „Nilizuru Austria na Ujerumani“, Kiongozi, 15.3.1962; „Utawala wa Kikomunisti“, Kiongozi, 15.7.1962.

90 Dieses vielsagende Wortspiel geht zurück auf Rüdiger Marco Booz, Hallsteinzeit. Deutsche Aussenpolitik 1955-1972, Bonn 1995.

91 Gray, Germany‘s Cold War, S. 117.

92 Kilian, Die Hallstein-Doktrin, S. 164-170 
kampf anspornen konnten, ohne politische Kompromisse eingehen zu müssen. ${ }^{93}$ Beide Aspekte - Abstrafung und Belohnung - werden im Fall Tansanias sichtbar.

\section{Tansanias Rückweisung konditionalisierter „Entwicklungshilfe“}

Am 26. April 1964 gelangte Dar es Salaam durch die Vereinigung von Tanganjika und Sansibar ins Visier der Hallstein-Doktrin. ${ }^{94}$ In den meisten Fällen war die BRD der DDR in einer deutsch-deutschen Neuauflage des Wettlaufs um Afrika ${ }^{95}$ darin zuvorgekommen, Vertretungen in gerade unabhängig gewordenen Staaten einzurichten und mögliche Zweifel mit dem Versprechen von Entwicklungshilfe (oder Androhung ihres Entzugs) auszuräumen. ${ }^{96}$ Sansibars revolutionäre Regierung wandte sich aber umgehend an die kommunistische Welt, weil Bonn wie andere westliche Länder aufgrund der unklaren politischen Lage vor Ort zögerte. Für die DDR handelte es sich um die erste diplomatische Anerkennung außerhalb des sowjetischen Lagers.

Sansibars Beziehungen mit kommunistischen Ländern schürten im Westen Furcht, dass hier eine Entwicklung wie im Falle Kubas drohte. Nyerere blieb nicht verborgen, dass westliche Geheimdienste über eine Intervention nachdachten und Ostafrika zum Austragungsort des Ost-West-Konfliktes werden könnte. Schon seit den späten 1950er-Jahren hatte er mit dem Verweis auf panafrikanische Visionen versucht, ostafrikanische Unabhängigkeitsbewegungen (und damit zukünftig Regierungen und Staaten) politisch zu einen - mit bescheidenen Ergebnissen. Anfang 1964 gelang es Nyerere, Karume von den Vorteilen der Union zu überzeugen, hinter verschlossenen Türen die Vereinigung von Sansibar und Tanganjika im April $1964 \mathrm{zu}$ besiegeln und geheime britische Pläne, militärisch einzugreifen, wieder in den Schubladen verschwinden $\mathrm{zu}$ lassen. ${ }^{97}$

93 Engerman, The Second World's Third World, S. 197, Übersetzung E. B.

94 In der angegebenen Sekundärliteratur sind die Geschehnisse der Jahre 1964 und 1965 ausführlich beschrieben, weswegen sie hier nur knapp wiedergegeben werden.

95 Gray, Germany's Cold War; vgl. auch die Rede 1961 zum Second Scramble in Nyerere, Freedom and Unity. Einen ähnlichen diplomatischen Wettlauf gab es zwischen der VR China und Taiwan. Danke an Sarah Hanisch für diesen Hinweis.

96 Zur „Verhinderungspolitik“ siehe Kilian, Die Hallstein-Doktrin, S. 30, 34-39.

97 Die Union ist Gegenstand zahlreicher historischer Darstellungen. Die aktuellsten Werke, in denen die Ereignisse sowie frühere Analysen ausführlich diskutiert werden, sind Bjerk, Building a Peaceful Nation; Roberts, Politics; Issa G. Shivji, Pan-Africanism or Pragmatism? Lessons of the Tanganyika-Zanzibar Union, Dar es Salaam 2008; Amrit Wilson, The Threat of Liberation. Imperialism and Revolution in Zanzibar, London 2013. 
Für die DDR war die Vereinigung in diplomatischer Hinsicht ein Rückschlag. Sansibar verfügte in der komplizierten politischen Konstruktion der Union zwar nach wie vor über eine eigene Regierung und Gesetzgebung, war aber in mehreren Ressorts, darunter jenem der Außenpolitik, fixer Teil der tansanischen Unionsregierung. Bonn agitierte gegen die Beibehaltung einer DDR-Vertretung für die ganze Union und wählte zuerst die Option des Zuckerbrots. Die BRD versprach zusätzliche Ausbildungs- und Materialhilfe für die Polizei und sicherte zu, alle Projekte, die die DDR in Sansibar begonnen hatte, vollständig und z.T. sogar zu günstigeren Bedingungen weiterzuführen. ${ }^{98}$ Der Bruch mit der DDR war für Nyerere jedoch keine Option, da dies die ohnehin fragilen Beziehungen mit Sansibars Führung schwer belastet und die Existenz der jungen Union postwendend gefährdet hätte. Als Nyerere die Eröffnung eines DDR-Generalkonsulats (anstelle einer Botschaft) in Dar es Salaam genehmigte und explizit betonte, dass dies keine diplomatische Anerkennung bedeute, tauschte die BRD das Zuckerbrot für die Peitsche.

Am 24.2.1965 beschloss das bundesdeutsche Kabinett, als Reaktion auf die Eröffnung des DDR-Generalkonsulats die militärische Ausbildungshilfe für Tansania einzustellen. Für postkoloniale Staaten war es essenziell, Militär- und Polizeieinheiten zu modernisieren und Luftschutzstaffeln, Küstenwache, Nachrichten- und Geheimdienste aufzubauen, um die fragile nationalstaatliche Souveränität nach innen und außen $\mathrm{zu}$ demonstrieren und $\mathrm{zu}$ erhalten. ${ }^{99}$ Erst im Vorjahr hatten Teile des Militärs in Tanganjika gemeutert und einen Putsch angedroht; die BRD zielte mit dem plötzlichen Rückzug aus Maßnahmen, die für den Aufbau souveräner Staatlichkeit zentral waren, also bewusst auf den empfindlichsten Nerv. In einer Blitzaktion wurden in der Hoffnung, dass dies die tansa-

98 Kilian, Die Hallstein-Doktrin, S. 198.

99 Tatsächlich waren Entwicklungshilfe und die Vorstellung „autoritärer Entwicklung“ in den 1960er Jahren eng miteinander verknüpft. Siehe Bradley R. Simpson, Economists with guns. Authoritarian development and U.S.-Indonesian relations, 1960-1968, Stanford 2008. Für westund ostdeutsche Versuche des Staatsaufbaus in Syrien siehe Trentin, Modernization as State Building. Die Forschungen zur Militärhilfe von BRD und DDR stehen noch weitgehend am Anfang. Für einen konzisen Überblick siehe Bernd Lemke, Deutsche Militärhilfe für afrikanische Staaten im Kalten Krieg. Workshop am Militärgeschichtlichen Forschungsamt, Potsdam, 12. Juni 2008, in: Militärgeschichtliche Zeitschrift 67/2 (2008), S. 483-485. Grundlagenarbeit für die Militärhilfe der DDR leistete Klaus Storkmann, Geheime Solidarität. Militärbeziehungen und Militärhilfen der DDR in die „Dritte Welt“, Berlin 2012. Siehe auch Joseph Sassoon, The East German Ministry for State Security and Iraq, 1968-1989, in: Journal of Cold War Studies 16/1 (2014), S. 4-23; Carola Eugster, Soldatische Mobilität im „Kalten Krieg“. Deutsche Ausbildungshilfe für afrikanische Soldaten in Afrika und in der Bundesrepublik in den 1960er Jahren, in: Christoph Rass, Hg., Militärische Migration vom Altertum bis zur Gegenwart, Paderborn 2016, S. 165-188. 
nische Regierung „wahrscheinlich besonders hart treffen würde“ innerhalb von 22 Stunden insgesamt 60 Personen, darunter Luftfahrtberater, Techniker und Marinepersonal, abgezogen. ${ }^{100}$ Das Ergebnis entsprach keineswegs der Intention.

Als Leitfigur im Befreiungskampf und der Blockfreienbewegung musste Nyerere auf mehr Rücksicht nehmen als die germanozentrischen Ost-West-Animositäten, die Bonns Handlungen leiteten. Auch innenpolitisch gefährdete der Erpressungsversuch Nyereres Ruf, der durch das Zuhilferufen britischer Truppen gegen die Meuterer im Vorjahr ohnehin stark angeschlagen war, und verlangte eine starke symbolische Gegenantwort, selbst wenn diese mit wirtschaftlichen Opfern verbunden sein sollte. Gegen Botschafter Schroeders Erwartung, dass „,[d] er vorgeführte Kraftakt sicherlich imponieren“ werde, ${ }^{101}$ zitierte Nyerere Schroeder zu sich und teilte unmissverständlich mit, jetzt auf die gesamte westdeutsche Hilfe verzichten $\mathrm{zu}$ müssen, um sein Gesicht $\mathrm{zu}$ wahren. Eine entsprechende Meldung erschien wenig später in der tansanischen Presse. Als ostentative Zurschaustellung nationaler Selbstbestimmtheit war die Reaktion erfolgreich, in mehreren Interviews erinnerten sich TansanierInnen noch fünf Jahrzehnte später mit Stolz an Nyereres Prinzipienfestigkeit und die Verteidigung der nationalen Souveränität in dieser Situation.

In erster Linie ging es nach dem symbolischen Akt um Schadensbegrenzung in der Innenpolitik und bei Verbündeten in der postkolonialen Welt. Am 3. März 1965 hatte Nyerere das TANU National Executive Council in bereits gemäßigten Worten über den Disput mit der BRD unterrichtet. Als Fait accompli teilte er mit, dass nicht alle Westdeutschen ausgewiesen würden: „Jenen, die für die Regierung arbeiten, zahlen wir ihre Gehälter weiter und sie werden bleiben. Alle anderen, die unter staatlichen Entwicklungshilfeabkommen gekommen sind, sollen gehen.“102 Am 19. März 1965 versandte Nyerere ein Memorandum an alle anderen afrikanischen Staatschefs (sowie andere PolitikerInnen, darunter sein Freund

100 BArch Koblenz, B 102/68167, Liste „Projekte, deren Einstellung die tansanische Regierung wahrscheinlich besonders hart treffen würde“, o.O., o.D.; Kilian, Die Hallstein-Doktrin, S. 204207, $225-227$.

101 Zit. nach Kilian, Die Hallstein-Doktrin, S. 204.

102 CCMA, 50/A, Protokoll des Treffens des TANU National Executive Council [Halmashauri Kuu ya Taifa], Dar es Salaam, 3.3.1965, S. 5. Im Original: „Ondoeni misaada yoyote iliyobaki. Haiwezekani kuendelea na misaada mingine kutoka Jerumani Magharibi. Hatufukuzi Wajerumani. Wale wanaofanya kazi Serikalini na tunawalipa mishahara watabaki. Wengine wote waliokuja katika mipango ya Serikali ya Msaada waondoke.“ Vgl. auch ein Parteirundschreiben in CCMA, 675 TANU Press Releases, Sauti ya TANU, 14.3.1965. Nyerere betonte bei einem Parteitreffen kurz nach den Ereignissen das Prinzip, keine Hilfe anzunehmen, die die Entscheidungs- und Gedankenfreiheit beeinträchtigen oder die Würde Tansanias schädigen (kuvunja heshima) könnte eine Formulierung, die auf die Aufrechterhaltung der politischen Souveränität abzielte. 
Willy Brandt und US-Präsident Johnson), in dem er Bonn scharf dafür kritisierte, deutschlandpolitische Querelen zulasten Tansanias auszufechten. ${ }^{103}$ In Bonn waren die außenpolitischen Hardliner verblüfft, wie Nyerere durch seinen kompletten Verzicht auf BRD-Hilfe „das Gesetz des Handelns an sich riss.“ 104 Der „Kraftakt“ war zum Bumerang geworden. Zwei alternative Reaktionen wurden nun erörtert. Eine Option war, auch zivile Projekte zu streichen, damit „die Einstellung der deutschen Hilfe wirklich spürbar und für die anderen Länder abschreckend wirkt“. ${ }^{105}$ Moderate Stimmen meinten hingegen, dass nun ,jede verbleibende Verhandlungschance“ genutzt werden solle, da eine weitere Kürzung der Entwicklungshilfe der DDR zugutekomme. ${ }^{106}$ Die westlichen Verbündeten der BRD kritisierten die Kurzschlussreaktion mit der Streichung der Militärhilfe scharf und fürchteten einen Einflussgewinn Chinas und der Sowjetunion, ${ }^{107}$ da Großbritannien und die USA aufgrund diplomatischer Krisen zu diesem Zeitpunkt ebenfalls keinen Zugriff mehr auf Tansania hatten.

Nyerere lag jedoch weiterhin viel am Zugriff auf die Ressourcen der BRD. Im April berichtete BRD-Botschafter Schroeder von einem weiteren Treffen mit Nyerere, in dem dieser den Wunsch geäußert habe, dass möglichst alle Projekte weitergeführt werden sollten, ohne allerdings eine entsprechende öffentliche Erklärung abgeben zu wollen, um sein Gesicht zu wahren. Besonders wichtig sei ihm der Erhalt der Experten. ${ }^{108}$ Selbst in dieser radikalen Reaktion, mit der Nyerere den „nationalen Stolz“ und die Selbstbestimmung demonstrativ wiederherzustellen suchte, war die ungestörte Weiterführung von Entwicklungspro-

103 Ägypten habe für das gleiche „Vergehen“ nur ausstehende Kreditzusagen eingebüßt, nicht aber die Militärhilfe. Eine von Nyerere nicht intendierte Folge dieses Rundschreibens dürfte auch gewesen sein, dass sich in der Folge keine weitere Regierunge Afrikas die Finger an der deutschlandpolitischen Frage verbrennen wollte. Das äußerte sich nicht ausschließlich in einer Umgehung der diplomatischen Anerkennung der DDR: das gerade unabhängig gewordene Sambia etwa lehnte BRD-Kapitalhilfe im selben Jahr aufgrund der damit verbundenen politischen Konditionalitäten ab. Gray, Germany‘s Cold War, S. 161; Kilian, Die Hallstein-Doktrin, S. 204-207, $225-228$.

104 BArch Koblenz, B 102/68167, Erdmann (BMWi), Aufzeichnung über das derzeitige Verhältnis zu Tansania, 7.3.1965.

105 Ebd., Erdmann an AA und BMZ, Bonn, 2.3.1965.

106 Ebd., Erdmann, Aufzeichnung über das derzeitige Verhältnis zu Tansania, 7.3.1965, S. 3.

107 Engel/Schleicher, Die beiden deutschen Staaten, S. 169.

108 BArch Koblenz, B 102/68167, Drahtbericht BRD-Botschafter Schroeder an AA, Dar es Salaam, 5.4.1965; siehe auch ebd., Schnellbrief AA an BMWi, BMZ, BMF, BMELF, BMV u. a. anlässlich einer Kabinettsvorlage des AA vom 17.2.1965 zu Tansania, Bonn, 23.3.1965, S. 2-3. 
jekten und staatlicher Aktivität eins seiner Hauptanliegen. ${ }^{109}$ Nyerere balancierte also zwischen dem Prinzip politischer Souveränität einerseits - wie seine Verlautbarungen an die Öffentlichkeit und andere Staatsführer zeigen - und der pragmatischen Aufrechterhaltung von Ressourcenflüssen und Personalentsendung andererseits. Diese Gespräche fanden allerdings, um das „Gesicht zu wahren“, entweder hinter verschlossenen Türen oder über Vermittler statt.

In den folgenden vier Jahren wurden zwischen der BRD und Tansania aufgrund der Haltung des Auswärtigen Amts keine neuen Vereinbarungen über Entwicklungshilfe getroffen. Da aber die bestehenden zwölf Projekte der Technischen Hilfe den abgeschlossenen Verträgen entsprechend weiterliefen ${ }^{110}$, bekam Tansania immer noch deutlich mehr Mittel zur Verfügung gestellt als die meisten anderen afrikanischen Länder. Das Volumen kirchlicher Projekte, das in den kommenden Jahren weiter stieg ${ }^{111}$, war hier noch nicht mit eingerechnet. Für die eingebüßte Militärhilfe der BRD sprangen Kanada und die Niederlande bereitwillig ein, um wenig später an Bedeutung von China überholt zu werden.

Neben der Möglichkeit, den Wegfall von Ressourcen durch die Hinwendung $\mathrm{zu}$ anderen Gebern zu kompensieren, begrenzten auch wirtschaftliche Interessen die Auswirkungen der bundesdeutschen Abstrafungsfantasien. In dieser Hinsicht war man sich in Bonn und Dar es Salaam einig. In der Note, die die tansanische Regierung schickte, um die Einstellung jeder „Hilfe“ (aid) als Reaktion auf den Entzug der Militärhilfe zu fordern, fand sich die ausdrückliche Feststellung, dass die BRD die Hilfe für deutsche Investoren in Tansania (Exportkreditversicherun-

109 So begründete Nyerere seine Handlung bereits wenig später vor den leitenden FunktionärInnen der Partei. Auch in der tansanischen Presse erschienen zahlreiche Beiträge zu diesem Ereignis, wobei die BRD aufs Schärfste kritisiert wurde.

110 BArch Koblenz, B 102/212635, Handzettel Tansania, 26.10.1967, S. 2.

111 Während der diplomatischen Krise zwischen 1965 und 1970 stellte die BRD deutlich mehr Mittel für private Träger in Tansania zur Verfügung als zuvor (Wirth, Aspekte, S. 109). Verlässliche Zahlen sind in diesem stark verästelten Sektor, der nicht nur Hilfswerke, sondern auch Partnerschaften kleiner Gemeinden umfasst, äußerst schwierig zu erheben. Eine Schätzung der Bundesregierung zählt 1970127 Kirchenprojekte in Tansania, mit einem Volumen von über 54 Mio. DM (BArch Koblenz, B 102/86572, Development Assistance to Tanzania - Statement by the Government of the Federal Republic of Germany, 20.4.1970). Für die 1990er Jahre nimmt Köhler an, dass etwa 30 Mio. DM jährlich über kirchliche Partnerschaften, Hilfs- und Missionswerke flossen (im Verhältnis zu 50 Mio. DM zugesagter staatlicher Finanz- und technischer Hilfe pro Jahr). Für die Jahre von 1969-73 belaufen sich die Schätzungen auf je 20 Mio. DM vom Kirchlichen Entwicklungsdienst, Brot für die Welt und die Evangelische Zentralstelle für Entwicklungshilfe, was etwa $20 \%$ der gesamten Gelder entsprochen haben soll, die Afrika zugewiesen worden waren. Köhler, Zum Stellenwert, S. 21-22, 25. 
gen etc.) nicht aussetzen solle. ${ }^{112}$ DEG-Projekte waren von Bonn aufgrund privatwirtschaftlicher Eigeninteressen ohnehin bereits als „unbedingt fortzusetzen“ eingestuft worden. ${ }^{113}$ Das Gleiche galt für eine geologische Mission auf Rohstoffsuche „im Interesse der internationalen Erforschung Afrikas“. ${ }^{114}$ Der Außenhandel und bundesdeutsche Exportgarantien blieben ebenfalls unangetastet. ${ }^{115}$ Auch die von Tansania bezahlten Experten durften bleiben, ebenso - nach einigen Verhandlungen - die Freiwilligen des DED, die in der Zwischenzeit schon auf gepackten Koffern auf ihre Abreise gewartet hatten und letztlich durch ihren Status als Entsandte einer „unpolitischen“ GmbH das Bleiberecht erwirkt hatten. ${ }^{116}$

Die entsandten Experten und EntwicklungshelferInnen ${ }^{117}$ reagierten überwiegend mit Unverständnis auf die Linie ihrer Regierung. Nachdem sich die Wogen wieder geglättet hatten und die tansanische Regierung von der Forderung des Personalabzugs wieder abgerückt war, optierten die meisten aus beruflichen und privaten Gründen für einen Verbleib im Land. ${ }^{118}$ Eine wichtige politische Vermittlerrolle in der Krise nahm der Regierungsberater Hans Geuting ein. Als diplomierter Landwirt war Geuting bis 1963 für die Firmen Daimler-Benz und Magirus-Deutz tätig gewesen. ${ }^{119}$ Nach der Vereinigung Tanganjikas und Sansibars 1964 wurde er ins Direktorat für Entwicklungsplanung der Präsidialkanzlei

112 BArch Koblenz, B 102/68167, Note des tansanischen Außenministeriums vom 13. März, Anlage zu Schnellbrief AA an BMWi, BMZ, u. a. anlässlich einer Kabinettsvorlage des AA vom 17.2. 1965 zu Tansania, Bonn, 23.3.1965, S. 1.

113 BArch Koblenz, B 102/212635, Erdmann (BMWi) an AA und Bundesminister für wirtsch. Zusammenarbeit, Bonn, 2.3.1965.

114 BArch Koblenz, B 102/68167, Erdmann (BMWi) an AA und Bundesminister für wirtsch. Zusammenarbeit, Bonn, 2.3.1965, S. 2; ebd., Pauls (AA) an BMWi, BMZ, BMF, BMELF, BMV u.a., Bonn, 23.3.1965, S. 2.

115 BArch Koblenz, B 102/68167, Pauls (AA) an BMWi, BMZ, BMF, BMELF, BMV u.a. anlässlich einer Kabinettsvorlage des AA vom 17.2.1965 zu Tansania, Bonn, 23.3.1965, S. 3.

116 Hein, Die Westdeutschen, 91-92; Günter Wöhlk, Warten auf Koffern - Hallstein-Doktrin in Tansania, in: Willi Erl, Hg., Betrifft: Zusammenarbeit: 25 Jahre Deutscher Entwicklungsdienst, Berlin 1988, S. 52-56.

117 Frauen gab es nur in Diensten des DED, die entsandten Experten waren allesamt Männer. Siehe BArch Koblenz, B 102/68167, Liste „Experten in Tansania“, o.O., o.D. [1965].

118 BArch Koblenz, B 102/68167, Erdmann (BMWi) an Baetzgen/Keiser, Bonn, 17.3.1965. Diejenigen, die tatsächlich abberufen wurden, konnten problemlos einen Einsatz im Nachbarland Kenia beginnen. Um eine Provokation gegenüber Nyerere zu vermeiden bat die kenianische Regierung lediglich darum, dass die Fachkräfte einen Zwischenaufenthalt in der BRD einlegten. 119 Biografische Informationen entstammen aus: Das Bundesarchiv, Geuting, Horst B. K., in: Die Kabinettsprotokolle der Bundesregierung online. bundesarchiv.de/cocoon/barch/z/z/z1960a/ kap1_7/para2_32.html (Zugriff: 14.06.2015) 
transferiert, wo er sein enges Verhältnis zu Nyerere weiter pflegen konnte. Im Verlauf der diplomatischen Krise forderte Geuting, selbstbewusst dank seiner Nähe zum Präsidenten, die Abberufung von BRD-Botschafter Schroeder, der maßgeblich dazu beigetragen hatte, dass Tansania abgestraft wurde. ${ }^{120}$ Außerdem überbrachte Geuting Nyereres Wiederannäherungsversuche zur Botschaft, damit der Präsident sein Gesicht wahren konnte. In Bonn hatte Geuting mit Entwicklungsminister Scheel und dem bereits erwähnten Kai-Uwe von Hassel, nunmehr Verteidigungsminister, mächtige Fürsprecher, die ihm zugestanden, in seinem Aufbegehren gegen das Auswärtige Amt das Vertrauen von Nyerere gesichert und die Lage entschärft zu haben. ${ }^{121}$ Das Auswärtige Amt hingegen haderte mit Geutings Kompetenzaneignungen und seinem Frontalangriff gegen den Botschafter. In einer Diskussion des Bundeskabinetts, an der auch Bundeskanzler Erhard teilnahm, wurde festgelegt, Geuting „,aus der unmittelbaren Nähe von Präsident Nyerere [zu] entfernen“, ihn seines Beraterstatus' zu entledigen und als Projektleiter eines 1963 begonnenen, aber bereits als aussichtslos angesehenen Landwirtschaftsprojekts in Ifakara, hunderte Kilometer von Dar es Salaam entfernt, einzusetzen. ${ }^{122}$ Geutings Vermittlungsversuche waren somit gescheitert; die politische Disziplinierung schadete allerdings nicht nur ihm.

Die Auseinandersetzung um die Hallstein-Doktrin setzte der BRD-Präsenz in Regierungsrängen ein jähes Ende; alle späteren Berater aus der BRD hatten keinen Regierungsberaterstatus mehr, sondern nur noch Expertenstatus. Zumindest den deutschlandpolitischen Sieg konnte die BRD aber doch davontragen: Der DDR misslang es in den folgenden Jahren, weitere afrikanische Staaten zur Anerkennung zu bewegen. Kuba blieb bis 1969 der einzige Staat im globalen Süden, der volle diplomatische Beziehungen mit der DDR aufgenommen hatte, erst dann folgten Somalia und eine Reihe arabischer Länder. Umso wichtiger waren der DDR-Führung in den Jahren zuvor daher Sansibar und Tansania, wo die außenpolitischen Beziehungen noch am aussichtsreichsten schienen.

120 Kilian, Die Hallstein-Doktrin, S. 211-213.

121 BArch Koblenz, B 102/68167, Keiser (BMWi) an Minister, Bonn, 20.4.1965; Das Bundesarchiv, Protokoll der 165. Kabinettssitzung am 20.5.1965, Tagungspunkt 3. Tansania; hier: Fortsetzung der Projekte der Technischen Hilfe, in: Die Kabinettsprotokolle der Bundesregierung online. bundesarchiv.de/cocoon/barch/10/k/k1965k/kap1_2/kap2_21/para3_3.html (Zugriff: 14.06.2016)

122 Das Bundesarchiv, Protokoll der 165. Kabinettssitzung am 20.05.1965, Tagesordnungspunkt 3. Tansania; hier: Fortsetzung der Projekte der Technischen Hilfe, in: Die Kabinettsprotokolle der Bundesregierung online. bundesarchiv.de/cocoon/barch/10/k/k1965k/kap1_2/kap2_21/para3_3.html (Zugriff: 14.06.2016). Geuting blieb, vom Regierungsberater zum GAWI-Experten „degradiert“, bis 1966 in Ifakara und betreute danach Landwirtschaftsprojekte in Thailand. Anschließend arbeitete er in leitenden Funktionen in internationalen Organisationen der UNO und der FAO in anderen asiatischen und afrikanischen Ländern. 


\section{Postrevolutionäre Kooperation und Desillusionierung: Sansibar und die DDR}

Während Tanganjika einen weitgehend gewaltfreien und geordneten Übergang von der kolonialen in die postkoloniale Ära erlebte, entluden sich schwelende Spannungen im Sultanat Sansibar kurz nach der Unabhängigkeit von Großbritannien in einer Revolution. ${ }^{123}$ Eine Gruppe junger Männer, die sich in erster Linie aus einem radikalen Flügel der Jugendorganisation der oppositionellen Afro-Shirazi Party (ASP) und entlassenen Polizisten rekrutierte, stürzte am 12. Januar 1964 die sultansfreundliche Regierung, die kurz zuvor gewählt worden war. Die Verhältnisse in Sansibar wandelten sich in der Folge so radikal und schnell wie in kaum einem anderen afrikanischen Land. ${ }^{124}$ Die DDR profitierte von diesem Wandel und hatte selbst auch ihren Anteil daran. In den kommenden Jahren half die ostdeutsche Regierung, so die kritische Bilanz von Sansibars Kooperation mit kommunistischen Staaten von Gary Thomas Burgess, einen Überwachungsstaat zu etablieren und ein ,Jahrzehnt der Beschlagnahmungen, des Mangels, der Überwachung und der Furcht“ einzuläuten. ${ }^{125}$

Der noch vor jedem Eintreten der DDR eingesetzte Revolutionsrat verfolgte die „politische und ökonomische Zerstörung der arabischen Oligarchie“ mit Verhaftungen, Beschlagnahmungen und der Ausweisung des Sultans und tolerierte die Welle der Gewalt, die die Revolution freisetzte. ${ }^{126}$ Die Ethnisierung der Politik im kosmopolitischen Sansibar ging auf historisch gewachsene Ungleichheitsstrukturen zurück. ${ }^{127}$ Die britische Kolonialpolitik hatte die indirekte Herrschaft über das Sultanat ausgeübt und der arabischstämmigen Bevölkerung weitreichende soziale und politische Privilegien zugesprochen. Omanische Eliten dominierten die Plantagenwirtschaft, einige wenige indische Familien den Finanzsektor und den Handel. Weite Teile der afrikanischen Bevölkerung - wobei es auch hier wichtige Unterschiede, z.B. zwischen rezenten ImmigrantInnen vom Festland

123 Die Deutung dieser Revolution ist bis heute zentraler Teil politischer Auseinandersetzungen. Siehe Marie-Aude Fouéré, Recasting Julius Nyerere in Zanzibar: The Revolution, the Union and the Enemy of the Nation, in: Marie-Aude Fouéré, Hg., Remembering Julius Nyerere in Tanzania: History, Memory, Legacy, Dar es Salaam 2015, S. 171-196; Roman Loimeier, Memories of Revolution: Zur Deutungsgeschichte einer Revolution (Sansibar 1964), in: Africa Spectrum 41 (2006), 175197.

124 Einzig Guinea erlebte einen ähnlich radikalen Bruch, so Esmond Bradley Martin, Zanzibar. Tradition and Revolution, London 1978, S. 60.

125 Burgess, Race, S. 23

126 Michael F. Lofchie, Zanzibar: Background to Revolution, Princeton, N.J. 1965, S. 257.

127 Neben strukturellen Faktoren spielten natürlich auch Diskurse eine wesentliche Rolle in der Konstruktion von Feindbildern. Detailliert zur Rolle sansibarischer Intellektueller in der Politisierung ethnischer Kategorien siehe Glassman, War of Words 
und bereits seit Generationen ansässigen Sansibaris gab - blieben hingegen in Handel, Verwaltung und Bildungssystem unterrepräsentiert. Diese Gruppen von „verarmten Kleinbauern und Saisonarbeitern vom Festland“ waren es, so Roman Loimeier, „die während der [...] 1950er Jahre die politische Basis der Afro-Shirazi Party (ASP, gegr. 1957) und später die soziale Basis der Revolution bildeten“. ${ }^{128}$ Die ASP sprach sämtlichen „nicht-afrikanischen“ Gruppen ab, zu Sansibar zu gehören. Der ASP und ihrem Ziel der Befreiung von den „Arabern“ standen die Zanzibar Nationalist Party (ZNP, gegr. 1955) und die Zanzibar and Pemba Peoples' Party (ZPPP, gegr. 1959) gegenüber, die zwar auch für die Unabhängigkeit Sansibars eintraten, aber das omanische Sultanat beibehalten wollten und sich vor allem über eine muslimisch-kosmopolitische Identität definierten. Ein progressiver, teils marxistischer Flügel der ZNP wandte sich jedoch gegen diese Vorstellungen; aus ihm entstand 1963 die Umma-Partei unter der Führung von Abdulrahman Mohammed Babu. Obwohl die ASP bei den Parlamentswahlen im selben Jahr 54,2\% der Stimmen gewonnen hatte, blieb sie durch das britische System des Mehrheitswahlrechts von der Regierungsbildung ausgeschlossen. Nach der Revolution, die das Sultanat wie auch die ZNP/ZPPP-Regierung kurz nach den Wahlen stürzte, übernahmen ASP- und Umma-Kader im Revolutionsrat unter der Leitung des ehemaligen Matrosen Abeid Amani Karume, der eine breite Basis hinter sich wusste, die Macht.

Die Westmächte zögerten mit der Anerkennung des Regimes und schafften so ein Vakuum. Dass Sansibar sich umgehend an die sozialistische Welt wandte, ist neben diesem Zögern vor allem auf den Einfluss linker Kräfte in der Umma-Partei und der ASP zurückzuführen. ${ }^{129}$ Bei diesen linken Kräften, die sich oft explizit als Marxisten verstanden, handelte es sich um kosmopolitische Intellektuelle, die in vielen Fällen auf Aufenthalte in Großbritannien, Indien und kommunistischen Länder wie China, Kuba und der DDR zurückblickten und ihr Weltbild im Laufe ihrer Reisen geformt hatten. Inspiration für Sansibars Zukunft bezogen sie weniger von den afrikanischen und arabischen Sozialismen Julius Nyereres, Kwame Nkrumahs oder Gamal Abdul Nassers, sondern in erster Linie von Fidel Castro, Mao Zedong und bisweilen auch Josef Stalin. ${ }^{130}$ Zwar war die Revolution nicht von dieser Gruppe ausgegangen, aber einige der Umma-Kader hatten es verstanden, im Verlauf der Ereignisse die Ordnung wiederherzustellen und einige der Machtpositionen in der Regierung und im gesetzgebenden Revolutionsrat zu

128 Loimeier, Zeitlandschaft, S. 31.

129 A. M. Babu, I Was the First Third World Minister to Recognise the GDR, in: Haroub Othman, Hg., Babu: I Saw the Future and it Works. Essays Celebrating the Life of Comrade Abdulrahman Mohamed Babu, 1924-1996, Dar es Salaam 2001, S. 48-58.

130 Burgess, Race, S. 21. 
besetzen. ${ }^{131}$ Karume sah seine Macht durch Babu und andere Marxisten, die breite Popularität in Gewerkschaften und Teilen der urbanen Bevölkerung genossen, gefährdet. Schon im März wurde Umma von der ASP geschluckt und Sansibar kurz darauf zum Einparteienstaat erklärt. Babu, Kassim Hanga (der in Moskau studiert hatte und mit einer russischen Ehefrau zurückgekehrt war) und andere wurden auf Posten der neuen Unionsregierung auf dem Festland versetzt, was ihnen dort Einflussmöglichkeiten verschaffte und der sozialistischen Transformation auf dem Festland einen Schub verlieh, aber die marxistische Präsenz in Sansibar schwächte - zugunsten von Karumes Machtpolitik.

Für die DDR brachte die Union einen diplomatischen Rückschlag (die Herabstufung der Botschaft auf ein Generalkonsulat und damit den Verlust der diplomatischen Anerkennung) und den Zugang zu neuen entwicklungspolitischen Wirkungsfeldern. Das Politbüro der DDR beschloss im Juli 1964 aus einer Position der Stärke zu handeln und die Beziehungen auf das Festland auszuweiten. ${ }^{132}$ Sansibar sollte aber vorrangig unterstützt werden, was wirtschaftliche Hilfe ebenso wie „systemstabilisierende“ Maßnahmen zur „Verteidigung der Revolution“ durch die Staatssicherheit einschloss. ${ }^{133}$ Eindeutig überschätzten die politischen Eliten in Berlin hier den Einfluss Sansibars als „Faust in Tansania“ auf das Festland und glaubten, wie die Süddeutsche Zeitung sarkastisch bemerkte, „in dieser Weltecke wackle der Schwanz mit dem Hund.“134 Noch 1969 hieß es in einem Delegationsbericht der DDR, es gelte, die „Überschätzung der auf dem Festland vorhandenen Ansatzpunkte einer progressiven Entwicklung und [...] eine Unterschätzung der Bedeutung Sansibars für die Formierung der fortschrittlichen Kräfte in Tansania [...] endgültig zu überwinden“. ${ }^{135}$ In der Außendarstellung in Tansania hatte die DDR schon sehr viel früher von einer offenen Bevorzugung der „fortschrittlichen Kräfte“ in Sansibar abrücken müssen. Seit Beginn der Kooperation wurde die DDR verdächtigt, die Union politisch zu unterwandern. Im Editorial des TANU-eigenen Organs warf Nyerere der DDR am 19. März 1965 vor, die Revolution für eigene Zwecke zu instrumentalisieren:

131 Shivji, Pan-Africanism, S. 64.

132 Matthes, Zur Entwicklung, S. 70 - 75.

133 Wilson Center Digital Archive, Streng vertraulicher Bericht über das Treffen zwischen KGBVorsitzendem Semichastny und DDR-Minister für Staatssicherheit Mielke, 30.11.-1.12.1964, Berlin, 2.12.1964. digitalarchive.wilsoncenter.org/document/115713 (Zugriff: 18.6. 2015).

134 Afrika-Politik mit Braunbuch und Rotlicht, Süddeutsche Zeitung, 8. 2.1966.

135 BArch Berlin, DC 20/11525, Flegel, Bericht einer Regierungsdelegation in die VRT aus Anlass des 5. Jahrestages der sansibarischen Revolution, Berlin, 22.1.1969, S. 8, 12. 
We have evidence that the East Germans are attempting to destroy our Union in the interests of their own desires. [...] The Afro-Shirazi Party revolution in Zanzibar was not a revolution kindly undertaken by Africa for the sake of East Germany. ${ }^{136}$

Da die DDR auf dem Festland Fuß fassen wollte, mussten Gegenbeweise zu diesem Spaltungsvorwurf erbracht werden. Im April 1965 forderte Nyerere, nach wie vor erzürnt über den westdeutschen Erpressungsversuch, DDR-Hilfe bei der Wirtschaftsplanung Sansibars im Rahmen der Union. Die Experten sollten Bereiche identifizieren, in denen wirtschaftliche Synergien von Festland und Sansibar schlagend werden konnten - ein „Prüfstein für die Hilfsmöglichkeiten“ der DDR, der Ost-Berlin zum schnellen Handeln veranlasste. ${ }^{137}$ Eine Gruppe von DDRPlanern wurde eilends entsandt, um eine Studie über ökonomische Integrationsmöglichkeiten zwischen Sansibar und Festland zu erarbeiten und mögliche Maßnahmen mit mehreren Ministern der Unionsregierung abzustimmen. Jegliche Schritte in Richtung einer zentralen Planung oder engeren Kooperation mit dem Festland mussten aber schon an Karumes Souveränitätsvorstellungen scheitern, ging es ihm doch nicht um die Integration mit dem Festland, sondern um den Aufbau seines insularen Autoritarismus. Zur Konsolidierung seiner Machtposition wie auch der damit zusammenhängenden Umsetzung seiner Modernisierungsvorstellungen war Karume jedoch ebenso auf externe Unterstützung und ausländisches Personal angewiesen.

Der Import von Fachkräften wurde erst im Gefolge der Revolution notwendig. Wie die DDR zwischen 1949 und 1961 verlor Sansibar zwischen 1964 und 1972 etwa ein Zehntel seiner Bevölkerung durch Abwanderung. Zum Zeitpunkt der Unabhängigkeit im Dezember 1963 war die Personallage auf Sansibar, im Gegensatz zum Festland, relativ vorteilhaft und der Großteil der Stellen in Verwaltung, Schulen und Wirtschaft von Sansibaris besetzt gewesen. Ein bedeutenderer Faktor für den Fachkräftemangel nach der Revolution war Karumes Identitätspolitik, in der Sansibar nicht als kosmopolitische oder multiethnische, sondern als afrikanische Gesellschaft konzipiert wurde, in der Personen arabischer, indischer und komorischer Herkunft als Fremde galten. ${ }^{138}$ Sie waren 1964-1972 Repressionen ausgesetzt, die vor allem die Ärmeren unter ihnen trafen, während die Eliten sich absetzen konnten. Zu den Massakern, die im Zuge der Revolution verübt wurden - konservative Schätzungen gehen von 3.000 bis 11.000 Toten aus - kamen Enteignungen, Deportationen, Vergewaltigungen, Zwangsverheira-

136 The Nationalist, Editorial, 19.3.1965, zit. n. Shivji, Pan-Africanism, S. 103.

137 BArch Berlin, DE 1/52555, Winzer (MfAA) an Apel (Stv. Ministerrats- und SPK-Vorsitzender), Berlin, 5.4.1965.

138 Loimeier, Zeitlandschaft, S. 36. 
tungen und Zwangsarbeit in den Jahren darauf. ${ }^{139}$ Unter den 35.000 Personen, die dem postrevolutionären Sansibar fluchtartig den Rücken kehrten, befanden sich überproportional viele VertreterInnen der „Intelligenz“. Die etwa 8.000 bis 10.000 Personen, die in den Oman gingen, wurden dort mit offenen Armen empfangen, um Verwaltung, Wirtschaft und Sozialwesen zu modernisieren. ${ }^{140}$

Der Revolutionsrat verfügte zudem im März 1964 die Ausweisung aller Kolonialbeamten. Innerhalb von sechs Monaten waren alle 130 verbliebenen britischen Angestellten und Beamten mit der Ausnahme eines Zahnarztes sowie fast alle der etwa 500 westlichen expatriates ausgereist. ${ }^{141}$ Die entstandenen Lücken wurden zu einem Teil durch politische Loyalisten ohne fachliche Qualifikationen gefüllt, zu einem anderen Teil durch StudienabsolventInnen aus Übersee (v. a. aus Osteuropa) und Fachkräften aus sozialistischen Ländern. Unter den DDR-Auslandskadern waren neben Finanz- und Planungsberatern (siehe Kapitel 6.1) auch LehrerInnen und ExpertInnen im Bildungsbereich tätig, außerdem medizinisches Personal, das nach den 60 LehrerInnen die zweitgrößte Fachgruppe ausmachte. 1969/70 weilten über 100 DDR-ExpertInnen in Sansibar, 200 Ostdeutsche insgesamt; zusätzlich zu 700 ChinesInnen und 50 Entsandten aus der Sowjetunion. ${ }^{142}$

Dazu schnürte die DDR ein Hilfspaket, das die Errichtung von 150 „modernen“ Wohneinheiten und Rahmenkredite in der Höhe von zehn bis fünfzehn Millionen DM für DDR-Güter und -dienstleistungen beinhaltete. Angetrieben von Karume, der das Leben in „modernen“ Häusern als unerlässliches Merkmal des Fortschritts ansah, war der Wohnungsbau für die DDR auch ein direktes Konkurrenzprojekt zum BRD-Wohnungsbau in Dar es Salaam. ${ }^{143}$ Hinzu kamen Stipendien für Ausbildungsprogramme in der DDR sowie die Entsendung von technischem Personal und Beratern des Ministerium für Staatssicherheit (MfS) für den Sicherheitsdienst; auch eine Poliklinik, die Algerien (wohl aufgrund des Drucks der BRD) abgelehnt hatte, konnte Sansibar angeboten werden. ${ }^{144}$

In der DDR, wie auch in anderen RGW-Staaten, waren die Grenzen zwischen regulären Wirtschaftsbeziehungen und Transfers und Vereinbarungen, die unter

139 Chachage, Environment, S. 41; Loimeier, Zeitlandschaft, S. 37-38.

140 Martin, Zanzibar, S. 71.

141 Ian Speller, An African Cuba? Britain and the Zanzibar Revolution, 1964, in: Journal of Imperial and Commonwealth History 35/2 (2007), S. 283-302, hier: S. 295-297

142 Engel/Schleicher, Die beiden deutschen Staaten, S. 179-180.

143 Die Bauarbeiter verlangten eine 80-prozentige Lohnerhöhung, ausgerichtet an dem, was in einem benachbarten US-Schulprojekt gezahlt wurde. Da die Materialien vor Ort, d. h., in Ostafrika, teurer waren als erwartet, musste die DDR den Großteil aus dem eigenen Land importieren. Siehe Kilian, Die Hallstein-Doktrin, S. 184-185, 217, 219-221.

144 Detailliert beschrieben in Engel/Schleicher, Die beiden deutschen Staaten, S. 160-161. 
Begriffen wie „sozialistischer Hilfe“ liefen, fließend. Für gänzlich unentgeltliche Hilfeleistungen nahm die DDR den Begriff der „Solidarität“ in Anspruch, aber auch diese konnten fallweise mit kommerziellen Instrumenten in Zusammenhang stehen. ${ }^{145}$ Das konkrete Mischverhältnis von kommerziellen, vergünstigten und unentgeltlichen Leistungen hing von der politischen Opferbereitschaft in der DDR und dem Verhandlungsgeschick der Beteiligten ab. ${ }^{146}$ Die Instrumente (weniger die Institutionen), die in der westlichen Entwicklungshilfe und der sozialistischen Anwendung fanden, sind sich nicht zuletzt aufgrund der Konkurrenzsituation in vielerlei Hinsicht ähnlich: Es handelte sich gleichermaßen um Ausbildungsplätze, Personaleinsätze und verschiedene Formen von Projekten. ${ }^{147}$

Die übersichtliche Fläche des Sansibar-Archipels und eine Bevölkerungszahl von nicht einmal 300.000 Menschen schürte die Erwartung historischen Ausmaßes, dass „ostdeutsche Hilfe [Sansibar] in ein Schaustück sozialistischer Wohltätigkeit verwandeln könnte“. ${ }^{488}$ Nach wie vor wirtschaftlich weitgehend isoliert, bot Sansibar der DDR die seltene Gelegenheit, Erfahrungen in Außenwirtschaftsbeziehungen zu sammeln und mit den Instrumenten technischer, sicherheitspolitischer und personeller Kooperation zu experimentieren. ${ }^{149}$ Die DDR intensivierte ihre Anstrengungen auf Sansibar, um auf die Forderungen des Revolutionsrates Taten folgen zu lassen. 1966 war die DDR wichtigster Geber und auch in den Jahren darauf bewerkstelligte nur China noch umfassendere Transfers. In Führungskreisen gab es einem ehemaligen Auslandskader zufolge sogar Vorstellungen, Sansibar wie eine DDR-Kolonie zu planen und so in die sozialistische Zukunft zu führen. ${ }^{150}$ Derartige Visionen wurden, wenn sie tatsächlich existierten, freilich nicht öffentlich verlautbart.

145 Berthold Unfried, Instrumente und Praktiken von „Solidarität“ Ost und „Entwicklungshilfe“ West: Blickpunkt auf das entsandte Personal, in: Berthold Unfried/Eva Himmelstoss, Hg., Die eine Welt schaffen: Praktiken von „Internationaler Solidarität“ und „Internationaler Entwicklung“, Leipzig 2012, S. 73-98, hier: S. 77.

146 Unfried, Instrumente, S. 79-80.

147 Siehe hierzu auch die Perspektive der (keinesfalls passiven) „Empfänger“: Daniel Speich, The Kenyan Style of „African Socialism“: Developmental Knowledge Claims and the Explanatory Limits of the Cold War, in: Diplomatic History 33/3 (2009), S. 449-466, hier: S. 451.

148 Gray, Germany‘s Cold War, S. 155, Übersetzung E. B. Vgl. auch Interviews \#23 und \#29, ehemalige Dolmetscher einer FDJ-Brigade in Sansibar: Es gab in DDR-Führungskreisen auch die Vorstellung, dass die DDR Sansibar mitverwalten und zum Sozialismus führen könne.

149 Bericht der SED GO Sansibar, 7.4.1967, zit. nach Franziska Benger, Die Entwicklungszusammenarbeit der DDR in Sansibar/Tansania, in: Ulrich van der Heyden/Franziska Benger, Hg., Kalter Krieg in Ostafrika: Die Beziehungen der DDR zu Sansibar und Tansania, Berlin 2009, S. 341-389, hier: S. 367; Winrow, The Foreign Policy of the GDR in Africa, S. 64.

150 Interview \#29, Dolmetscher einer FDJ-Brigade in Sansibar. 
Für die zuständigen DDR-Akteure war ein derart umfassendes materielles Engagement wie in Sansibar mit enormen Herausforderungen verbunden. Das lag nicht zuletzt daran, dass sich zahlreiche Institutionen mit Planung und Umsetzung entwicklungspolitischer Maßnahmen beschäftigten, es jedoch kein koordinierendes Organ oder gar ein spezielles Ministerium gab. ${ }^{151}$ Lediglich die allgemeine Lenkung war zentralisiert: Das Politbüro im Zentralkomitee der SED, also ein kleiner Kreis ranghoher Parteifunktionäre, fasste die Beschlüsse. ${ }^{152}$ Regionalabteilungen des Außen- und Außenwirtschaftsministeriums verhandelten die Verträge über die Bereiche der Kulturell-Wissenschaftlichen Zusammenarbeit (KWZ) und der Wissenschaftlich-Technischen Zusammenarbeit (WTZ), die der Technischen Hilfe und Bildungshilfe des Westens ähnelten. ${ }^{153}$ WTZ- und KWZAbkommen umfassten Delegationsreisen, Warenlieferungen und reine Personaleinsätze, während „Projekte“ im westlichen Verständnis - vorerst - die Ausnahme darstellten. ${ }^{154}$ Eine eigene Entwicklungsbank wie die KfW gab es in der DDR nicht, zumal DDR-Kredite in der Regel nicht zur freien Verfügung gestellt wurden, da dies einen Devisenaufwand bedeutet hätte. Wo in Verhandlungen und Abkommen von Darlehen die Rede war, wurden diese üblicherweise nicht als freies Kapital zur Verfügung gestellt, sondern direkt mit dem Erwerb ostdeutscher Waren und Dienstleistungen verrechnet. ${ }^{155}$ Ein direktes Pendant zur westlichen Finanzhilfe gab es folglich nicht.

Viele der weichenstellenden politischen Entscheidungen im revolutionären Sansibar hatten sozialistischen Charakter, wurden von DDR-Beratern jedoch nur wenig beeinflusst. Bei den radikalen soziopolitischen Maßnahmen direkt nach dem Umsturz hatten oft sansibarische Linke um Babu ihre Positionen noch durchsetzen können. ${ }^{156}$ Die wichtigste dieser Maßnahmen war Nationalisierung

151 Sieht man einmal vom nur wenige Monate existierenden Ministerium für wirtschaftliche Zusammenarbeit (MWZ) während der de Maizière-Regierung ab. Neben dem Ministerium für Auswärtige Angelegenheiten (MfAA) und dem Ministerium für Außenhandel (MAH), die beide zentrale Aufgaben, z.B. in der Anleitung von Auslandskadern wahrnahmen, waren auch die Ministerien für Nationale Verteidigung, Volksbildung, Hoch- und Fachschulwesen, Landwirtschaft, Industrie und Gesundheitswesen an entwicklungspolitischen Maßnahmen beteiligt.

152 Birgit Fröhlich, Gedanken zur Entwicklungszusammenarbeit der DDR mit Afrika, in: Ulrich van der Heyden u.a., Hg., Die DDR und Afrika: Zwischen Klassenkampf und neuem Denken, Münster 1993, S. 148-164, hier: S. 149-151.

153 Burghard Claus/Hans-Helmut Taake, Die Entwicklungspolitik der DDR - Ein Rückblick, in: Ulrich van der Heyden u.a., Hg., Die DDR und Afrika: Zwischen Klassenkampf und neuem Denken, Münster 1993, S. 245-259, hier: S. 246-247.

154 Fröhlich, Gedanken zur Entwicklungszusammenarbeit der DDR, S. 149-151.

155 Lorenzini, Dilemmas, S. 64.

156 Dieser Absatz basiert auf Loimeier, Zeitlandschaft, S. 36. 
und Umverteilung von Land. Durch die Enteignung und Umverteilung von Land, insbesondere der Kokosnussplantagen, wurde die feudale Klasse demontiert. Die Regierung investierte in Infrastruktur sowie kostenfrei zugängliche Gesundheitsvorsorge und Bildung. Die Expansion in diesen Bereichen war auch auf externe Ressourcen und ausländisches Personal angewiesen. Äußerst unpopulär in der Bevölkerung waren Maßnahmen zur Schaffung des sozialistischen „Neuen Menschen“, darunter die zeitweilige Ersetzung des Religionsunterrichts durch die neuen Schulfächer „Politik“ und „Wissenschaft“ (1965). Auch in diesen Fragen spielten sansibarische Linke, nicht DDR-Berater, die tragende Rolle.

Solche Maßnahmen trugen dazu bei, dass DDR-BeobachterInnen Sansibar als potenzielles neues Mitglied im sowjetisch geführten, sozialistischen Weltsystem ansahen. Präsident Karume vertrat jedoch, im Gegensatz zu den linken politischen Gruppen, einen antiimperialistischen Nationalismus, der mit sozialistischen Konzepten nur teilweise kompatibel war. Karumes Vision der Moderne kreiste von der bereits erwähnten Identitätsfrage abgesehen um mehrere Kernelemente, darunter autoritäre Sozialstaatlichkeit, eine disziplinierte und vorhersagbar produzierende Bevölkerung, modernste Technologie und Industrialisierung (v.a. in der Konsumgüterindustrie) und nationale Souveränität und Autonomie, die durch eine diversifizierte Wirtschaft gewährleistet werden sollte. Karume verfolgte keinen globalen Kampf gegen den Kapitalismus, sondern die Herrschaftssicherung und nationalistisches „racial development“157, von dem „Araber“ und „Inder“ (gleich welcher Klassenzugehörigkeit) ausgeschlossen werden sollten, damit die „afrikanische“ Mehrheit profitieren konnte. Die Umverteilung von Land und Eigentum war jedoch nur bedingt eine Umverteilung von oben nach unten; in erster Linie handelte es sich um einen staatlich abgesicherten Transfer der Privilegien von den vorwiegend arabischen und indischen Eliten zur Führungsschicht der ASP. ${ }^{158}$ Der Versuch, wirtschaftliche und politische Macht zu entflechten, stand dabei im Gegensatz zum Festland nicht auf der Agenda. Karume häufte wie andere Mitglieder des Revolutionsrates ein beträchtliches Privatvermögen an und wetterte 1967 gegen den leadership code der Deklaration von Arusha mit der Begründung, dass die Trennung politischer und wirtschaftlicher Ämter afrikanisches Unternehmertum verhindere und so die asiatische Vorherrschaft in der Wirtschaft stärke. ${ }^{159}$

Die beidseitige Desillusionierung bei Vertretern Sansibars und der DDR war ein gradueller Prozess. Zentral war der wachsende Frust Karumes und anderer

157 Burgess, Race, S. 22.

158 Chachage Seithy L. Chachage, Environment, Aid and Politics in Zanzibar, Dar es Salaam 2000, S. 45.

159 Chachage, Environment, S. 41; Burgess, Race, S. 124. 
sansibarischer Politiker über fehlschlagende DDR-Wirtschaftsprojekte, in denen einige strukturelle Probleme zutage traten, die auch andere Beispiele von Ost-SüdBeziehungen limitierten. Ein Kernproblem war, dass die DDR kaum über Devisen verfügte. Kredite waren daher wie erwähnt in der Regel an den Erwerb von DDRErzeugnissen gebunden. Um die Dollarsphäre des Weltmarkts $\mathrm{zu}$ umgehen, schlossen RGW-Länder immer wieder Verträge mit Ländern des globalen Südens ab, durch die sie Rohstoffe und landwirtschaftliche Produkte gegen Industrieerzeugnisse auf Verrechnungsbasis tauschten. Für diese bilaterale Form des barter trade war die Exportstruktur Sansibars allerdings denkbar ungeeignet. Als Resultat der jahrzehntelangen Förderung der Plantagenökonomie verfügte Sansibar im Wesentlichen nur über ein Exportgut, für das in der DDR keine nennenswerte Nachfrage bestand: Nelken. Der Ausweg aus diesem strukturellen Dilemma verlangte Kreativität. Im April 1964 begab sich Außenminister Babu nach Indonesien, einem der Hauptabnehmer sansibarischer Nelken, um ein trilaterales „SüdSüd-Ost“-Abkommen zu arrangieren. Bei einer Umsetzung hätte Sansibar Nelken nach Indonesien geliefert, Indonesien Rohstoffe gleichen Werts in die DDR exportiert und die DDR Technologien zur landwirtschaftlichen und industriellen Modernisierung nach Sansibar verschifft. Babus Verhandlungserfolge in Jakarta waren jedoch hinfällig, als Nyerere und Karume zeitgleich die Vereinigung Sansibars und Tanganjikas beschlossen. ${ }^{160}$ Die Handelsprobleme blieben somit ungelöst.

Die industriellen Vorhaben richteten sich einerseits notgedrungen an Exportkapazitäten der DDR aus, stimmten aber auch mit sansibarischen Zielen überein, eine diversifizierte Nationalökonomie auf lokaler Ressourcenbasis aufzubauen. Die DDR bemühte sich im Rahmen ihrer Möglichkeiten auf Sansibars Wünsche einzugehen und begann mit dem Aufbau einer Konservenfabrik zur Früchteverwertung, einer Molkerei sowie einer Fischfangflotte. ${ }^{161}$ Später kamen Reismühlen sowie eine Koprapresserei hinzu. Der Technologietransfer scheiterte allerdings schon an der unzureichenden Koordination der DDR-Außenwirtschaftstätigkeit. Während Aspekte wie die Unterschätzung der realen Kosten, ungenügende Nachfrage nach Fertigwaren vor Ort oder die Notwendigkeit rentabilitätsgefährdender Importe geradezu klassische Probleme von Entwick-

160 Wilson, Threat of Liberation, S. 59-60; A. M. Babu, Zanzibar and the Future, in: Haroub Othman, Hg., Babu: I Saw the Future and It Works. Essays Celebrating the Life of Comrade Abdulrahman Mohamed Babu, 1924-1996, Dar es Salaam 2001, S. 26-38, hier: S. 31-32.

161 Matthes, Zur Entwicklung, S. 64. 
lungsprojekten gleich welcher Provenienz sind, ${ }^{162}$ ist die Häufung der Komplikationen bei den angegebenen Projekten bemerkenswert. Die „Sardinenfangeinheiten“ mit ihren Schleppnetzen erwiesen sich angesichts des Korallenriffs, das den Sansibar-Archipel umgab, als genauso ungeeignet für den Fischfang wie die schweren Landmaschinen für den Reisanbau auf den lokalen Böden. Für die Produkte der verarbeitenden Lebensmittelindustrie wie Sahne, Margarine und Öl gab es keinen Markt und auch die „Kompottlinie“ der Konservenfabrik stellte sich als unrentabel und verlustbringend heraus. ${ }^{163}$ Besonders verärgert war Karume, als die DDR ihre Zusage zu einem Fischereiprojekt 1967 wieder zurückzog, weil die Kosten deutlich $\mathrm{zu}$ niedrig veranschlagt worden waren. ${ }^{164} \mathrm{Hinzu}$ kamen Meinungsverschiedenheiten über die Qualität der Importe. Die DDR konnte die vereinbarten Konsum- und Industriegüter entweder gar nicht, nur zu überteuerten Preisen oder nur in minderwertiger Qualität (u.a. als Gebrauchtware) liefern. Karume erwartete „modernste Maschinen“, wie sie seiner Meinung nach in der DDR verwendet wurden. Der Anblick der gelieferten, veralteten DDR-Apparaturen habe ihm „das Herz gebrochen“ und ihn dazu veranlasst, gegen seine Intention in England zu kaufen, wie er 1970 klagte. ${ }^{165}$ Die Reismühlen aus der DDR bedeuteten ihm „nicht Fortschritt, sondern Rückschritt“. 166

Den DDR-Vertretern vor Ort fehlten freilich die Möglichkeiten, derartige Verfehlungen wieder auszubügeln. Statt wie erhofft „mit relativ niedrigem Aufwand von Sansibar ausstrahlend mehr und mehr Einfluss in ganz Ostafrika zu gewinnen“, fügten „ernste Versäumnisse bei der Realisierung der ökonomischen Verpflichtungen [...] der politischen Stellung der DDR und des sozialistischen Lagers in Sansibar/Tansania Schaden zu“, wie es 1967 in einem Bericht der lokalen SEDGrundorganisation hieß. ${ }^{167}$ Dieser Imageschaden betraf nicht nur den Vergleich mit westlicher, sondern insbesondere auch fernöstlicher Entwicklungshilfe und Wirtschaftskooperation. DDR-Delegationen gegenüber lobten Vertreter Sansibars

162 Siehe für eine Kategorisierung typischer Projektprobleme, u.a. unterteilt in angebots- und nachfrageseitige, das schon 1967 erstmals veröffentliche aber nach wie vor relevante Einsichten bietende Buch von Albert O. Hirschman, Development Projects Observed, Washington, D.C 1995. 163 Siehe die veritablen Katastrophenberichte von DDR-Vertretern in Sansibar aus den Jahren 1966 und 1967, publiziert im Anhang von Benger, Entwicklungszusammenarbeit.

164 BStU, MfS, HVA 229, Einzel-Information über außen- und innenpolitische Probleme Tansanias, Berlin, 15.12.1967, Bl. 144.

165 BArch Berlin, DC 20/11615, Vermerk über die abschließende Unterredung des Leiters der Regierungsdelegation der DDR mit Karume, Sansibar, 8.5.1970, Fol. 16.

166 BArch Berlin, DC 20/11615, Hartmann (DDR-Handelsrat), Gespräch mit Karume, Sansibar, 23.9.1969.

167 Bericht der SED GO Sansibar, 7.4.1967, zit. nach Benger, Die Entwicklungszusammenarbeit der DDR, 367. 
chinesische Projekte besonders und verfolgten damit „offensichtlich die Absicht, die anderen sozialistischen Staaten zu einer effektiveren Unterstützung zu veranlassen“. 168

Mit der partiellen Umwandlung der Regierungskredite in Schenkungen konnte die DDR keinen Stimmungswandel erreichen, fast alle DDR-Lieferungen wurden als mangelhaft bis ungenügend erachtet. 1967 bat der sansibarische Finanzminister Abdulaziz Twala, der in Moskau studiert hatte und der DDR generell freundlich gesonnen war, daher um die Reduzierung des Kreditrahmens von fünfzehn Millionen DM, der nur zu zwei Dritteln ausgeschöpft worden war; ebenso möge die DDR mit ihren Rückzahlungsforderungen warten, bis die Fabriken tatsächlich produzierten und Profite abwarfen, die dann zur Tilgung der Kredite verwendet werden konnten. ${ }^{169}$ Weitere Vorhaben wie das überdimensionierte Wohnbauprojekt Michenzani Flats, dessen Realisierung nach einer Hochrechnung des DDR-Konsuls angesichts der Rohstofflage über ein halbes Jahrhundert gedauert hätte, wurden nicht finalisiert. 1970 forderte Karume nicht nur die Rücknahme der „veralteten“ Anlagen (z.T. tatsächlich bereits gebrauchte Maschinen), sondern auch gleich die Abreise des DDR-Konsuls. ${ }^{170}$ Die Kooperation mit Großprojekten kam nach 1970 zum Erliegen. Chinas wachsender Einfluss war fraglos ein weiterer wichtiger Faktor in der Distanzierung Sansibars von der DDR sowie in der Bewertung der DDR-Maßnahmen. Da die fehlgeschlagenen Wirtschaftsprojekte zwischen der DDR und Sansibar auch die politischen Beziehungen in Mitleidenschaft gezogen hatten, reiste das verbliebene zivile DDRPersonal, darunter Architekten und eine FDJ-Brigade, 1971/72 aus. Sansibar hatte die Verträge nicht verlängert und verließ sich auf China. Lediglich im Sicherheitsund Geheimdienstbereich lief die Kooperation noch über Jahre hinweg weiter. ${ }^{171}$ Hier hatte sich das DDR-Engagement stärker als in jedem anderen Bereich bis in den Alltag der Sansibaris hinein ausgewirkt: In der Karume-Ära erlangte der sansibarische Geheimdienst eine ungeheure Macht. Sansibaris erinnern sich an neue Foltermethoden sowie ein Klima der Einschüchterung und totalen Über-

168 BArch Berlin, DC 20/11615, Flegel, Bericht einer Regierungsdelegation in die VRT aus Anlass des 5. Jahrestages der sansibarischen Revolution, Berlin, 22.1.1969, S. 3.

169 BArch Berlin, DC 20/11615, Tansania - Stand der Kreditnutzung, 31.5.1967, Fol. 40 - 44.

170 Matthes, Zur Entwicklung, S. 64-66.

171 Ebd., S. 64-67. Die Arbeit des MfS in Sansibar soll so „erfolgreich“ gewesen sein, dass sich der sansibarische Geheimdienst bald verselbstständigte und Ausmaße annahm, die selbst die DDR-Geheimdienstler besorgten, siehe Markus Wolf, Spionagechef im geheimen Krieg. Erinnerungen, München 1997. 
wachung, in dem Spitzel allgegenwärtig waren und Männer nicht einmal ihren Ehefrauen vertrauten. ${ }^{172}$

Nachdem der Einzelhandel 1967 nationalisiert worden war und Karume auf Nahrungsmittelimporte zugunsten der „Förderung“ von self-reliance verzichtete, kam es 1969-1972 zu Versorgungsengpässen - obwohl Sansibar zeitgleich vom hohen Nelkenpreis profitierte und Fremdwährungsreserven in Höhe von 25 Millionen britischen Pfund ansammelte. ${ }^{173}$ Am 7. April 1972 wurde Karume ermordet. Obwohl die genauen Hintergründe bis heute ungeklärt sind, gilt als gesichert, dass ehemalige Umma-Mitglieder in den Anschlag verwickelt waren. Wenig überraschend fiel der Verdacht in erster Linie auf Babu, der umgehend in Dar es Salaam festgenommen wurde. Er und 43 andere Angeklagte wurden teils in $a b$ sentia in einem Prozess mit antikommunistischen Charakter wegen Hochverrats zur Todesstrafe verurteilt. Nyerere lieferte die am Festland Inhaftierten allerdings nicht aus (nachdem Ausgelieferte zuvor von Karume öffentlich exekutiert worden waren); Babu blieb bis 1978 im Gefängnis und ging dann ins Exil. ${ }^{174}$ Die DDR spielte zu dieser Zeit bereits keine Rolle mehr in Sansibar; nach Gesprächen mit Karumes Nachfolger Aboud Jumbe verzichtete sie 1975 zudem auf alle ausstehenden Kreditrückzahlungen. ${ }^{175}$ Die von China und der DDR errichteten Fabriken produzierten Mitte der 1970er- Jahre kaum noch. Jumbe leitete ein Öffnung Sansibars ein, die sich auch darin äußerte, dass ab Mitte der 1970er-Jahre eine kleine Zahl integrierter Experten und GTZ-Fachkräfte aus der BRD in Bauprojekten, Stadtplanung und Denkmalschutz tätig waren und die Einführung des Farbfernsehens vorantrieben (während auf dem Festland die erste TV-Übertragung erst 1994 stattfand). ${ }^{176}$ Der Schwerpunkt der BRD blieb jedoch das Festland, wo die DDR bis Anfang der 1970er-Jahre nur in einigen wenigen Bereichen präsent war.

\section{Die Renaissance bundesdeutscher Sympathien für Tansania}

Bis 1968 köchelten die Beziehungen zwischen Dar es Salaam und den beiden deutschen Staaten weiter auf Sparflamme. Seit der Deklaration von Arusha, die von der DDR 1967 aufgrund ihrer antikapitalistischen Rhetorik und Nationalisierungsbestrebungen optimistisch begrüßt worden war, zählte Tansania in Ost-

172 Burgess, Race, S. 126.

173 Martin, Zanzibar, S. 129.

174 Roberts, Politics, S. 191-193.

175 Matthes, Zur Entwicklung, S. 87-88.

176 Ulrich Malisius, Vergessener Reichtum - Altstadtsanierung in Sansibar, in: Willi Erl, Hg., Betrifft: Zusammenarbeit: 25 Jahre Deutscher Entwicklungsdienst, Berlin 1988, S. 184-190. 
berlin zu jenen Ländern, die als „sozialistisch orientiert“ galten. ${ }^{177}$ Die grundsätzlich positive Einschätzung Tansanias als Staat „sozialistischer Orientierung“ ging jedoch einher mit der kritischen Feststellung, dass die Macht in den Händen einer „kleinbürgerlich-nationalistischen“ Gruppe um Nyerere konzentriert sei und die Ujamaa-Ideologie Elemente der katholischen Soziallehre und „afrikanisch verbrämt[e] Züge des Sozialreformismus“ vereine. ${ }^{178}$ Die „unwissenschaftliche“ Basis von Ujamaa, so eine von Funktionärseite intern immer wieder vorgebrachte Meinung, verhindere den Aufbau einer sozialistischen Gesellschaft. Dieses Urteil verhärtete sich, nachdem eine Reihe potenzieller bzw. tatsächlicher DDR-Alliierter - darunter die Sansibaris Babu und Hanga - auf dem Festland marginalisiert bzw. in Sansibar exekutiert wurden ${ }^{179}$ und Chinas Engagement unübersehbare Ausmaße annahm.

In politischer und ideologischer Hinsicht bestanden also große Differenzen. Eine ökonomische Basis der Beziehungen war ebenfalls nicht in Aussicht. 1968 schrieb ein Vertreter der DDR in Tansania, er sehe „keine ausreichende Grundlage für eine wirtschaftliche Zusammenarbeit mit ökonomischem Nutzen“. ${ }^{180}$ Diese Einschätzung sollte für die nächste Dekade Bestand haben. Zwischen 1965 und 1978 bewegte sich das Außenhandelsvolumen zwischen gerade einmal 0,7 und 8,3 Millionen Valutamark jährlich. Die DDR knüpfte jedoch zur selben Zeit engere Verbindungen mit den in Tansania stationierten Befreiungsbewegungen, etwa der FRELIMO, deren Anführer sich dem Marxismus-Leninismus annäherten. Da die FRELIMO ihr Quartier in Tansania aufgeschlagen hatte und die DDR auch Hilfslieferungen und Personal in die Camps entsenden wollte, musste ein Schwerpunkt der DDR-Afrikapolitik weiterhin in Tansania liegen. ${ }^{181}$ Gerade für das Festland sollten es aber lediglich ,politisch wirksame, ökonomisch nichtaufwendige Vorhaben“ sein, weswegen die DDR sich weitgehend auf Personalentsendung (siehe unten) und Ausbildungsmöglichkeiten (siehe Kapitel 4) beschränkte; nicht zuletzt, da man Projektprobleme und Fehlinvestitionen wie in Sansibar scheute. ${ }^{182}$

177 Spanger/Brock, Die beiden deutschen Staaten, S. 131.

178 BArch Berlin, DE 1/58694, Vertrauliche Dienstsache - Länderinformation Vereinigte Republik Tansania, o.D., S. 4.

$179 \mathrm{Zu}$ Exekutionen und politischen Gefangenen in Sansibar und auf dem Festland siehe Paul Bjerk, Julius Nyerere, Athens, Ohio 2017, S. 98-101.

180 Pampel 1968 zit. nach Benger, Die Entwicklungszusammenarbeit der DDR, S. 342.

181 George Roberts, Ostpolitik in Afrika: Tanzanian Politics, Non-Alignment, and the InterGerman Cold War, 1964-1972, Unveröffentlichtes Manuskript [2015], S. 10.

182 BArch Berlin, DC 20/11525, Flegel, Bericht einer Regierungsdelegation in die VRT aus Anlass des 5. Jahrestages der sansibarischen Revolution, Berlin, 22.1.1969, S. 12. 
In Bonn grollte das Auswärtige Amt noch wegen Nyereres „Missachtung“ der Hallstein-Doktrin und verweigerte sich neuen Vertragsabschlüssen, solange das Generalkonsulat der DDR in Dar es Salaam geduldet wurde. ${ }^{183}$ Die tansanische Regierung hoffte weiterhin auf die Normalisierung der Beziehungen zur BRD und hielt die DDR entsprechend auf Distanz. ${ }^{184}$ Noch 1968 beklagte sich Nyerere darüber, dass Tansanias Beziehungen zum reichsten europäischen Land aufgrund der DDR geschädigt waren. Die Gesprächsbereitschaft blieb vorerst aus. Die Deklaration von Arusha sandte 1967 eine Schockwelle durch westliche Investorenkreise, die aber schnell abflaute. Zwar waren auch Beteiligungen der DEG und deutscher Privatfirmen von Nationalisierungen betroffen, allerdings konnten alle Entschädigungsfragen zur Zufriedenheit der deutschen EigentümerInnen gelöst werden. Der Aufwärtstrend der tansanischen Wirtschaft nach den Nationalisierungen tat sein Übriges; das bundesdeutsche Wirtschaftsministerium stellte noch im selben Jahr fest, dass „der befürchtete Zusammenbruch Tansanias [...] nicht eingetreten“ war. ${ }^{185} 1969$ reiste Finanzminister Jamal nach Bonn, um Finanzierungen und Technische Hilfe für die Projekte des kommenden Entwicklungsplans einzuwerben. Auf Nachfrage versicherte Jamal, dass das deutsche Kapital sicher sei und erläuterte, dass die staatliche Kontrolle der wichtigsten Produktionsmittel in Tansania keine vollständig verstaatlichte Wirtschaft bedeute. Die Regierung erachte privatunternehmerisches Know-how für die allgemeine Wirtschaftsentwicklung des Landes als äußerst wichtig. Demonstrativ betonte er beim Treffen im Wirtschaftsministerium aber auch die Eigenständigkeit Tansanias und die Distanz zum Westen wie zum Osten: „Wir sind weder Kapitalisten, noch Marxisten. “186

Der Weg für diese Verhandlungen war durch einen Meinungsumschwung in Bonn geebnet worden. Der bereits erwähnte von Hassel hatte den Kontakt zu Nyerere gehalten und 1968 schlussendlich erfolgreich bei Bundeskanzler Erhard geworben, Tansania den Spielraum einer Blockfreienpolitik zuzugestehen, zumal Nyerere durch die Union mit Sansibar ein „afrikanisches Kuba“ verhindert habe

183 Aus BRD-Sicht lag die Ursache natürlich bei Nyerere, nicht bei der eigenen Position: „Unsere Beziehungen zu Tansania seien korrekt, aber abgekühlt, da Nyerere uns aus innenpolitischen Gründen nicht näherkommen könne.“ Protokoll der 102. Kabinettssitzung am 16. 11.1967, Tagesordnungspunkt 4, Situation im afrikanischen Raum. bundesarchiv.de/cocoon/barch/0000/k/ k1967k/kap1_2/kap2_47/para3_5.html (Zugriff: 14.06.2015)

184 Matthes, Zur Entwicklung, S. 70 -71; Roberts, Politics, S. 97.

185 BArch Koblenz, B 102/212635, Handzettel „Tansania“, 26.10.1967, S. 2.

186 BArch Koblenz, B 102/86572, Vermerk über Ergebnisse des Besuches vom tansan. Finanzminister Jamal am 15.10. (Entwurf), Bonn, 23.10.1969, S. 2. Der letzte Satz des Zitats ist auf diesem Vermerk handschriftlich durchgestrichen und scheint in der finalen Version nicht mehr auf. 
und nach wie vor zusichere, die DDR nicht anzuerkennen. ${ }^{187}$ Tansaphile Beamte im BMZ zeigten sich erfreut, als die Neuvergabe von Hilfe wieder anlief. Noch als Nachwirkung der Krise von 1965 konnte Nyerere, nach wie vor enttäuscht von der überharten Reaktion der BRD, wie man im Auswärtigen Amt wusste, nunmehr eine „Rekompensation“ für seine „Linientreue“ erhoffen. ${ }^{188}$ Noch im selben Jahr verkündete die BRD, nun mit einer sozialliberalen Regierung, ihre Bereitschaft, Tansania wieder Entwicklungshilfeleistungen zuzusagen. Auch Willy Brandts Ostpolitik ebnete den Weg für eine Normalisierung der Beziehungen. BRD-Vertreter ließen sich aber noch 1968 von Tansania zusichern, dass BRD-Personal in Bildungseinrichtungen und Forschungsprojekten keinesfalls einem DDR-Kader unterstellt würde. ${ }^{189}$ Mit der Wiederannäherung 1969 sollte die Zusammenarbeit mit DDR-Personal als „Beweis der Toleranz“ nicht mehr behindert werden. ${ }^{190}$

\subsection{Friedliche Koexistenz: Ujamaa und das goldene Zeitalter der Entwicklungspolitik, 1970-1977}

Anfang der 1970er-Jahre war Tansania als weltweit einziger Staat Schwerpunktland nicht nur der BRD-Entwicklungshilfe, sondern auch der DDR-Außenpolitik. ${ }^{191}$ Die DDR konnte nach fünf Jahren des Wartens und Verhandelns einen Durchbruch erzielen und bei einem Besuch von Außenminister Winzer 1970 Abkommen über Handel sowie Wissenschaftlich-Technische Zusammenarbeit mit Tansania schließen. ${ }^{192}$ Die Aufnahme voller diplomatischer Beziehungen folgte auf die Unterzeichnung des deutsch-deutschen Grundlagenvertrags vom 21.12.

187 BArch Koblenz, B 213/7672, Bundesminister Kai-Uwe von Hassel an Bundeskanzler Erhard, Bonn, 9.9.1968.

188 BArch Koblenz, B 102/86803 Bd. 3, Hebich (BRD-Botschaft) an AA, Dar es Salaam, 2.10.1969. 189 Zuständig für die Rekrutierung von expatriates bzw. die Zuweisung von Arbeitsplätzen war neben den Ministerien die Central Establishment Division im President's Office. BArch Koblenz, B 213/7876, AA an BMZ, Bonn, 23.1.1968; Hebich (BRD-Botschaft) an AA, Dar es Salaam, 29.11.1967. In ähnlicher Weise musste das sansibarische Gesundheitsministerium chinesische und sowjetische Fachkräfte möglichst getrennt voneinander einsetzen, um Konflikte zu vermeiden. Siehe Hong, Cold War Germany, S. 311.

190 BArch Koblenz, B 213/7672, BRD-Botschaft an AA, Dar es Salaam, 9. 8.1969, S. 15.

191 Kebschull, FRG and GDR in the Third World, S. 160.

192 Matthes, Zur Entwicklung, S. 73-75. Tansania ließ im Abkommen u. a. den Passus über die gegenseitige Unterstützung in internationalen Organisationen streichen, um die eigene Entscheidungsfreiheit (und die Beziehung $\mathrm{zu}$ westlichen wie anderen nicht-blockgebundenen Staaten) nicht zu kompromittieren. PAAA, C 772/74, Zielke (DDR-Konsul), Aktenvermerk über Gespräch mit Mbapila, Dar es Salaam, 2.5.1969 
1972. Weitere „Fortschritte in den bilateralen Beziehungen“, so der ehemalige DDR-Botschafter Matthes, hingen jedoch „fast ausschließlich von DDR-Initiativen ab. "193 Diese Initiativen waren jedoch angesichts des Debakels in Sansibar und einem anhaltenden Misstrauen gegenüber Ujamaa ebenfalls nur auf wenige Einsatzfelder begrenzt.

In der Bundesrepublik wurde Tansania jedoch zum Paradebeispiel für das neue Modell altruistischer Hilfe. Unter den neuen Richtlinien der sozialliberalen Regierung sowie den persönlichen Freundschaften Willy Brandts und Erhard Epplers zu Julius Nyerere und Amir Jamal (langjähriger Minister in wichtigen Ressorts wie Finanzen und Wirtschaft) ${ }^{194}$ wurde Tansania zu einem Schwerpunkt der bundesdeutschen Afrikapolitik, dessen Bedeutung nicht allein mit geopolitischen und wirtschaftlichen Interessen, sondern nur mit Bezug auf das entwicklungspolitische Feld erklärbar ist. ${ }^{195}$ Als erstes Länderprogramm des BMZ überhaupt wurde 1971 ein Plan für Tansania mit den Schwerpunkten Landwirtschaft, Industrie, staatliche Entwicklungsinstitutionen und integrierte ländliche Entwicklung ausgearbeitet, der mit langfristigen Mittelzusagen einherging. ${ }^{196}$ Kein anderes afrikanisches Land stand bei der SPD ${ }^{197}$ und bei den entwicklungspolitisch einflussreichen Kirchen ${ }^{198}$ so hoch im Kurs wie Tansania. Die Projekte, die in diesen Jahren initiiert wurden, liefen oft über Jahrzehnte.

\section{Neue Ausmaße von „Hilfe“ und Verschuldung}

Entwicklungspolitische Projekte wie die Errichtung der Ingenieursfakultät (Kapitel 7) oder das regionale Entwicklungsprogramm in Tanga (Kapitel 8) wurden dabei oft auf Anfrage der tansanischen Regierung umgesetzt. Schon 1966 hatte Tansania erste Anfragen für eine Art Regionalplanung an die BRD gestellt, allerdings für die Regionen Mtwara und Mbeya. ${ }^{199} 1971$ waren tansanische Akteure

193 Matthes, Zur Entwicklung, S. 75-76.

194 Erhard Eppler, Arm, aber nicht chancenlos, in: der Überblick 2 (2002), S. 45; Engel/Schleicher, Die beiden deutschen Staaten, S. 177.

195 Ebd.

196 Michael Bohnet, Development Policy in Sub-Saharan Africa and the Case of Tanzania, in: Ulf Engel u.a., Hg., Tanzania Revisited: Political Stability, Aid Dependency, and Development Constraints 2000, S. 3-16, hier: S. 10.

197 Vinnai, Die Arbeit der FES, S. 110, 152-155.

198 Köhler, Stellenwert Tanzanias, S. 21-22. Köhler, selbst ehemaliger Parlamentarischer Staatssekretär des BMZ, vertritt in diesem Text die These, dass die engen Beziehungen zwischen Tansania und der BRD ursächlich auf die Relationen im kirchlichen Bereich zurückzuführen sind. 199 BArch Koblenz, B 102/86803, BRD-Botschaft an AA, Dar es Salaam, 1.8.1966. 
bemüht, konkrete Projekte in Tanga „für die BRD“ zu identifizieren. ${ }^{200}$ Der Auftakt der Regionalplanung in Tansania überlappte nicht nur mit dem entwicklungspolitischen Trend des Grundbedürfnisansatzes, sondern auch mit den neuen Länderplanungen, die ab Anfang der 1970er Jahre im BMZ angefertigt wurden. Tanga war ein Labor, in dem der neue Ansatz, von „Projektitis“ und „Insellösungen“ abzugehen und die Projekte regional und sektoral untereinander abzustimmen, erprobt wurde. ${ }^{201}$ In der Praxis erhielt das von tansanischer Seite vertretene Verständnis einer Region als Großraum den Vorzug vor dem deutschen, kleinräumiger definierten Ansatz. Minister Eppler hatte bereits die Unterstützung einer ganzen Region zugesagt, aber BMZ-Beamte in Bonn hatten die Projektreichweite auf den Distrikt Korogwe reduziert. ${ }^{202}$ Das tansanische Büro des Premierministers sperrte sich gegen diese politisch inopportune Bevorzugung eines einzelnen Distrikts und setzte durch, die ganze Tanga-Region in den Plan (und die nachfolgende Finanzierung und Implementierung von Einzelprojekten) einzubeziehen. ${ }^{203}$ Die Regionalbehörden übten Druck auf das deutsche Team aus, das im Laufe von zwei Jahren, während viele Teams anderer Länder bereits nach wenigen Monaten Pläne ablieferten, noch immer nichts vorgelegt hatte. In Tanga erwartete man zudem nicht nur einen Plan, sondern möglichst schnell ,sichtbare Resultate“. ${ }^{204}$ So begann im Oktober 1974 die Umsetzung erster Projekte. ${ }^{205}$ Die tansanische Seite hatte es verstanden, die eigenen Wünsche, sowohl in Bezug auf die Größe als auch die Implementierung die eigene Position durchzusetzen.

Tansania profitierte dabei von Entwicklungsminister Epplers (SPD, 19681974) Anstrengungen, eine „kopernikanische Wende“ in der bundesdeutschen Entwicklungspolitik herbeizuführen und den Bedürfnissen der „Entwicklungsländer“ Vorrang vor Industrieinteressen zu einzuräumen. ${ }^{206}$ Die stark christlich geprägte Strömung, der Eppler angehörte, gewann Ende der 1960er-Jahre an Einfluss und „stellte das Motiv der Solidarität, verstanden als Menschheitssoli-

200 BArch Koblenz, B 213/7675, BRD-Botschaft an BMZ, Dar es Salaam, 23.9.1971.

201 Pollvogt, Zur Anatomie, S. 106-107.

202 Pilgram/Zils, TIRDEP, S. 27.

203 BArch Koblenz, B 213/7680, Aktualisierung des Länderhilfeprogramms Tansania, 8.6.1973, o.O., S. $60-61$.

204 Hofmeier sieht hier einen Unterschied zu Dar es Salaam: „Im Gegensatz zu den an aufwendige Planung und langsame Abwicklung aller internationalen Entwicklungshilfeorganisationen gewöhnten und entsprechend leidgeprüften Beamten der zentralen Ministerien in der Hauptstadt erwarteten die entscheidenden Leute in der Region möglichst schnell sichtbare konkrete Resultate.“ Hofmeier, Die Tanga-Region, S. 317.

205 Interview \#28, GTZ-Projektleiter; Pilgram/Zils, TIRDEP, S. 28.

206 Köhler, GTZ, S. 131-133. 
darität vor politischer Systemsolidarität, in den Vordergrund.“207 Während „genuine Entwicklungspolitiker“, also jene mit einem Interesse am Umbau der internationalen Wirtschaftsordnung, auch von „Solidarität“ sprachen, blieb „Hilfe“ (und später „Zusammenarbeit“) in der offiziellen Nomenklatur doch der bestimmende Begriff. ${ }^{208}$ Drei Aspekte waren programmatisch für die bundesdeutsche Entwicklungspolitik der 1970er Jahre: die Priorisierung der ärmsten Länder, die Grundbedürfnisorientierung und ländliche Entwicklung. ${ }^{209}$ Hier war die BRD Teil des westlichen entwicklungspolitischen Trends. Eppler setzte aber auch eigene Akzente und ging auf die stetige Forderung vieler Länder des globalen Südens ein, projektungebundene Warenhilfe nunmehr grundsätzlich (aber nicht ausnahmslos) ohne Lieferbindung zu vergeben, sodass mit BRD-Krediten Waren auf dem Weltmarkt erworben werden konnten. ${ }^{210}$ Die BRD mit ihrer Marktmacht konnte sich diesen Schritt erlauben, da auch ohne vertragliche Bindungen zahlreiche Aufträge an bundesdeutsche Firmen vergeben wurden und Gelder somit direkt zurückflossen (bzw. erst gar nicht in die „Empfängerländer“ gelangten). Eppler scheiterte jedoch mit seinem Versuch, diesen Grundsatz auch bei anderen westlichen Gebern im DAC durchzusetzen. ${ }^{211}$ Innenpolitisch gelang es ihm, die Position des BMZ zu stärken: 1972 war die Entscheidungshoheit über die entwicklungspolitischen Kernkompetenzen (Formulierung von Grundsätzen sowie Entscheidungen über Kapital- und Technische Hilfe) gesichert. ${ }^{212}$ Allerdings behielt das Auswärtige Amt weiterhin seine Hoheit in außenpolitischen Fragen, während Finanzministerium und der Haushaltsausschuss des Bundestages die finanziellen Spielräume absteckten. Grundsätzlich erachtete auch Eppler privatwirtschaftliche Interessen und staatliche Entwicklungshilfe als kombinierbar, es sei „völlig legitim, wirtschaftliche Interessen in diesem Lande für die Entwicklungspolitik nutzbar zu machen, [i]llegitim wäre lediglich das umgekehrte Verfahren: Entwicklungspolitik zum ausführenden Organ wirtschaftlicher Interessen zu degradieren.“213 Innenpolitisch blieb das BMZ trotz der Profilierung ein „Mauerblümchen in der Ressorthierarchie“, nicht zuletzt weil entwicklungspoli-

207 Unfried, Instrumente, S. 75.

208 Ebd., S. 75.

209 Ziai, Globale Strukturpolitik, S. 102.

210 Dieser Grundsatz wurde ab 1973 angewandt. Siehe BArch Koblenz, B 102/138294, Matthöfer (BMZ) an Wirtschaftsminister Friderichs, Bonn, 8.8.1973.

211 Zur Frage der Lieferentbindung in der BRD-Entwicklungspolitik und dem Versuch, dieses Prinzip im DAC durchzusetzen, siehe BArch Koblenz, B 102/138294.

212 Stockmann u.a., Entwicklungspolitik, S. 66; Messner, Entwicklungspolitik, S. 419.

213 Eppler in den BMZ-Mitteilungen 4/1970 zit. nach Rainer Brähler, Entwicklungspolitik und Bildungshilfe. Geschichte, Funktion, Legitimation, Frankfurt/Main 1986, S. 123. 
tische Themen trotz einer wachsenden Dritte-Welt-Bewegung kaum Wählerstimmen mobilisieren konnten. ${ }^{214}$ Eppler gelang es nicht, andere Ressorts für die Anliegen des globalen Südens zu sensibilisieren. ${ }^{215}$

So wirkten schon unter Epplers Nachfolger Egon Bahr (SPD, 1974-1976) wirtschaftliche Interessen im Zuge der Auswirkungen der ersten Ölkrise wieder stärker auf die Entwicklungspolitik ein. Der neue Bundeskanzler Helmut Schmidt schenkte Forderungen nach einer Neuen Weltwirtschaftsordnung, wie sie u.a. Nyerere vorbrachte, kein Gehör. Die Regierung zielte darauf ab, neue Rohstoffquellen zu erschließen und Arbeitsplätze in der Industrie trotz Nachfragerückgang zu erhalten. Der Grundsatz, dass westdeutsche Gelder bei Warenhilfe ungebunden zu sein hatten, wurde „im Rahmen der entwicklungspolitischen Vertretbarkeit“216 durch Ausnahmen für Consultingleistungen, Schiffs- und Lokomotivbau sowie andere „sensible Wirtschaftszweige“, die Exporteinbrüche verzeichneten, aufgeweicht. ${ }^{217}$ Die bundesdeutsche Bearbeitung der kapitalistischen Überproduktionskrise traf sich mit dem Interesse auf tansanischer Seite, bereits defekte chinesische Lokomotiven zu ersetzen oder Maßnahmen zu setzen, um die Abhängigkeit von Ölimporten zu verringern. 1975 drängte Nyerere die BRD, prioritär in die Erschließung tansanischer Kohle- und Eisenerzvorkommen zu investieren. ${ }^{218}$ Investitionen mit westdeutscher Beteiligung, darunter die Erkundung von Uranvorkommen, die Beschaffung von Eisenbahnlokomotiven oder der Bau einer Papierfabrik ${ }^{219}$ wurden geplant bzw. weiter umgesetzt. Die bisherigen Ergebnisse der tansanisch-deutschen Kooperation waren jedoch ernüchternd.

1972, zur Blütezeit der Dependenztheorie an der Universität Dar es Salaam, übten Wissenschaftler in der tansanischen Presse scharfe Kritik am Bau der bereits erwähnten Düngemittelfabrik, die zu diesem Zeitpunkt das größte Industrieprojekt in Tansania darstellte. Statt Importe zu substituieren, machte das Vorhaben weitere Importe und Investitionen notwendig, die durch die Aufwertung der D-Mark noch deutlich teurer ausfielen als geplant. Gleichzeitig sank der Weltmarktpreis für Dünger und dadurch die Exporterlöse, die Tansania sich von dem Ausmaß der Produktion erhofft hatte. Die Düngemittelfabrik stand symp-

214 Nuscheler 1995 zit. nach Ziai, Globale Strukturpolitik, S. 96.

215 Elshorst, Organisation, S. 20 -21.

216 BArch Koblenz, B 102/216260, Bundesministerin für wirtschaftliche Zusammenarbeit Schlei an Wirtschaftsminister Lambsdorff, Bonn, 7.10.1977.

217 Siehe z. B. BArch Koblenz, B 102/178519 Bd. 8, Vermerk über Staatssekretär-Besprechung am 24. 2.1977; ebd., B 102/216270, Preuß an German Airport Equipment, Bonn, 27.3.1979.

218 BArch Koblenz, B213/7682, BRD-Botschaft an AA, Dar es Salaam, 10.12.1975.

219 PAAA, C 6115, Botschaft der DDR in der VR Tansania, „Jahresanalyse 1978“, Dar es Salaam, 5.1.1979, Fol. S. 161-162. 
tomatisch für Fehlplanungen und die Vertiefung statt Überwindung von Abhängigkeiten vom Weltmarkt und westlichen Konzernen. ${ }^{220}$ In der BRD-Botschaft wuchs die Angst vor Skandalen, der Zerstörung des westdeutschen Rufs und der Belastung der politischen Beziehungen nicht nur aufgrund der Düngemittelfabrik, sondern auch aufgrund einer „Häufung“ von „Wucher- und Scheingeschäfte[n]“, „bei denen letzten Endes immer Tansania der Verlierer“ war. So exportierten etwa einige bundesdeutsche Firmen völlig unbrauchbare Maschinen aus dem 19. Jahrhundert. ${ }^{221}$ Die deutschen ExpertInnen vor Ort sprachen sich wiederholt ausdrücklich gegen kapitalintensive Vorhaben aus, die nur der deutschen Wirtschaft nutzten, aber kaum Effekte in Tansania, insbesondere der Schwerpunktregion Tanga, versprachen. Dazu gehörte etwa der Straßenbau in Lushoto - der dann trotzdem durchgeführt wurde. ${ }^{222}$

Die Spannungen zwischen den Netzwerken „alteingesessene[r] Wirtschaftskreise“ und VertreterInnen entwicklungspolitischer Positionen, die auch in der Botschaft anzutreffen waren, bestanden fort. ${ }^{223}$ Der „gute deutsche Name in diesem Lande“ war gleichwohl von der Kritik an den Investitionen und unlauteren Firmenpraktiken nicht gefährdet, wie die Botschaft berichtete: Nyerere war nach wie vor von der Qualität westdeutscher Erzeugnisse überzeugt; schon in den 1960er-Jahren hatte er die Anweisung gegeben, „bei staatlichen Maschinenbestellungen Deutschland erste Priorität zu geben“ und diese Anweisung 1971 für alle staatlichen Unternehmen wiederholt - womöglich einmal mehr, um die Abhängigkeit von Großbritannien weiter zu verringern. ${ }^{224} \mathrm{Zu}$ diesem Zeitpunkt bestanden jedoch bereits fünfzehn Prozent der tansanischen Auslandsverschuldung in deutschen Guthaben. 1976 schwang sich die BRD kurzzeitig zum größten Außenhandelspartner Tansanias auf. ${ }^{225}$ 18,1\% aller tansanischen Exporte gingen nach Westdeutschland, während umgekehrt 15,4\% aller tansanischen Importe aus der BRD stammten, was nur von Großbritannien übertroffen wurde. ${ }^{226}$ Aus

220 Andrew Coulson, Tanzania's Fertilizer Factory, in: Andrew Coulson, Hg., African Socialism in Practice. The Tanzanian Experience, Nottingham 1979, S. 184-190.

221 BArch Koblenz, B 213/7675, BRD-Botschaft an AA, Dar es Salaam, 22.9.1971.

222 BArch Koblenz, B 213/33047, H. (TIRDEP) an BfE, Tanga, 5.11.1974.

223 BArch Koblenz, B 213/7672, BRD-Botschaft an AA, Dar es Salaam, 9.8.1969, S. 7-8.

224 BArch Koblenz, B 213/7672, Anlage zum Schreiben der BRD-Botschaft an AA, Dar es Salaam, 9.8.1969, S. 8.

225 Röhnelt, Die bundesdeutsche Entwicklungshilfe, S. 59-60; Wirth, Aspekte, S. 37.

226 Röhnelt, Die bundesdeutsche Entwicklungshilfe, S. 59-60, 70-72. Deutsche Firmen in Tansania bzw. Firmen mit Beteiligung mit Kapital aus der BRD waren (Stand 1974) z. B. Gauff KG, Kilimanjaro Textile Corporation, Lufthansa, Simba Plastics oder Tanganyika Sisal Spinning Co. Ltd. (TASCO). Deutsche Beteiligungen gab es auch an Großfarmen und Plantagen. Siehe Schneider-Barthold, Tanzania, S. 229-230. 
bundesdeutscher Perspektive blieb Tansania jedoch eine wirtschaftliche Marginalie. Die bundesdeutschen Privatinvestitionen nach Tansania hatten bis 1977 DM 23,9 Millionen ausgemacht, was nur 1,1 Prozent der vorwiegend nach Südafrika und Libyen gehenden Direktinvestitionen am Kontinent entsprach. ${ }^{227}$ Auch die Bedeutung der „Entwicklungshilfe“ als Subvention für strauchelnde BRD-Wirtschaftszweige war in anderen Ländern weitaus umfassender als in Tansania, wie z. B. Lieferungen der exportorientierten Lokomotivbauindustrie im Rahmen von Warenhilfeprogrammen belegen. ${ }^{228}$

Scharfe Kritik von tansanischer Seite musste die BRD bis 1974 für ihre Beziehungen zur Kolonialmacht Portugal (die als NATO-Verbündeter militärische Hilfe und als „Entwicklungsland“ Entwicklungshilfe aus der BRD erhielt) und zu den weißen Minderheitsregimen in Rhodesien und Südafrika hinnehmen. Die DDR wurde nicht müde, die BRD anhand dieser Beziehungen als imperialistisch zu „entlarven“. ${ }^{229}$ Publizistische Kreise in Tansania - einige Journalisten hatten Seminare und Studiengänge in der DDR absolviert - stimmten in die Kritik ein, aber nur wenige PolitikerInnen sahen darin einen zureichenden Grund, um die Beziehungen mit der BRD infrage zu stellen oder auch nur entscheidend zu belasten. Nyerere versuchte bisweilen gar zu vermitteln. Die in Dar es Salaam ansässige Führung der mosambikanischen FRELIMO etwa verweigerte bis 1973 kategorisch die Kooperation mit der Friedrich-Ebert-Stiftung (FES) in Tansania. ${ }^{230}$ Der Vorsitzende der FRELIMO Samora Machel ging Treffen mit FES-Vertretern aus dem Weg, obwohl Nyerere ihm mehrmals zur Kontaktaufnahme geraten hatte. ${ }^{231}$ 1976 gewann Tansanias geostrategische Position nochmals an Bedeutung. Die sozialistische Orientierung Angolas und Mosambiks nach den Unabhängig-

227 Rolf Hofmeier Möglichkeiten und Grenzen deutscher Entwicklungspolitik gegenüber Afrika, in: Helmut Bley/Rainer Tetzlaff, Afrika und Bonn: Versäumnisse und Zwänge deutscher AfrikaPolitik, Reinbek bei Hamburg 1978, S. 192-253, hier: S. 247.

228 Siehe Dokumente über das Rehabilitierungsprogramm für die Tazara-Bahn in PAAA, ZW 125228

229 Schleicher, Afrika in der Außenpolitik der DDR, S. 25; siehe auch PAAA, AV Neues Amt 13466, BRD-Botschaft Tansania, Länderaufzeichnung über die Vereinigte Republik Tansania, Stand 1.3.1976.

230 PAAA, B58 III B 2/1069, BRD-Botschaft der an AA, Dar es Salaam, 8.12.1970. Das entsprechende Interview hatten DED-Entwicklungshelfer mit Samora Machel geführt.

231 FES-Schreiben vom 27.3.1973 zit. nach Volker Vinnai, Demokratieförderung in Afrika. Die Zusammenarbeit der Friedrich-Ebert-Stiftung mit politischen Parteien und Befreiungsbewegungen in Afrika. Schriftenreihe der Friedrich-Ebert-Stiftung, Münster 2007, 38. Die Opposition im Bundestag hatte zudem auch kräftig gegen mögliche Zusammenarbeit mit den „kommunistischen/marxistischen Terroristen“ polemisiert. Zum Verhältnis der BRD zu Portugal siehe auch Lopes, West Germany. 
keiten 1975 machte offensichtlich, dass der Westen im südlichen Afrika an Boden verlor; gleichzeitig setzte sich der Befreiungskampf gegen die weißen Minderheitsregime in Südafrika und Rhodesien fort. Wie unter der US-amerikanischen Carter-Regierung, die nach dem Desaster in Vietnam auf Diplomatie setzte, wurden auch in der BRD Gruppen einflussreicher, die auf eine Annäherung setzten. Entwicklungsministerin Marie Schlei (SPD, 1976-1978) knüpfte 1976 Kontakte zu Befreiungsbewegungen wie dem ANC - die laut Protesten der konservativen Opposition nach wie vor als „terroristische Organisationen“ einzustufen waren - und schaffte es, eine Erhöhung der Mittel für die Gruppe der „Konfliktrandstaaten“ (Frontline States) im südlichen Afrika durchzusetzen. Während Schleis Amtszeit wurden die Mittel für diese Länder vervierfacht. ${ }^{232}$ Zehn Prozent aller Mittel, die afrikanischen Ländern in bilateralen Abkommen zugesagt wurden, waren Tansania gewidmet. ${ }^{233}$

Diese umfassenden zugesagten Mittel wurden jedoch nie voll ausgeschöpft. Eine Unterscheidung zwischen Zusagen und Verwendung lässt die zunehmende Überforderung der tansanischen Bürokratie mit der Verwaltung der westlichen Transfers kenntlich werden. 1977 wurden nur 75 Prozent der geplanten BRD-Entwicklungshilfegelder ausgegeben, „weil die tansanischen Partner [...] keine höheren Geldmengen absorbieren konnten“. ${ }^{234}$ Aus bundesdeutscher Sicht lag die Ursache der fehlenden „Absorptionskapazität“, wie die zweckgerechte Verwendung von Ressourcen im technizistischen Jargon des Feldes genannt wird, in der tansanischen Verwaltung, während Tansania (und andere Empfängerländer) das bundesdeutsche „Antragsprinzip“ kritisierten, demzufolge Entwicklungshilfe immer nur auf Basis einzelner Projektanträge vergeben wurde und somit im Gegensatz zu Rahmenkrediten einen enormen bürokratischen Aufwand verursachte. In der Praxis ${ }^{235}$ wurde das Antragsprinzip zudem oft umgekehrt: „Die deutschen Regierungsdelegationen kamen ja schon mit unterschriftsreifen Projektvorschlägen an, immer“, erinnerte sich ein ehemaliger BMZ-Beamter, der in seiner Zeit als GTZ-Projektleiter auch Anträge für die tansanischen Institutionen ausformulierte:

232 Bohnet, Geschichte, S. 87-89.

233 Röhnelt, Die bundesdeutsche Entwicklungshilfe, S. 43-44.

234 Ebd., S. 69-70.

235 Wie weiter oben beschrieben wurde es in den 1980er Jahren auch formell möglich, dass die BRD die Vorschläge einbrachte. 
Alle Papiere, die nach Deutschland gehen, habe ich geschrieben. [...] Diese sogenannten Regierungsverhandlungen waren ja keine Verhandlungen. Die Summe stand schon fest, alles, das war schon im Haushaltsausschuss genehmigt, bevor es überhaupt anfing. ${ }^{236}$

Hauptmodus der Technischen Hilfe war bis in die 1970er-Jahre die Finanzierung, Begleitung und Durchführung von einzelnen Projekten, die in den tansanischen Fünfjahresplänen aufgelistet waren. DDR-seitig wurden diese Pläne nicht als tatsächliche Planung, sondern nur als „Programmierung“ eingeschätzt ${ }^{237}$. Praktisch dienten Tansania die Entwicklungspläne als aid shopping list, aus der sich Geber die ihnen genehmen Projekte herauspicken sollten. So überreichte Tansania (nach Vorabsprachen) der BRD 1977 in Hinblick auf die Periode von 1978-1981 eine Liste von sechzehn Projekten, viele davon zur Fortführung, mit der Bitte um Technische Hilfe im Wert von 133 Mio. DM. ${ }^{238}$ Da Tansania unmöglich auf die Kriterien und Vorzüge aller einzelnen Geber eingehen konnte, wurden auch gleich Anfragen für technical missions gestellt, die dann für die entsprechende Detailausarbeitung der Vorhaben zu sorgen hatten. ${ }^{239}$ Diese Strategie war zweischneidig: Sie erhöhte die Chancen, dass Projekte tatsächlich gefördert und umgesetzt wurden, minimierte aber den tansanischen Einfluss und jede Chance auf eine abgestimmte Gesamtplanung. Auf Planungsebene hingegen hatte sich das BRD-Personal - so eine Einschätzung der Botschaft im Jahr 1972 - längst an Alleingänge gewöhnt und ging davon aus, „dass die Planung von Projekten im Wesentlichen ihre Sache sei“, mit dem Ergebnis, dass sich die tansanischen Stellen selbst dann nicht einschalten konnten, wenn sie dessen fähig und willens waren. ${ }^{240}$

Die tansanische Regierung versuchte wiederholt (mit Schützenhilfe einiger BRD-ExpertInnen, die vom Ideal der Partnerschaftlichkeit auf Augenhöhe überzeugt waren), einen Teil der Entwicklungshilfe vom Projektprinzip auf Programmhilfe umzustellen. ${ }^{241}$ Solche Rahmenkredite, wie sie die skandinavischen

236 Interview \#25, Ehemaliger GTZ-Projektleiter.

237 PAAA, MfAA, B 272/74, Generalkonsulat der DDR in der VR Tansania, „Bericht zu einigen Problemen des Planungssystems in der VRT/Festland“, Dar es Salaam, 16. 8.1969.

238 Röhnelt, Die bundesdeutsche Entwicklungshilfe, S. 116-117.

239 BArch Koblenz, B 102/86803, Principal Secretary Treasury an BRD-Botschafter, Dar es Salaam, 22.9.1969.

240 BArch Koblenz, B 213/7678, Müllenheim (BRD-Botschaft) an AA, Dar es Salaam, 19.7.1973. Die Botschaft liefert in diesem Schreiben dafür auch konkrete Belege.

241 Eine dieser vorsichtigen Anfragen, mit Verweis auf die skandinavische Praxis, stammt aus dem Jahr 1969 (BArch Koblenz, B 102/86803, BRD-Botschaft an AA, Dar es Salaam, 2.10.1969). Siehe auch Interview \#102, GTZ-Experte, sowie Rolf Hofmeier, Die Tanga-Region - Regionaler Schwerpunkt der deutschen Entwicklungshilfeprogramme in Tansania, in: Werner Pfennig u.a., 
Länder oder auch Kanada vergaben, eröffneten der Empfängerregierung einen beträchtlichen Handlungsspielraum, da so die zu fördernden Projekte innerhalb eines breit abgesteckten Bereichs selbst ausgewählt werden konnten. ${ }^{242}$ In Bonn wurde ein solches Vorgehen aus haushaltsrechtlichen Gründen lange Zeit strikt abgelehnt. Wie ein ehemaliger Projektleiter überspitzt formulierte, war im „Grunde genommen [...] der Finanzminister in Bonn zuständig [gewesen], was man in Usambara macht“. ${ }^{243}$

Inhaltlich verschob sich die Orientierung der Projekte nicht einfach in Richtung Grundbedürfniserfüllung, wie die Diskurse nahelegen, sondern verbreiterte sich. Der insgesamt 22,5 Millionen DM (ohne tansanische Leistungen) teure Versuch zum Aufbau einer landwirtschaftlichen Versuchs- und Lehranstalt in Ifakara wurde von Presse und Botschaft gleichermaßen als „Ruine“ und „Pleiteprojekt" ohne vorzeigbare Resultate bezeichnet und schließlich durch ein Machtwort von Entwicklungsminister Bahr für beendet erklärt - entgegen dem Wunsch Nyereres, der sich weiterhin neue Erkenntnisse für die landwirtschaftliche Entwicklung erhoffte. ${ }^{244}$ Ein neuer Schwerpunkt ab Anfang der 1970er-Jahre waren Bildungsprojekte mit einem technischen Einschlag, in erster Linie die Ingenieurfakultät an der Universität Dar es Salaam (siehe Kapitel 7) und das Technical College in Arusha. Die Ausbildung technischer und ingenieurwissenschaftlicher Fachkräfte in Tansania wurde damit stark von der BRD geprägt, zumal auch noch die Unterstützung der staatlichen National Engineering Company (siehe Kapitel 6.3) und des Institute of Production Innovation hinzukamen. Ab Mitte der 1970er gewann die multisektorale ländliche Entwicklung an Bedeutung - das Regionalentwicklungsprogramm in der nordöstlichen Tanga-Region wurde zu einem der weltweit größten GTZ-Projekte (siehe Kapitel 8). Ein Projekt zur Züchtung produktiverer Kokosnussvarietäten, kofinanziert von der Weltbank, nahm finanziell ebenfalls beträchtliche Ausmaße an und lief über mehr als zwei Jahrzehnte.

In der Finanzhilfe dominierten industrielle und infrastrukturelle Entwicklungsprojekte. Das 1970 begonnene Umsiedlungsprojekt in Buguruni, einem Stadtteil Dar es Salaams, wurde von der KfW 1979 als Fehlschlag eingeschätzt nicht nur angesichts organisatorischer Schwierigkeiten und jahrelanger Verzö-

Hg., Entwicklungsmodell Tansania, Sozialismus in Afrika: Geschichte, Ökonomie, Politik, Erziehung, Frankfurt/Main, New York 1980, S. 310-339, hier: 326-330. Ein Plädoyer für Programmhilfe gibt auch Werner Dolph, Die ungeliebten Experten, in: Die Zeit, 15.6.1973.

2421976 erklärte sich die BRD bereit, den Modus der Programmfinanzierung zu testen - ein Experiment, das in den 1980er Jahren wieder beendet wurde. BArch Koblenz, B 213/33056, Ehmann (BMZ), Protokoll eines Gesprächs mit Finanzminister Jamal, Bonn, 4.3.1976.

243 Interview \#25, ehemaliger GTZ-Projektleiter.

244 Der Spiegel 1979/19, S. 150. 
Tabelle 3.1: Wichtigste Projekte der entwicklungspolitischen Zusammenarbeit zwischen der BRD und Tansania, Stand 1982 (Quelle: PAAA, AV Neues Amt 13466, Länderaufzeichnung Tansania 1982)

\begin{tabular}{lll}
\hline Projekt / Programm & Zusagen in Mio. DM / ExpertInnen & Projektbeginn \\
\hline Finanzielle Zusammenarbeit & & \\
\hline 4 städtische und 1 ländliches & 108 & 1973 \\
Wasserversorgungsvorhaben & & \\
2 Straßen in Daressalam & 71 & 1973 \\
Ländliche Straße in den Usambara-Bergen & 25 & 1980 \\
8 Warenhilfen & 127 & 1973 \\
Kidatu-Kraftwerk & 70 & 1978 \\
Metera-Kraftwerk & 48,5 & 1982 \\
Elektrifizierung von Landstädten & 21 & 1976 \\
Papierfabrik Mufindi & 70 & 1978 \\
Lokomotiven für die tansanische Eisenbahn & 29 & 1978 \\
Eisenbahnbrücken der Tanzania Railways & 15 & 1980 \\
Corporation (TRC) & & \\
Fernmeldeeinrichtung der TRC & 7 & 1980 \\
Papierfabrik Mufindi & 80 & 1978 \\
Sägewerk der Tanzania Wood Industries & 10 & 1980 \\
Corporation (TWICO) & & 1973 \\
2 Entwicklungsbanken & 30 & 1970 \\
Infrastrukturprojekt in Buguruni & 12 &
\end{tabular}

\section{Technische Zusammenarbeit}

Tanganyika Development and Finance Co. $\quad$ 4,4 / 2

1978

Ltd.

Faculty of Engineering Dar es Salaam

$71,8 / 14$

1974

Buguruni Housing Project

$1,8 / 1$

1978

National Transport Corporation

$11,3 / 4$

1976

District Laboratory

$4,2 / 2$

1980

Technical College Arusha

$33,6 / 13$

1976

National Engineering Company

$13 / 7$

1976

Institute of Production Innovation

$7,9 / 3$

1978

Förderung der Kokosnusswirtschaft

$21,5 / 11$

1978

MATI Nyegezi (Landwirtschaftl. Ausbildung)

$16,9 / 5$

1978

Tanga Integrated Rural Development

87,4 / 19

1974

Programme (TIRDEP)

College of Business Education Dodoma

$10 / 2$

1978

Ausbildung von Orthopädie-Technikern

$8,3 / 3$

1980 
gerungen beim Bau neuer Wohneinheiten, sondern auch aufgrund von Schwierigkeiten, „die Menschen aus ihrer gewohnten Umgebung zu vertreiben“. ${ }^{245}$ Entsprechende Projektkonzeptionen, die die Aus- und Rücksiedlung von mehreren Tausend Menschen bedeuteten, galten ,aus heutiger Sicht wegen der sozioökonomischen Problematik abzulehnen“. ${ }^{246}$ Dieses Projekt weist zudem auch darauf hin, dass Zwang bei Umsiedlungsvorhaben nicht nur auf dem Land, sondern auch in (peri-)urbanen Räumen Anwendung fand - und hier westliche Geber wie die BRD eine direkte Mitverantwortung zu tragen hatten.

Tansanias Schwerpunktstatus für die BRD schlug sich quantitativ auch in der Personalentsendung nieder. 1970 waren über eintausend GAWI-Fachkräfte im Auslandseinsatz, davon 45 (also über vier Prozent) in Tansania. ${ }^{247}$ In den Jahren 1976 und 1982 war diese Zahl auf 69 bzw. 86, also auf über sechzehn Prozent aller weltweit entsandten GTZ-ExpertInnen, angewachsen - mehr als in jedem anderen afrikanischen Land. ${ }^{248} 1977$ listete die GTZ in Tansania vierzehn Projekte der Technischen Hilfe, was ebenfalls alle anderen afrikanischen Länder übertraf (Tabelle 3.1). ${ }^{249}$ Darüber hinaus blieb Tansania ein klassisches Entsendeland für den DED, der wie die Freiwilligendienste anderer westlicher Länder in erster Linie offene Positionen im Gesundheits- und Bildungswesen beschickte. Die Zahl der Entsandten stieg zwischenzeitlich auf ein Rekordhoch von 122 (1975) und pendelte sich bis Anfang der 1980er zwischen 80 und 90 ein. 1989 waren noch 50 DEDEntwicklungshelferInnen im Land aktiv. ${ }^{250}$

\section{Ein unnatürliches Bündnis}

Die DDR brach ihre Zelte in Sansibar 1971/72 fast vollständig ab und setzte die Personalentsendung mit einem Fokus auf das Festland fort. In den späten 1960er

245 PAAA, ZW 125226, KfW, Abschlusskontrollbericht und Vorschlag für die Verwendung von Restmitteln - Infrastruktur Buguruni (Tansania), o. D. [1979], S. 2.

246 Ebd., S. 10.

247 PAAA, ZA 100921 (GAWI Dienstrecht u.a.), Personal-Statistik 1971, S. 16.1965 waren es 36, 1967 47, Tiefststand 1969 mit 33 und von da an Anstieg bis 1971 auf 46. Die Verzögerung des Anstiegs bzw. des Abfalls im Abgleich mit den politischen Ereignissen ergibt sich daraus, dass die GAWI bereits begonnene Projekte noch abschloss bzw. neue Verträge üblicherweise erst mehrere Monate nach ihrer Unterzeichnung implementiert wurden.

248 Länderaufzeichnungen in PAAA, AV Neues Amt 13466. Die tatsächlichen Zahlen könnten sogar noch höher sein, da in den Übersichten nur die wichtigsten Projekte aufgeführt waren. 249 Auslandskurier Nr. 7 (18. Jahrgang), Juli 1977, S. 3.

250 DED, „List of German volunteers as at April 1989“, Kopie im Besitz des Autors (zur Verfügung gestellt von ehemaligen DED-Entsandten). 
und frühen 1970er-Jahren ging die DDR auf tansanische Entsendewünsche für ausführendes Personal (z. B. für LehrerInnen oder medizinisches Personal) ein, obwohl Berater- oder Ausbildereinsätze in zentralen Stellen als „wirksamer“ erachtet wurden. Hier ging es nicht um ökonomischen Gewinn, sondern um Einflussmöglichkeiten. Übliche Kriterien, mit denen die Botschaft für oder gegen Einsatzmöglichkeiten und das „Halten von Positionen“ argumentierte, waren „Wirksamkeit“ und „Einflussnahme“251 - also fachliche und politische Aspekte, nicht ökonomische Effizienz.

TierärztInnen (1966 - ca. 1980) waren die am längsten präsente Gruppe der Wissenschaftlich-Technischen Zusammenarbeit. Aus Sicht der ostdeutschen Veterinärmedizin eignete sich Tansania hervorragend als Ausbildungsstätte, Datenquelle und Absatzmarkt für neue Produkte, die aufgrund der Forschungen entwickelt wurden (das Gleiche ließe sich für westdeutsche Landwirtschaftsprojekte zeigen, und zwar in viel größeren Proportionen). Die entsandten VeterinärInnen testeten einige Produkte, etwa das Schädlingsbekämpfungsmittel Pedix 67, das den Zeckenbefall von Rindern abtötete und günstiger war als ein vergleichbares englisches Produkt. Ein Entsandter schlug vor, „dass sich unsere HPA [Handelspolitische Abteilung des Generalkonsulats, Anm. d. Verf.] den TestBericht aus Tabora schicken lässt und kommerzielle Verhandlungen mit der tansanischen Seite aufnimmt, um dieses Mittel zu exportieren.“252 Somit war Tansania auch als Labor für die noch im Aufbau befindlichen DDR-Tropenwissenschaften von enormer Bedeutung; WissenschaftlerInnen aus Leipzig waren oft gesehene Gäste im Land.

Noch langlebiger war nur die DDR-Präsenz im Bildungssektor. Den Beginn machten in der zweiten Hälfte der 1960er-Jahre FachlehrerInnen in naturwissenschaftlichen Fächern an Sekundarschulen. Tansania versuchte durch die Anfrage an die DDR 1968 die Lücken zu stopfen, die durch den Abzug des britischen Lehrpersonals entstanden waren. Eine außergewöhnlich einflussreiche Rolle nahm ein DDR-Experte ein, der sich Anfang der 1970er Jahre im FRELIMOExilcamp in Bagamoyo, das zugleich als Ausbildungsstätte diente, vom misstrauisch beäugten Lehrer zunehmend zu einem Vertrauensmann der ansässigen FRELIMO-Führung hinaufarbeitete. ${ }^{253}$ Ab Mitte der 1970er Jahre verlagerte sich der Schwerpunkt der Personalentsendung zu Technischen Colleges und Lehrer-

251 PAAA, C 773/74, Schreiben Handelsrat Hartmann an HA-Leiter WTZ mit Entwicklungsländern im Min. für Außenwirtschaft Müller, Dar es Salaam, 3.7.1970, Fol. 40.

252 BArch Berlin, DR 3/2. Schicht/B 1449/1b, Michalski, Bericht über meinen Besuch im Veterinary Investigations Centre (VIC) Tabora, Dar es Salaam, 16. 2.1968, S. 3.

253 BArch Berlin, DR 2/25496, O. B., Bericht über den Einsatz als Berater und Lehrer bei der FRELIMO, Dar es Salaam, 21 November 1972, S. 10. 
bildungsinstituten - eine Entwicklung, die aus der zunehmenden Nationalisierung des Lehrkörpers in den Sekundarschulen resultierte und die folglich auch LehrerInnen anderer Staaten, darunter DED-EntwicklungshelferInnen, durchliefen. ${ }^{254} \mathrm{Ab} 1969$ unterrichten DDR-UniversitätslehrerInnen in Dar es Salaam in geistes-, kultur- und sozialwissenschaftlichen Fächern (siehe Kapitel 7).

1970 waren 33 (durch staatliche Institutionen entsandte) DDR-SpezialistInnen auf dem tansanischen Festland aktiv, 1980 nur noch 17, und 18 im Jahr 1990. Selbst die Entsandten des FDGB und jene ExpertInnen mit eingerechnet, die in FRELIMO- und ANC-Flüchtlingscamps unterrichteten oder Bauprojekte umsetzten, erreichte die Gesamtzahl nie wieder auch nur annähernd die gleiche Höhe wie in Sansibar Ende der 1960er Jahre. Fast alle - ausgenommen die hier nicht mit eingerechneten technischen Spezialisten im kommerziellen Projekt zum Aufbau einer Textilfabrik in Mbeya - arbeiteten nicht in Projekten, sondern waren in tansanische Strukturen integriert und besetzten reguläre Planstellen des öffentlichen Dienstes unter meist tansanischen Vorgesetzten.

Einzelne DDR-Berater arbeiteten in den Ministerien für Landwirtschaft (ab Anfang der 1970er-Jahre), Nationale Erziehung (mind. 1974-1980), Wasser und Ressourcen (1971-1981) sowie Planung, Bau und Finanzen (alle 1980er-Jahre). Für die meisten dieser Berater sind kaum Archivalien auffindbar, laut Interviewaussagen mussten einige von ihnen keine schriftlichen Berichte verfassen. Zwei Bildungsberater am Institute of National Education arbeiteten die Lehrpläne für eine polytechnische Schulbildung nach DDR-Vorbild an tansanischen Grundschulen aus. Abgesehen von einigen Modellversuchen blieben die Bemühungen polytechnischen Unterricht einzuführen wirkungslos, zumal die DDR nicht auf tansanische Forderungen einging, auch Unterrichtsmaterialien und Werkzeuge bereitzustellen. ${ }^{255}$ An diesem Beispiel zeigt sich die Diskrepanz zwischen dem intern proklamierten DDR-Interesse, Konzepte und Modelle zu übertragen, während Tansania vor allem an materiellen Transfers interessiert war. Die Einschätzung eines der DDR wohlgesinnten Dekans an der Universität Dar es Salaam aus dem Jahre 1981, das tansanische Bildungssystem bewege sich hin zu einem Muster „modelled off the GDR experience“, zeugt von einem gewissen Einfluss, ist jedoch deutlich überzogen. ${ }^{256}$

254 BMZ, B 213/63790, BRD-Botschaft, Entwicklungspolitischer Zweijahresbericht, Dar es Salaam, August 1987, S. 8.

255 BArch Berlin, DR 2/50567, Lehrergruppe in der VR Tansania, Jahresbericht 1979, Dar es Salaam, 15.11.1979, S. $23-25$.

256 BArch Berlin, DR 2/50567, Dean of Faculty of Commerce and Management Edwards, Working Paper „Curriculum Development - A Comparative Review“ for Curriculum Development Committee, Ministry of National Education, Tanzania, o.O., 1981, S. 42. 
Prestigeträchtige Großprojekte schienen angesichts der zunehmenden internationalen Anerkennung der DDR ab 1970 nicht mehr gewinnbringend und zudem riskant, da vorangegangene Versuche in Sansibar zu Konflikten und Enttäuschungen geführt hatten. Dieses Schicksal ereilte auch kleinere Vorhaben auf dem Festland. So hatte die DDR zur Unterstützung ihrer VeterinärexpertInnen einen Laborwagen geschickt, der mangels Ersatzteilen für über zwei Jahre nicht einsatzfähig war. Eine Anlage zur Fleischverarbeitung wurde ohne Anleitungen zur Inbetriebnahme geliefert, zudem blieb auch hier die Ersatzteilfrage ungeklärt. Die DDR-Kräfte vor Ort kamen zu dem Schluss, dass solche Geschenke der DDR wenig Nutzen brachten, zu Abhängigkeiten führten und allen Seiten - außer dem lachenden Dritten, der BRD - einen Bärendienst erwiesen:

Dieses kostspielige Geschenk [der Laborwagen] wirkt nun permanent als politisches Argument gegen die sozialistische DDR, denn natürlich werden Vergleiche zu der fast perfekt organisierten Unterstützung durch Westdeutschland gezogen. [...] Man zweifelt hier bereits daran, daß die DDR ein verläßlicher, guter Partner sein kann. ${ }^{257}$

Materielle Transfers in den folgenden Jahren beschränkten sich daher auf Solidaritätssendungen über den FDGB und das Deutsche Rote Kreuz für Sansibar und die in Tansania präsenten Befreiungsbewegungen, v.a. die FRELIMO und den ANC, sowie vereinzelte Lieferungen in geringem Umfang als flankierende Maßnahmen zum Personaleinsatz im Bildungsbereich.

Das in materieller Hinsicht bescheidene Ausmaß der Kooperation steht in einem Spannungsverhältnis zur Einschätzung von Ulf Engel und Hans-Georg Schleicher, dass Tansania in den 1970er-Jahren zu einer „zentralen Arena für die Afrikapolitik“ der DDR wurde. ${ }^{258}$ Die Gründe dafür waren politischer, wirtschaftlicher und ideologischer Natur. Die immer wieder als Gemeinsamkeit betonten Grundsätze des Antirassismus und Antiimperialismus konnten die Kluft zwischen den Sozialismusentwürfen, vor allem aber den inkompatiblen strukturellen Positionen auf dem globalen Feld nicht überbrücken. Entscheidend waren in Verbindung mit diesen Positionen auch persönliche Ansichten, die mit ökonomischen und ideologischen Fragen zusammenhingen. Klauseln, die die DDR gerne in Abkommen untergebracht hätte, lehnte Nyerere in Verhandlungen aufgrund bestehender Vereinbarungen mit der BRD ab - „mit dem Hinweis, dass seine Hände gebunden wären, und zwar an wirtschaftliche Hilfe - und er nannte einen

257 BArch Berlin, DR 3/2. Schicht/B 1449/1b, Parteisekretär SED GO Tabora und Staatl. Leiter der Spezialistengruppe Tabora an Limex, MHF und Rat für Land- und Nahrungsgüterwirtschaft, Tabora, 26.7.1971, S. 2, 4.

258 Engel/Schleicher, Die beiden deutschen Staaten, S. 178. 
Millionenbetrag“, wie der ehemalige Botschafter verzeichnete. ${ }^{259}$ Wirtschaftliche und politische Interessendivergenzen setzten der „Freundschaft“ also Grenzen. Im Ost-West-Konflikt verortete sich Tansania eindeutig in einer blockfreien Position, während die DDR im Warschauer Pakt und in ein Nahverhältnis mit der UdSSR gebunden war. ${ }^{260}$ Nyereres Außenpolitik war aus DDR-Sicht keine konsequente Blockfreienpolitik, sondern eine instabile „Schaukelpolitik“, die auf dem vermeintlich falschen (und oft als „maoistisch“ diskreditierten) Prinzip des NordSüd-Gegensatzes beruhte. ${ }^{261}$

Seit den 1960er-Jahren proklamierten Eliten aus der Sowjetunion und der DDR, in Rückgriff auf die Theorie der drei revolutionären Hauptströme, dass zwischen der sozialistischen Welt und den nationalen Befreiungsbewegungen bzw. jungen Nationalstaaten wie Tansania eine Interessenidentität im Kampf gegen den Imperialismus und daher ein „natürliches Bündnis“ bestehe. Vom Blockfreienvertreter Nyerere hieß es hierzu ganz eindeutig, Tansania habe weder permanente Feinde noch permanente Freunde und erst recht keine „natürlichen Freunde“, wie er 1979 in Kuba verlauten ließ. ${ }^{262}$ Schon 1961 hatte Nyerere die Staaten des „sozialistischen Blocks“ dafür kritisiert, sich in Afrika nicht anders als die Staaten des „kapitalistischen Blocks“ zu verhalten und den eigenen Reichtum zur Erlangung von Macht und Prestige einzusetzen - nicht aber zur Erfüllung menschlicher Grundbedürfnisse, wie es im Zentrum seiner Politik stehen sollte. Die entscheidende Unterteilung der Welt bestehe somit nicht zwischen Ost und West oder Kapitalismus und Sozialismus, sondern zwischen dem reichen Norden und dem armen Süden. ${ }^{263}$

Der bekennende Katholik Nyerere lehnte den doktrinären Marxismus-Leninismus samt dem Postulat vom Klassenkampf als wichtigster fortschrittsbringender Dynamik als unbrauchbar für Tansania ab und betonte auch in den direkten Gesprächen mit dem DDR-Botschafter, „dass seine Sozialismusauffassung bedeutende Unterschiede zum osteuropäischen Sozialismus aufweise. “264 Derartige Distanzierungen gab es in Richtung Sozialdemokratie nie. Manche Äußerungen, die Tansania vor allem strategisch als rhetorische Schilde zur Verteidi-

259 Matthes, Zur Entwicklung, S. 80.

260 Ebd., S. 75-76.

261 Interview \#110, DDR-Diplomat.

262 Rede von Julius Nyerere im September 1979 in Havanna, zit. nach O. M. Ole-Parsalaw, On Non-Alignment, in: Mbioni IX/6 (1980), S. 1, Übersetzung E. B.

263 Die Rede The Second Scramble for Africa wurde erstmals 1961 gehalten, sie ist abgedruckt in Julius Nyerere, Freedom and Unity: A Selection from Writings and Speches, 1952-1965, Dar es Salaam 1966.

264 Matthes, Zur Entwicklung, S. 76. 
gung der eigenen Souveränität oder Beruhigung westlicher Staaten dienen sollten, interpretierte die DDR als dezidiert antisowjetisch und antikommunistisch, so etwa Nyereres (aus einer antiimperialistischen Haltung erwachsener) Protest gegen den Einmarsch der Sowjetunion im Prager Frühling 1968. Eine Kooperation zwischen der SED und der TANU konnte sich auf dieser Basis (vorerst) nicht entwickeln, war die tansanische Regierungspartei doch keine „Partei neuen Typus“, sondern - so ein DDR-internes Urteil - eine Partei mit dem „Charakter einer Sammlungsbewegung“, die es nie geschafft hatte, ihre Führungsrolle in Staat und Gesellschaft durchzusetzen. ${ }^{265}$ Man sollte zudem nie vergessen, so Botschafter Matthes 1975, dass Tansania eine „in der Entwicklung Jahrhunderte umfassende Rückständigkeit zu überwinden hat und ein vom Kleinbürgertum getragenes revolutionär-demokratisches Konzept verwirklicht, das vom Marxismus-Leninismus noch weit entfernt ist."266 In dieser Darstellung der Gesellschaftsmodelle waren die Sowjetunion und die DDR Tansania geschichtlich um Längen voraus; Tansania befand sich auf einer fernen Vorstufe dessen, was die DDR bereits erreicht hatte. Entsprechend gering war die Bereitschaft, Ujamaa als eigenständiges Modell ernst zu nehmen. Auch den westlichen Entwicklungshilfetrend zur Befriedigung von Grundbedürfnissen, der viele Schnittmengen mit Ujamaa aufwies, machte die DDR nicht mit: „Globale Probleme wie Hunger, Armut, Krankheit, und Unterentwicklung wurden allein der Verantwortlichkeit des Kapitalismus zugewiesen und ihre Relevanz für die eigene konkrete Politik kaum berücksichtigt. “267

Aus Sicht der tansanischen Regierung und Verwaltung wiederum war die DDR kein sonderlich attraktiver Partner, obwohl das Engagement für die Befreiungsbewegungen durchaus Anerkennung fand. ${ }^{268}$ Die Position der DDR in den

265 BArch Berlin, DE 1/58694, Vertrauliche Dienstsache - Länderinformation Vereinigte Republik Tansania, S. 5. Siehe auch PAAA, MfAA C 6115, DDR-Botschaft Dar es Salaam, ,Jahresbericht 1976“, Dar es Salaam, 3.1.1977, Fol. 45. Erst 1985 wurde durch den Abschluss einer Vereinbarung ein „neues Niveau“ der Parteibeziehungen erreicht, das Delegationsaustausch, Urlauberaustausch und die Ausbildung von jährlich zwölf CCM-Kadern in der DDR beinhaltete. Siehe SAPMO BArch Berlin, DY 30/15206 Rechenschaftsbericht der Leitung an die Wahlberichtsversammlung der GO der SED DSM, 25.11.1985, Bl. 165.

266 PAAA, MfAA, C 1039/78, DDR-Botschaft in Tansania, Analyse der auslandsinformatorischen Arbeit im Jahre 1975, Dar es Salaam, 28.11.1975, Fol. 21.

267 Schleicher, Afrika, S. 18.

268 Interview \#12, ehemaliger FDGB-Stipendiat, Journalist und Schriftsteller aus Sansibar. Vgl. auch E-Mail eines ehemaligen DDR-Diplomaten an den Autor, 1.10.2015: Die Beziehungen seien „auch nicht frei von Argwohn beider Seiten in Bezug auf die Politik beider Staaten gegenüber den $\mathrm{B}$ [efreiungsbewegungen] und dem OAU-Befreiungskomitee [gewesen], da beide auch unterschiedliche Auffassungen [hatten].“ Das Eintreten der Befreiungsbewegungen bzw. Angolas, Mosambiks und Äthiopiens für die DDR ermöglichte eine vertrauensvollere Zusammenarbeit zwischen Tansania und der DDR in diesen Fragen. 
globalen Kräfteverhältnissen war doppelt ungünstig: Gesehen als Stellvertreterin (oder zumindest enge Verbündete) der Sowjetunion und als wirtschaftlich privilegiertes Land des Nordens (unterstützt durch die Selbstdarstellung der DDR als zehntgrößte Industrienation der Welt) wurden materielle Leistungen erwartet, die die DDR in den frühen 1970er-Jahren in afrikanischen Ländern weder erbringen konnte noch wollte. Der erste Botschafter der DDR in Tansania schätzte rückblickend realistisch ein, dass die DDR ,[i]n der Arm-Reich-Auseinandersetzung in der Welt [...] als reiches Land“ und daher „[i]m Ringen um eine neue internationale Wirtschaftsordnung [...] auch nicht uneingeschränkt als Verbündeter gesehen“ worden war. ${ }^{269}$ In einem Gespräch mit DDR-Diplomaten betonte der tansanische Finanzminister Jamal schon 1970, dass die DDR und Tansania in einem Verhältnis entwickeltes Land-Entwicklungsland (also nicht in einem Bündnis sozialistischer Länder) stünden und man daher nun gerne einmal ein größeres Objekt der DDR in Tansania sehen würde - wozu es aber erst kam, als die DDR ihre Südpolitik stärker kommerzialisierte. ${ }^{270}$

\subsection{Konvergenz: Die Ökonomisierung und Konditionalisierung der Entwicklungspolitik, 1977-1990}

Während sich der Ost-West-Konflikt ab Ende der 1970er-Jahre wieder verschärfte und damit die politische Dividende der Entwicklungspolitik in den Vordergrund rückte, gewannen auch wirtschaftliche Eigeninteressen an Bedeutung. In Bezug auf die Ökonomisierung der Entwicklungspolitik lässt sich dann auch eine Konvergenz zwischen BRD, DDR und Tansania zeigen. Die christlich-liberale Bundesregierung unter Kohl entdeckte den Antikommunismus wieder, um politische Verhältnisse in Afrika zu lesen und verlangte Strukturanpassungsmaßnahmen in Tansania. Die DDR machte weitere Transfers (nicht explizit, aber de facto) zunehmend von tansanischen Kreditrückzahlungen abhängig, während Tansania wieder intensiver zwischen verschiedenen Gebern manövrierte, um Ressourcen zur Überwindung der Wirtschaftskrise zu lukrieren. Dazu gehörte auch eine Hinwendung in Richtung der RGW-Länder.

269 Matthes, Zur Entwicklung, S. 80.

270 PAAA, MfAA, C 772/74, Gesprächsnotiz DDR-Handelsrat Felber und DDR-Generalkonsul Butzke mit VRT-Finanzminister Jamal, Dar es Salaam, 5.12.1970. 


\section{Weltrevolution und Kommerz}

Zwei Trends kennzeichnen die DDR-Außenpolitik ab 1977: die noch stärkere Fokussierung auf politische Schwerpunktländer mit einer ähnlichen ideologischen Ausrichtung sowie der Versuch, sozialistische Hilfe „zum gegenseitigen Vorteil“ in Einklang mit nationalen Wirtschaftsinteressen zu bringen, also DDR-Erzeugnisse abzusetzen, neue Rohstoffquellen zu erschließen und somit Devisen zu generieren (bzw. einzusparen). Diese Doppelstrategie war intern schon länger proklamiert worden, wurde nun aber stärker forciert. Zur einheitlicheren Koordinierung von Wirtschafts- und Solidaritätsaktivitäten wurden auch neue Institutionen ins Leben gerufen, die die Verschiebung hin zu ökonomischen Motiven weiter vorantrieben.

1977 schuf das Politbüro eine Kommission unter der Leitung des ZK-Sekretärs der SED für Wirtschaftsfragen Günter Mittag, die für die Beziehungen mit afrikanischen, lateinamerikanischen und asiatischen Ländern zuständig war. ${ }^{271} 1977$, als sich die Aufmerksamkeit der DDR stärker auf Mosambik und Angola richtete (wo befreundete Befreiungsbewegungen nun regierten und in diesem Jahr explizit den Marxismus-Leninismus als Grundlage ihrer Politik ausriefen), verlor Tansania den Status als außenpolitisches Schwerpunktland. ${ }^{272}$ Hatte Außenminister Oskar Fischer noch 1976 auf seiner Ostafrika-Reise die Direktive bekommen, lediglich die politische Präsenz der DDR zu stärken, weil für „eine ökonomische Zusammenarbeit keine oder nur geringe Möglichkeiten bestehen“, so wurden ab 1977 reihenweise wirtschaftliche Vorhaben mit Äthiopien, Angola und Mosambik in Gang gesetzt. ${ }^{273}$ Den Hintergrund dazu bildeten einerseits politische Erwartungen, dass die Verhältnisse in den genannten Ländern und darüber hinaus eine einmalige historische Dynamik gewonnen hatten. Die Regierungen von Angola, Äthiopien und Mosambik proklamierten nun den „Wissenschaftlichen Sozialis-

271 Hans-Joachim Döring, Es geht um unsere Existenz. Die Politik der DDR gegenüber der Dritten Welt am Beispiel von Mosambik und Äthiopien, Berlin 1999, S. 44. Die Kommission (unter dem vollen Namen „Kommission zur Koordinierung der ökonomischen, kulturellen, wissenschaftlichtechnischen und der Tätigkeit im nichtzivilen Bereich in den Ländern Asiens, Afrikas und des arabischen Raumes“) befasste sich nur mit Ländern der „Dollarzone“, während die Beziehungen zu Staaten der „Rubelzone“ wie Kuba an anderer Stelle diskutiert wurden - was auf eine gewisse Überlappung von Intra-RGW- und Nord-Süd-Beziehungen verweist und belegt, dass in DDRPerspektive die Kategorisierung nach „Blöcken“, nicht nach „Entwicklungsstand“ vorgenommen wurde.

272 Peter Sebald, Völkerfreundschaft oder Auslandsinformation. Impressionen zum Wirken der Deutsch-Afrikanischen Gesellschaft., in: Ulrich van der Heyden u.a., Hg., Die DDR und Afrika: Zwischen Klassenkampf und neuem Denken, Münster 1993, S. 79-94, 89.

273 Zit. nach Döring, Existenz, S. 74. 
mus“, keinen Afrikanischen Sozialismus. Mitte der 1970er-Jahre, als sich die USA aus Vietnam zurückgezogen hatten, das portugiesische Kolonialreich zerfiel, der Systemkonflikt vorübergehend an militärischer Bedrohlichkeit verlor und der Industriekapitalismus in eine Krise gestürzt war, wirkte das „Modell West“ für viele verbraucht und wenig zukunftsträchtig. ${ }^{274}$ Die Anziehungskraft des Realsozialismus sollte für einige Jahre Aufwind haben, wovon auch die DDR profitierte. „In Afrika“, so Erich Honecker in einem Gespräch mit Fidel Castro, würden „nach dem sozialistischen Weltsystem die größten Möglichkeiten bestehen, im revolutionären Weltprozess einen bedeutenden Schritt voranzukommen“. ${ }^{275}$ Afrika schien das schwächste Glied in der Kette des Imperialismus. Honecker und andere Führungsfiguren der SED hatten durch ihre Erfahrungen vor und während des Zweiten Weltkrieges (Verfolgung der kommunistischen Bewegung, Exil) einen starken biografischen Bezug zu internationalistischer Solidarität. Dementsprechend maßen sie der Hilfe für Befreiungsbewegungen, Bruderparteien und befreundeten Staaten größte Bedeutung bei - vertrauten die Umsetzung der zwischenstaatlichen Beziehungen jedoch Akteuren an, die sich vor allem um die ökonomische Sanierung der DDR sorgten. ${ }^{276}$

Die neu ins Leben gerufene Mittag-Kommission diente in erster Linie als Instrument zur Realisierung von Mittags Anordnungen, die unter eindeutig ökonomischen Prämissen standen. ${ }^{277}$ Durch die 1977 einsetzende Zinssteigerung auf internationalen Finanzmärkten stand die DDR, bereits verschuldet durch den Import von Konsum- und Investitionsgütern aus kapitalistischen Ländern, mit dem Rücken zur Wand. ${ }^{278}$ Sie ,fand sich damit in einer vergleichbaren Rolle mit Ländern der Dritten Welt“, da sie „zu den Verlieren und nicht zu den Gewinnern dieser Entwicklung“ zählte. ${ }^{279}$ Angesichts der hohen Schuldendienste verengte sich der wirtschaftliche Handlungsspielraum für die DDR. Kosten-Nutzen-Rech-

274 Ebd., S. 26.

275 Zit. nach ebd., S. 58.

276 Schleicher, Entwicklungszusammenarbeit, S. 96-97.

277 Engel/Schleicher, Die beiden deutschen Staaten, 147; Günter Mittag, Um jeden Preis. Im Spannungsfeld zweier Systeme, Berlin 2015. Mittag war seit 1976 ZK-Sekretär der SED für Wirtschaftsfragen der Planwirtschaft und hatte spätestens ab diesem Zeitpunkt eine Führungsrolle in der Wirtschaftspolitik der DDR inne. Ein weiterer wichtiger Akteur in der Kommerzialisierung der Entwicklungspolitik war der Bereich Kommerzielle Koordinierung. Siehe hierzu Matthias Judt, Der Bereich Kommerzielle Koordinierung. Das DDR-Wirtschaftsimperium des Alexander SchalckGolodkowski. Mythos und Realität, Berlin 2013.

278 Döring, Existenz, S. 54-55; Stephen Kotkin, The Kiss of Debt. The Eastern Bloc Goes Borrowing, in: Niall Ferguson u. a., Hg., The Shock of the Global: The 1970s in Perspective, Cambridge, Mass. 2010, S. $80-94$.

279 Döring, Existenz, S. 54-55. 
nungen standen exemplarisch für die ,verstärkt ökonomisch determinierte Politik gegenüber den Entwicklungsländern“, die „die Aura von der altruistischen Hilfe der DDR zu zerstören begann.“280

Von beiden Trends, der Bevorzugung politischer Schwerpunktländer sowie der Ökonomisierung konnte Tansania kaum profitieren. Ein ehemaliger DDRDiplomat erwiderte auf die Frage, warum Nyerere erst 1989 die DDR besuchte und vorherige Besuchsvorhaben gescheitert waren: „Dem Axen war er nicht links genug und dem Mittag war er zu arm. “281 1982 hinterfragte der Staatliche Leiter der Lehrergruppe in Dar es Salaam die Kooperation von Tansania und der DDR im Bildungsbereich grundlegend. Beide Seiten würden weder ideologisch noch wirtschaftlich vom Personaltransfer profitieren, während die zunehmende Bedeutung von Swahili an den Bildungseinrichtungen den Einsatz von DDR-Kadern immer unwahrscheinlicher mache. Revolutionäre Änderungen im Bildungswesen seien nicht mehr zu erwarten. Überhaupt sei es „schwierig, die Ideologie der Arbeiterklasse zu verbreiten“, man stoße „bei Studenten und Lehrern auf politische Vorbehalte und ablehnende Haltungen“, habe keinen Einfluss auf das Bildungswesen und könne die Einsatzkosten durch die Bezahlung von tansanischer Seite nicht annähernd decken; dem Ministerium riet der Staatliche Leiter daher, über die Auflösung der DDR-Lehrergruppe in Tansania nachzudenken. ${ }^{282}$ Der Einsatz wurde nun nicht mehr nur in politischen Kategorien, sondern auch in ökonomischen Kosten-Nutzen-Rechnungen bewertet.

Der Delegationsaustausch zwischen der DDR und Tansania nahm nichtsdestoweniger in der zweiten Hälfte der 1970er Jahre wieder an Fahrt auf und führte zur Fortführung und Intensivierung der Kooperation in den Bereichen der Sicherheit, der Volks- und Hochschulbildung sowie dem Bau eines Textilkomplexes. ${ }^{283}$ Der Vertragsabschluss über die kommerzielle Errichtung eines Textilkombinates im Süden Tansanias in Mbeya mit einem (v. a. für DDR-Verhältnisse) beachtlichen Volumen von über fünfzig Millionen Valutamark im Jahr 1978 - also ein Jahr, nachdem Tansania seines Status' als außenpolitisches Schwerpunktland entledigt worden und die DDR-Exportoffensive „Entwicklungsländer“ angelaufen war - stellte einen bedeutenden Kontrapunkt in den bilateralen Beziehungen

280 Schleicher, Entwicklungszusammenarbeit, S. 108.

281 Interview \#110, ehemaliger DDR-Diplomat, u.a. in Tansania. Hermann Axen und Günter Mittag waren die entscheidenden Figuren im Zentralkomitee der SED für die außen- bzw. wirtschaftspolitische Orientierung der DDR.

282 BArch Berlin, DR 2/51007, Leiter der DDR-Lehrergruppe in der VRT, „Fortschreibung des Jahresberichtes zum Studienjahr 1981/82“, Dar es Salaam, 2.6.1982.

283 BArch Berlin, DE 1/58694, Überblicksliste „Delegationsverkehr“, o.O., o.D. 
dar. ${ }^{284}$ Der Abschluss fiel in die Phase, als Tansania dem zunehmenden Ausbleiben von Investitionen und Krediten aus dem Westen (und Chinas postmaoistischem Rückzug in innenpolitische Umstrukturierungen) mit einer verstärkten Orientierung gen Osteuropa begegnen wollte (siehe Kapitel 2). Begünstigt, aber keinesfalls verursacht durch das Wiederaufflammen des OstWest-Konfliktes näherten sich die Regierungen unter Verweis auf die geteilten außenpolitischen Positionen des Antiimperialismus und der Bekämpfung der Apartheid an. Waren von 1968 bis 1975 nur vier Minister und hohe Parteifunktionäre nach Ostdeutschland gekommen, waren es 1976 bis 1979 schon sieben, und von 1980 bis 1986 weitere fünfzehn. ${ }^{285}$ „Tanzania hails GDR“ titelte die Daily News am 5.5.1981 und zitierte das Lob der tansanischen Regierung für den „heroischen und selbstlosen Beitrag [der DDR] zum Befreiungskampf“; „Tanzania, GDR cement ties“ hieß es dann in der Ausgabe des Folgetages. ${ }^{286}$ Dem vorausgegangen war ein Besuch des Planungsministers Kighoma Malima, der 1980 ein Abkommen über Wissenschaftlich-Technische Zusammenarbeit in der DDR unterzeichnet hatte und seine Frau mit dem zukünftigen Planungsberater die sozialistischen Errungenschaften im Land besichtigen ließ. ${ }^{287}$ DDR-Plankomissionsvorsitzender Gerhard Schürer revanchierte sich mit einem Besuch 1981, um weitere Maßnahmen zu besprechen. Die beidseitige Charmeoffensive mündete sogar in einem Kooperationsabkommen zwischen den Regierungsparteien SED und CCM, dem ersten seiner Art, in dessen Folge jährlich CCM-Kader für Schulungen in die DDR kamen. Zumindest Teile der CCM schienen ihre Partei zur Kaderpartei leninistischen Typus entwickeln zu wollen.

Große Pläne wurden geschmiedet: Planungsminister Malima bekundete höchstes Interesse an DDR-Planungserfahrungen, um die Entwicklungsplanung zu stärken und ein planwirtschaftlich orientiertes System in Tansania einzuführen, durch das die Wirtschaftskrise überwunden werden sollte. Drei DDR-Beraterposten wurden Anfang der 1980er Jahre geschaffen, davon zwei in den politisch so zentralen wie sensiblen Bereichen Planung und Finanzen. Malima, der seine drei Universitätsabschlüsse bis hin zum Doktor in Ökonomie allesamt an prestigereichen Universitäten in den USA gemacht hatte, gehörte zur Gruppe jener CCMPolitikerInnen um Nyerere, die jede Konzession an die westlichen Strukturan-

284 Zum Vertragsabschluss über das Projekt am 22.5.1978 siehe PAAA, C 6115, DDR-Botschaft, Jahresanalyse 1978, Dar es Salaam, 5.1.1979, Fol. 154-155.

285 BStU, MfS, HA I/13548, Ländermappe Tansania, 1986, Bl. 144-146.

286 Daily News, „Tanzania hails GDR“, 5.5.1981; Daily News, „Tanzania, GDR cement ties“, 6.6. 1981.

287 Interview \#21, DDR-Planungsberater. 
passungsforderungen strikt ablehnten. ${ }^{288}$ Da für eine tatsächliche Einführung der Planwirtschaft in Tansania allerdings jegliche Voraussetzungen fehlten (siehe detailliert hierzu Kapitel 6.4), sind Zweifel über die von Malima vorgebrachten Motive angebracht. In jedem Fall hoffte er, die DDR zur Abarbeitung der eigenen „Einkaufsliste“ finanzierungsbedürftiger Projekte bewegen zu können. Womöglich zielte er auch darauf ab, mit einer demonstrativen Geste gen Ostblock die westlichen Länder wieder zu umfassenderen Leistungen anzuspornen. $\mathrm{Zu}$ den Vorhaben, für die sich noch keine Investoren gefunden hatten, gehörten mehrere große Industrieprojekte, der Ausbau des Eisenbahnnetzes von Arusha nach $\mathrm{Mu}$ soma und die Bereitstellung von Eisenbahnwaggons. ${ }^{289}$

Einige DDR-Berichterstatter vermerkten bis Mitte der 1980er Jahre mit Wohlwollen einen Trend, in dessen Zuge sich die CCM „,von einer national-demokratischen Massen- zu einer Vorhutpartei“ transformieren und dabei auch die „Erfahrungen der Parteien der SSG [sozialistischen Staatengemeinschaft] “ studieren wollte. ${ }^{290}$ In der letzten Phase handelte es sich im Gegensatz zu früheren Jahren allerdings zunehmend um Delegationen und Schulungen von Parteikadern, was auf die zunehmende Entzweiung zwischen der „alten Garde“ der CCM einerseits sowie dem CCM-Reformflügel und der Regierung andererseits zeugt (vgl. Kapitel 2.4). Letztlich blieb man in Ostberlin intern aber der Ansicht, dass sich die Politik der CCM auf Grundlage von Nyereres „nichtproletarischen Sozialismusvorstellungen“ vollziehe und die Partei ihrer Führungsrolle nicht gerecht werde. ${ }^{291}$

DDR-VertreterInnen antworteten daher auf tansanische Anfragen für Investitionen, „Entwicklungshilfe“ und Personalentsendungen mit dem demonstrativen Bedauern, „dass wir ein so kleines Land sind, was nur im begrenzten Maße Hilfe erweisen kann, d.h. die Wünsche zu helfen oft größer sind als die Möglichkeiten“, wie etwa Bildungsministerin Margot Honecker ihrem tansanischen Amtskollegen Jackson Makwetta mitteilte. ${ }^{292}$ Wie Malima, der Interesse an DDRPlanungsmethoden bekundet hatte, versicherte auch Makwetta, die polytechnische Bildung nach DDR-Vorbild an tansanischen Schulen einführen zu wollen. ${ }^{293}$

288 Starken Einfluss auf Malimas Position hatte anscheinend das Planungsdenken von W. Arthur Lewis (vgl. Eckert, „We Are All Planners Now“).

289 Daily News, „Tanzania, GDR cement ties“, 6.6.1981.

290 BStU, MfS, HA I/13548, Ländermappe Tansania, 1986, Bl. 105.

291 Ebd.

292 BArch Berlin, DR 2/50566, Bericht über den Besuch des Ministers für Erziehung der VRT, Jackson M. Makwetta, vom 19.1. bis 27.1.1987 in der DDR, Anlage 1: Gesprächsprotokoll 23.1.1987 (Makwetta, Krolikowski, M. Honecker, Sepetu).

293 BArch Berlin, DQ 4/5432, Bericht über Besuch des Ministers für Erziehung der VRT Makwetta vom 19.1. bis 27.1.1987 in der DDR. 
$\mathrm{Zu}$ diesem Zweck bat er um Lehrpersonal, Stipendien und Material für die Ausrüstung von sieben neuen Ausbildungszentren. In der DDR war man jedoch maximal bereit, „jemanden in Schlüsselpositionen des Ministeriums selbst einzusetzen“. ${ }^{294}$ Die Berater in den verschiedenen Ministerien sollten nunmehr nicht nur einen Einfluss auf die tansanische Politik ausüben, sondern durch ihr Insiderwissen auch Exportmöglichkeiten erschließen.

Theoretisch bestand durch die einsetzende Importliberalisierung (v.a. nach 1985) zunehmend die Möglichkeit, DDR-Exporte direkt in Kooperation mit tansanischen Betrieben zu realisieren. In dieser Hinsicht war die DDR gerne bereit, die Vorteile der oktroyierten Liberalisierungspolitik zu nutzen. Praktisch stieß dieses Vorhaben aber schnell an personelle Grenzen. Die handelspolitische Abteilung war lediglich mit dem Handelsrat besetzt, der im Alleingang nicht die nötigen Angebote erarbeiten konnte. ${ }^{295}$ Die feste Einbindung Tansanias in die westliche Sphäre war ein weiterer Bremsklotz für DDR-Bemühungen. Ein DDRBerater im tansanischen Planungsministerium sah kaum Möglichkeiten für DDRExporte, weil die meisten Darlehen für Tansania an Importe aus den Geberländern gebunden waren (Epplers Initiative, die Lieferentbindung im DAC durchzusetzen, war ja gescheitert) und Lieferungsvereinbarungen für Weltbank-Projekte der Zustimmung der Weltbank bedurften. ${ }^{296}$ Die Lieferung kompletter Anlagen für industrielle Großprojekte wie auch Exporte auf Kreditbasis schienen angesichts der Negativerfahrungen mit der Textilfabrik (siehe unten) ohnehin als inopportun, da Tansania die Kredite wohl nicht würde tilgen können und zudem Kreditbedingungen erwartete, die sich mit denen der kapitalistischen Länder messen konnten. ${ }^{297}$

Bei der Beziehung zwischen Tansania und der DDR handelte es sich um eine politische Zweckgemeinschaft ohne belastbare ökonomische Basis - wenngleich beide Parteien vorteilhafte Ressourcentransfers erhofften. 1981 bis 1985 wurden Waren im Wert zwischen 3,5 und 0,6 Millionen Valutamark pro Jahr umgesetzt, während der Handel der DDR mit anderen afrikanischen Ländern ein Volumen

294 BArch Berlin, DR 2/51008, Analysen Experteneinsatz im Ausland 1987/1989, Einschätzung zum Einsatz der KWZ- und WTZ-Experten der DDR in der VR Tansania, 1987.

295 BArch Berlin, DE 1/57846, R., Analyse des Außenhandels der Vereinigten Republik Tansania, Dar es Salaam, 17.4.1988.

296 BArch Berlin, DE 1/58114, R., Veränderungen in der Wirtschaftspolitik Tansanias, Dar es Salaam, 5.5.1987, 10. Siehe auch PAAA, C 6115, DDR-Botschaft Dar es Salaam, Jahresbericht 1975, Dar es Salaam 8.1.1976, Fol. 12. Die theoretisch von DDR-Seite stark kritisierte Politik der Importliberalisierung erachtete der Berichtgeber wohl auch aus diesen praktischen Gründen für die DDR als potentiell günstig, um eigene Güter in Tansania absetzen zu können.

297 BArch Berlin, DE 1/57846, R., Analyse des Außenhandels der Vereinigten Republik Tansania, Dar es Salaam, 17.4.1988, S. 13-16. 
über 100, teils gar über 500 Millionen Valutamark erreichte. ${ }^{298}$ Exporte nach Tansania waren der DDR ein zu hohes Risiko, da die Rückzahlung kommerzieller Kredite notorisch unsicher war. Angesichts bereits ausstehender Zahlungen wollte die DDR keine weiteren Waren auf Kreditbasis liefern. Der geplante Export von Lkw vom Typ W50 an das tansanische Militär etwa scheiterte am tansanischen Devisenmangel. ${ }^{299}$ Ab Mitte der 1970er importierte die DDR nur noch Cashewnüsse und in den Jahren 1979 und 1980 schließlich gar nichts mehr; ein Vorschlag der DDR über den Handel mit Kaffee schaffte es nie über die Beratungsstufe. ${ }^{300}$ Die DDR bot auch Veterinärpharmaka, medizinische Geräte, Jagdmunition, Seife, Fahrräder; Interesse bestand im Gegenzug an Kaffee, Baumwolle, Tabak und Tee aus Tansania. ${ }^{301}$ Offensichtlich war Tansania an frei verfügbarer harter Währung interessiert, denn die Versuche der DDR, die RGW-typischen Handelsbeziehungen auf Verrechnungsbasis einzuleiten, liefen allesamt ins Leere. ${ }^{302}$ Eine weitere Strategie der DDR zur Optimierung von Waren- und Finanzflüssen in diesen Jahren bestand darin, importierte Primärgüter wieder auf dem Weltmarkt abzusetzen. Für den Bau einer Druckerei in Sansibar gab es den Plan, „Nelken von Sansibar zu kaufen, diese zu vermarkten und aus dem Erlös die Rückzahlung des Kredites vorzunehmen und gleichzeitig die Finanzierungsvoraussetzungen für durch die DDR zu erbringende Bauleistungen für die Druckerei zu schaffen“. ${ }^{303}$ Dieses Vorhaben wurde aufgrund von Finanzierungsproblemen auf sansibarischer Seite und gestiegener Vorsicht der DDR nach jahrelanger Verzögerung erst Ende der 1980er in Angriff genommen. ${ }^{304}$

298 Schulz, Development Policy, 117-118.

299 PAAA, MfAA, ZR 1641/83, DDR-Botschaft, Jahresanalyse 1980, Dar es Salaam, 10.12.1980, S. 13.

300 BArch Berlin, DE 1/58694, Länderinformation VRT, S. 15-17.

301 SAPMO BArch Berlin, DY 30/15205, Hinweise für die Durchführung der Wahlversammlung der AV der DDR in der VRT, o.O., o.D. [1983]. Zum Handel auf Verrechnungsbasis siehe auch Lorenzini, Dilemmas of Solidarity.

302 Ein weiterer Grund für die Aversion Tansanias gegen alternative Handels- und Kreditregimes mögen auch die negativen Erfahrungen mit dem chinesischen Arrangement der Kreditzurückzahlung gewesen sein. Der Kredit wurde durch den Verkauf chinesischer Konsumgüter in Tansania vollzogen, wobei diese Güter dann andere, tansanische wie kenianische Erzeugnisse vom Markt verdrängten. $\mathrm{Zu}$ diesem ökonomischen Arrangement gibt es allerdings bisher keinerlei Studien.

303 SAPMO BArch Berlin, DY 30/15205 Hinweise für die Durchführung der Wahlversammlung der AV der DDR in der VRT, o.O., o.D. [1983].

304 Zur DDR-seitigen Vermutung, dass der Vertrag wegen Finanzierungsschwierigkeiten aufgelöst werden müsss, siehe: SAPMO BArch Berlin, DY 30/15206, Bericht der Leitung an die Wahlberichtsversammlung der GO der SED DSM, 25.11.1985, Bl. 165. Dass das Vorhaben doch realisiert 


\section{Joint Venture Ost-Süd-West}

Dank der 1977 ausgerufenen „Exportoffensive Entwicklungsländer“ der DDR kam es doch noch zu einem weiteren großen Investitionsprojekt in Ostafrika, wenngleich auf rein kommerzieller Basis: dem Bau einer Textilfabrik in Mbeya. Die kommerzielle Natur der Kooperation spiegelte sich schon in der DDR-Sprachregelung: Tansania war hier nicht „Partner“, sondern „Kunde“. Dieses Projekt ist in der Forschungsliteratur bisher gänzlich unerwähnt geblieben, wie überhaupt die konkrete Umsetzung von Industrieprojekten und Joint Ventures sozialistischer Länder im globalen Süden noch wenig untersucht ist. ${ }^{305}$ Die beim Bau dieser Textilfabrik aufgetretenen Schwierigkeiten illustrieren die Handlungsstrategien und Beschränkungen für ökonomische Ost-Süd-Beziehungen in der Spätphase des Kalten Krieges.

DDR-seitig war das staatliche textilmaschinenherstellende Kombinat Textima Karl-Marx-Stadt verantwortlich. Der tansanische Vertragspartner, das halbstaatliche Unternehmen Texco (National Textile Corporation), nahm zudem noch eine polnische und eine westdeutsche Firma für Ausrüstungslieferungen unter Vertrag. ${ }^{306}$ Das kommerzielle Projekt war also ein Joint Venture mit vier Vertragspartnern aus „Ost“, „West“ und „Süd“ und zeigt deutlich die Abwendung von jeglichen Versuchen, eine separate sozialistische Sphäre der Weltwirtschaft zu etablieren. Stattdessen sollten staatliche Unternehmen der DDR nun auch über Projekte im globalen Süden auf dem kapitalistischen Weltmarkt Profite generieren; die Kooperation mit westlichen, sogar westdeutschen Unternehmen war dabei kein Hinderungsgrund, sondern ermöglichte viele Vorhaben erst.

Dem 1978 geschlossenen Abkommen war ein erster, gescheiterter Versuch der Kooperation im Textilsektor vorausgegangen. Bereits 1964/65 war der Generaldirektor des Textima-Vorgängers VVB Baumwolle durch afrikanische Staaten ge-

\footnotetext{
wurde, legt folgendes Dokument nahe: BArch Berlin, DC 20/I/4/6425, Direktive für das Vorsitzendentreffen der Gemeinsamen Kommission DDR/VRT, 12.4.1989, Fol. 1728.

305 Instruktive Fallstudien finden sich bei Anna Calori u.a. (Hg.), Between East and South. Spaces of Interaction in the Globalizing Economy of the Cold War, Berlin/Boston 2019. Frühere Werke aus den 1980er Jahren behandeln die strukturelle Ebene, nicht aber konkrete Projekte: Andrzej Korbonski/ Francis Fukuyama, Hg., The Soviet Union and the Third World. The Last Three Decades, Ithaca 1987; Deepak Nayar, Hg., Economic Relations between Socialist Countries and the Third World, London 1977; Brigitte H. Schulz, William W. Hansen (Hg.): The Soviet Bloc and the Third World. The Political Economy and East-South Relations, Boulder 1989. Speziell zu staatlichen Unternehmen aus den osteuropäischen Ländern siehe Carl H. McMillan, Multinationals from the Second World. Growth of Foreign Investment by Soviet and East European Enterprises, New York 1987.
}

306 BArch Berlin, DC 20/I/4, 6222, Fol. 46. 
reist, um Investitionsmöglichkeiten auszuloten. 1966 ersuchte Tansania die DDR um Hilfe für den Aufbau einer Baumwollspinnerei - zu einer Zeit, als es „sich bei dem komplizierten Vorhaben um völliges Neuland für die DDR“ handelte. ${ }^{307}$ Tansania forderte damals Abnahmegarantien für die Baumwolle zu Preisen über Weltmarktniveau, was wohl der Hauptgrund dafür war, dass das Vorhaben zu den Akten gelegt wurde. ${ }^{308}$ Als ein Vertrag 1978 unter neuen Bedingungen unterzeichnet wurde, hatte die einst gut funktionierende Textilindustrie in der DDR mittlerweile enorm an Produktivität verloren; wo nicht, war sie von westlichen Technologieimporten abhängig. ${ }^{309}$ Die tansanische Seite verpflichtete sich zur Rückzahlung des kommerziellen Kredites der DDR in Devisen und hoffte ihrerseits auf baldige Exportgewinne durch die Möglichkeit zur Rohstoffverarbeitung und Wertschöpfung. Ein weiterer positiver Effekt solcher Vertragsabschlüsse für die DDR war die Schönung der Jahresbilanzen, um den Devisenmangel zu kaschieren und auf dem internationalen Kapitalmarkt weiterhin kreditwürdig zu erscheinen. ${ }^{310}$ Das Textilkombinat Mbeya sollte 2.500 ArbeiterInnen in drei Schichten beschäftigen und den heimischen wie internationalen Markt mit jährlich bis zu 24 Millionen Quadratmetern Baumwollstoffen beliefern. ${ }^{311}$ Es handelte sich in der Darstellung der SED-Parteivertretung in Dar es Salaam um „das entscheidende Kampffeld [...] auf außenwirtschaftlichem Gebiet“, wo Prestige und Profite auf dem Spiel standen. ${ }^{312}$ Ein Fernduell leistete man sich mit Japan, das zeitgleich eine Textilfabrik und damit ein „Konkurrenzprojekt“ in einer benachbarten Region Tansanias realisierte. ${ }^{313}$

1983 steckte das Projekt in so ernsthaften Schwierigkeiten, dass der DDRBauleiter Befürchtungen äußerte, es könne eine „Ruine“ bleiben. Seinem Bericht zufolge habe der tansanische Betrieb die vertraglichen Verpflichtungen nicht er-

307 SAPMO BArch Berlin, DY 3023/309, Minister für Leichtindustrie an Kandidaten des Politbüros Günter Mittag, Berlin, 28.3.1966, Fol. 29.

308 Siehe zur kritischen Einschätzung des Vorschlags SAPMO BArch Berlin, DY 3023/309, Stellungnahme der Abteilung Planung und Finanzen des ZK zum Investitionsobjekt „Spinnerei in Tansania“, Fol. 115 - 117. Zu den Bedenken der DDR-Seite siehe SAPMO BArch Berlin, DY 3023/309, Abt. Planung und Finanzen, Stellungnahme zur Konzeption der VVB Baumwolle, o.D., o.O.

309 Christian Heimann, Systembedingte Ursachen des Niedergangs der DDR-Wirtschaft. Das Beispiel der Textil- und Bekleidungsindustrie 1945-1989, Frankfurt/Main 1997.

310 Siehe das Interview mit Helmut Matthes in Döring, Existenz, S. 267.

311 BArch Berlin, DE 1/57846, Rohübersetzung des Uhuru-Zeitungsartikels „Probleme, die den Aufbau von Mbeyatex beeinträchtigen“, 9.3.1989.

312 SAPMO BArch Berlin, DY 30/15206, Bericht der Leitung an die Wahlberichtsversammlung der GO der SED DSM, 25.11.1985, Bl. 168-169.

313 SAPMO BArch Berlin, DY 30/15206, Vermerk über Gespräch des Baustellenleiters Mbeya mit dem vorgesehenen neuen Parteisekretär, Berlin, 9.1.1985, Bl. 1. 
füllt und sei damit für die Probleme verantwortlich, in der Öffentlichkeit werde die Fabrik jedoch trotzdem als DDR-Objekt gesehen. Zudem würden auch westliche Experten versuchen, den Bauablauf zu bremsen. ${ }^{314}$ Die Botschaft beklagte, dass die Vertragstexte „für die DDR ungünstige Auslegungen gestatten“; die tansanische Seite schien die Schlupflöcher also zu ihren Gunsten auszunutzen. ${ }^{315}$ Erhebliche Lieferprobleme und Verzögerungen bei der Bereitstellung von Personal gab es allerdings auch bei den involvierten ostdeutschen und polnischen Staatsbetrieben. ${ }^{316}$ Die DDR-Maschinen erwiesen sich für die Verarbeitung der lokalen Baumwollvarietät als völlig ungeeignet. ${ }^{317}$ Angesichts der tansanischen Zahlungsunfähigkeit wurde 1983, als die ersten Raten fällig wurden, vereinbart, dass die Tilgung des Kredites nunmehr ,über die Lieferung der produzierten Gespinste in die DDR“ erfolgen sollte, was relativ gesehen für Tansania die bessere Lösung war, aber für beide Seiten die Inbetriebnahme der Fabrik umso dringlicher erscheinen ließ. ${ }^{318}$ In der Zwischenzeit wurden die pünktlich gelieferten westdeutschen Maschinen unbrauchbar, weil der gesamte Boden renoviert und die sensible Technik derweil im Freien gelagert und der Witterung ausgesetzt werden musste. Derartige Verzögerungen trieben die Kosten weiter in die Höhe.

Zusätzlich erschwerten Wirtschaftsreformen den Weg zur Inbetriebnahme. Die Liberalisierung des Außenhandels ab 1984/85 torpedierte die ökonomischen Vorannahmen des Projekts, denn dadurch gelangten Textilien vom Weltmarkt nach Tansania, mit deren Preis und Qualität die tansanischen Produkte nicht konkurrieren konnten. Eine kostendeckende Produktion war daher nicht mehr zu erwarten. Wohl auch aus diesem Grund lieferten selbst kleinere Mängel dem tansanischen Vertragspartner einen passenden Vorwand, um die Übernahme der Anlagen und die Aufnahme des Dauerbetriebs, der Zuschüsse aus dem Staatshaushalt benötigt hätte, hinauszuzögern. Dieser Entscheidung ging auch eine

314 SAPMO BArch Berlin, DY 30/15205, Aussprache mit dem Leiter der Baustelle und dem Parteisekretär Mbeya, Herklotz, 27.1.1983.

315 PAAA, MfAA, ZR 1641/83, DDR-Botschaft, Jahresanalyse 1979, Dar es Salaam, 27.12.1979, S. 12. 316 SAPMO BArch Berlin, DY 30/15206, Bericht über die Parteiarbeit I/85 der GO Textilkombinat Mbeya/Tansania [1985], Bl. 30; ebd., DY 30/15207, Rechenschaftsbericht der Leitung an die Berichtswahlversammlung der GO der SED der Auslandsvertretung am 13.4.1987, Dar es Salaam, 15.4.1987, Bl. 83.

317 Interview \#21, ehemaliger DDR-Planungsberater in Tansania.

318 SAPMO BArch Berlin, DY 30/15206, Vermerk über Gespräch des Baustellenleiters Mbeya mit dem vorgesehenen neuen Parteisekretär, Berlin, 9.1.1985; ebd., DY 30/15205 „Hinweise für die Durchführung der Wahlversammlung der AV der DDR in der VRT“ [1983]. 
entsprechende Empfehlung der Weltbank voraus; der tansanischen Texco wurden die staatlichen Mittel in der Folge drastisch gekürzt. ${ }^{319}$

In der Zwischenzeit hatte sich in der Perspektive der DDR-Bauleitung auch „die Zusammenarbeit mit dem tansanischen Leiterpersonal auf der Baustelle verhärtet“, während die minderwertige Qualität der erzeugten Gewebe die Umsetzung der Alternativstrategie, den Export in die DDR, ausschloss. ${ }^{320}$ Das Vertrauensverhältnis zwischen den Vertragsparteien sank „auf den absoluten Nullpunkt““321, während die Fehler auf DDR-Seite sich nun auch vor Ort häuften: „Mangelhafte Bauaufsicht, Bestätigung von nicht mit dem Kunden abgestimmten Kompromisslösungen und Zulassung bautechnologischer Disziplinlosigkeiten führten zu Qualitätsmängeln, die in ihrem vollen Umfang noch nicht zu überschauen“ waren. ${ }^{322}$ Auf Drängen der DDR reiste Vizepräsident J. S. Warioba 1988 nach Ost-Berlin, um u. a. über die Kreditrückzahlungen zu verhandeln. Das Treffen war kein Durchbruch; es blieb dabei, dass Tansania den Kredit nur mit Baumwollgarn und Nesselgewebelieferungen tilgen wollte. ${ }^{323}$ In der tansanischen Presse hatte das Projekt und damit auch die DDR einen miserablen Ruf. ${ }^{324}$ Das SED-Organ Neues Deutschland - dies mag noch einen Unterschied zur BRD und den einflussreichen „Entwicklungshilfe-Skandalberichten“ $\mathrm{zu}$ illustrieren schwärmte hingegen noch am 7. Juli 1989, sämtliche Schwierigkeiten verschweigend, dass „die DDR schon seit einigen Jahren daran beteiligt“ war, „Mbeya als ein neuzeitliches Textilzentrum wieder entstehen zu lassen“. ${ }^{325}$

Ein noch größeres DDR-Textilprojekt in Mosambik, aus dem das größte Textilkombinat im subsaharischen Afrika hervorgehen sollte, wurde zum unvollendeten „weißen Elefanten“. ${ }^{326}$ Ganz so schlimm traf es Mbeya nicht. 1989 drängte

319 BArch Berlin, DE 1/58114, R., Halbjahresbericht - Berichtszeitraum II. Halbjahr 1986, Dar es Salaam, 2.1.1987, S. $9-13$.

320 SAPMO BArch Berlin, DY 30/15206, Bericht der Parteileitung der GO der SED Textilkombinat Mbeya, verlesen auf der Berichtswahlversammlung am 8.11.1985, Bl. 124, 129.

321 SAPMO BArch Berlin, DY 30/15207, Bericht der Leitung an die Berichtswahlversammlung der GO der SED der Auslandsvertretung am 13.4.1987, Dar es Salaam, 15.4.1987, Bl. 83.

322 Ebd.

323 BArch Berlin, DR 2/50566, Ergänzende Information zu einigen aktuellen Aspekten der Wirtschaftsbeziehungen DDR-Tansania [1987].

324 BArch Berlin, DE 1/57846, DDR-Regierungsberater an Stv. der DDR-Plankommission, Dar es Salaam, 21.3.1989.

325 Neues Deutschland, „Unsichtbare Fäden Lausitz-Mbeya“, 7.7.89. Enthalten in BArch Berlin, DQ 4/5432.

326 Hannelore Butters, Zur wirtschaftlichen Zusammenarbeit der DDR mit Mosambik, in: Matthias Voß, Hg., Wir haben Spuren hinterlassen!: Die DDR in Mosambik Erlebnisse, Erfahrungen und Erkenntnisse aus drei Jahrzehnten, Münster 2005, S. 199-215, hier: S. 171. 
die DDR auf die Übergabe und vollen Produktionsbeginn. ${ }^{327}$ In den folgenden Jahren arbeitete das Werk mit ca. 600 Angestellten und etwa einem Viertel der erhofften Auslastung. Das Unternehmen wurde 1996 privatisiert und später aufgrund von Rohstoffmangel, fehlender Baumwolle, geschlossen; 2011 wurde der Gebäudekomplex von einem Tabakkonzern zu Lagerzwecken gemietet. ${ }^{328}$ Die „wirtschaftliche Zusammenarbeit“ der DDR mit Sansibar wie auch mit dem Festland Tansanias ist bis hin zu diesem Projekt in Mbeya eine Geschichte gegenseitiger Enttäuschungen. DDR-Hoffnungen auf einen Re-Export tansanischer Erzeugnisse blieben genauso unerfüllt wie tansanische Erwartungen von Technologietransfers und Produktivitätssteigerung. Anstelle eines gegenseitigen Vorteils realisierte sich ein beidseitiger Nachteil, wenn auch strukturelle Bedingungen - so die alarmierende wirtschaftliche Lage der DDR wie Tansanias in der zweiten Hälfte der 1970er-Jahre - dazu führten, dass vorherige schlechte Erfahrungen beiseitegeschoben wurden.

Eine Kooperation mit der DDR, vor allem in Wirtschaftsfragen, schien informierten Kreisen in der CCM und der Regierung aus den gleichen Gründen unattraktiv, aus denen auch die Beziehungen mit anderen osteuropäischen Ländern sich als mühsam erwiesen hatten (siehe Kapitel 2.2). Eine DDR-Analyse kam ebenfalls zum Schluss, dass die Staaten des Warschauer Pakts von Tansania als ein wirtschaftlich wie politisch pragmatisch zu nutzender Faktor und nicht als Verbündete gesehen wurden. ${ }^{329}$ Der Schwerpunkt der Beziehungen zwischen Tansania und der DDR lag daher vor allem im Bereich der Personalentsendung und Stipendienvergabe. Die DDR-Botschaft kam nicht umhin, „eine eindeutig politische Determiniertheit des Experteneinsatzes festzustellen“, ${ }^{330}$ da die Kosten für die Einsätze aus den Gehaltszahlungen der tansanischen Seite und (teilweisen) Kostenübernahmen für Flüge nicht mehr gedeckt werden konnten. Gleichzeitig war der Einfluss in allen Einsatzbereichen von Bildung bis zu Planung und Finanzen äußerst gering. ${ }^{331}$

Der Enthusiasmus der späten 1970er-Jahre, in denen sich Politbüro-Mitglieder in afrikanischen Ländern die Klinke in die Hand gegeben hatten, flaute im Laufe

327 BArch Berlin, DC 20/I/4/6425, Direktive für das Vorsitzendentreffen der Gemeinsamen Kommission DDR/VRT, 12.4.1989, Fol. 1727.

328 Raia Mwema, „Kiwanda cha nguo Mbeya chageuzwa ghala la tumbaku“, 19.10.2011. raiamwema.co.tz/kiwanda-cha-nguo-mbeya-chageuzwa-ghala-la-tumbaku (Zugriff 6.10.2015).

329 BArch Berlin, DE 1/58694, Länderinformation VRT, o.D., S. 12.

330 BArch Berlin /DR 2/51008, Analysen Experteneinsatz im Ausland 1987/1989, Einschätzung zum Einsatz der KWZ- und WTZ-Experten der DDR in der VR Tansania, 1987, o.O., S. 4.

331 BArch Berlin, DR 2/51007, Leiter der Lehrergruppe der DDR in der VRT, „Fortschreibung des Jahresberichtes zum Studienjahr 1981/82“, Dar es Salaam, 2.6.1982. 
der 1980er-Jahre merklich ab. Das lag nicht nur daran, dass die aufkommende Friedens- und Entspannungspolitik sich auf Europa konzentrierte und der Fortgang der Weltrevolution in Afrika aus dem Blickpunkt rückte. Wie auch in westlichen Ländern kamen interne Analysen in der DDR zunehmend zu dem ernüchternden Schluss, dass die sozialistischen Experimente Angolas, Mosambiks und Äthiopiens keine gangbaren Entwicklungswege, sondern Sackgassen darstellten. $^{332}$ Die Zusammenarbeit der hoch verschuldeten Partnerländer mit dem Westen, um das wirtschaftliche Überleben zu sichern, schien nunmehr auch BeobachterInnen in der DDR alternativlos. ${ }^{333}$ Erwartungen, die ,jungen Nationalstaaten“ würden dem Fortschrittsmodell der „Ersten“ oder „Zweiten“ Welt folgen können, wichen pessimistischeren Argumentationssträngen, denen zufolge weder ein „Aufholen“ noch ein eigener Entwicklungsweg machbar sei.

Mit dem Ende der DDR wurden jene DDR-Experten und FreundschaftsbrigadistInnen, deren Tätigkeit von der BRD als „entwicklungspolitisch relevant“ eingestuft wurde, von GTZ, DED und dem Centrum für Internationale Migration und Entwicklung (CIM) übernommen. 1992 kaufte die GTZ das alte DDR-Botschaftsgebäude in Dar es Salaam auf. Kurz nach dem Fall der Mauer hatte Julius Nyerere im Rahmen eines Bonnaufenthalts zum ersten Mal die DDR besucht, inoffiziell. Ehemalige DDR-Diplomaten interpretierten diesen Besuch rückblickend als ein Plädoyer Nyereres für die weitere Existenz der DDR aber vermuteten auch, dass er womöglich die Zeichen der Zeit sah und Inspirationen für die anstehende politische Transition in Tansania suchte. ${ }^{334}$ Nyerere selbst bedankte sich im Januar 1990 tatsächlich per Brief bei Hans Modrow (zu diesem Zeitpunkt Vorsitzender des Ministerrates) und Gregor Gysi (im Dezember zum neuen Vorsitzenden der SED gewählt) für den Gedankenaustausch, dessen Ergebnisse er auch beim nächsten Treffen des Zentralkomitees der CCM vortragen wolle. Ein zentrales Problem für die DDR sah er darin, sozialistische Ideale im Zuge politischer Veränderungen zu verteidigen. Modrow versicherte er, einmal mehr die Distanz Tansanias zum Marxismus-Leninismus betonend:

[I]t is important that my colleagues in our Party understand something of what is happening in a country with which we have always had cordial relations, and with which we hope to continue to have the same friendship in the future. For we too are a One Party State: your

332 Schleicher, Afrika in der Außenpolitik der DDR, 18-20.

333 Ebd.

334 Interviews \#110 und \#116 mit ehemaligen DDR-Diplomaten, E-Mail eines ehemaligen DDRDiplomaten an den Autor, 1.10.2015. 
experience is relevant to us despite the differences in the ideological underpinning of the socialism espoused by both your Party and mine. ${ }^{335}$

Die wirtschaftliche Liberalisierung in Tansania war zu dieser Zeit längst eingeleitet. Diskussionen dazu hatten freilich schon ein Jahrzehnt zuvor begonnen, auch in der BRD.

\section{„Entideologisierung“ und „Politikdialog“}

Der Diskurs nachholender Entwicklung, der eine Konvergenz auf globaler Ebene vorausgesagt hatte, löste sich ab Mitte der 1970er Jahre in Wohlgefallen auf. ${ }^{336}$ 1977 kam es in entwicklungspolitischen Institutionen der BRD zu einer Debatte um die Erfolgsaussichten des tansanischen Entwicklungsmodells und die Rolle bundesdeutscher Unterstützung. Tansania spielte in diesen Diskussionen eine zentrale Rolle. Die proklamierte Ujamaa-Politik wurde dabei gleichermaßen als unumgänglicher Ausgangspunkt wie auch als Beeinträchtigung der Projektarbeit wahrgenommen. Als besonders problematisch galt der Einfluss der Partei auf die Verwaltung (eine technokratische Perspektive, die dem Prinzip der ,führenden Rolle der Partei“ in der DDR wie in Tansania entgegenstand). ${ }^{337}$ In der Debatte griffen westdeutsche Beamte nicht nur auf Statistiken über Produktionsrückgänge, sondern auch auf ihre Eindrücke zurück, dass sie während ihrer Dienstreisen auf eine passive bäuerliche Bevölkerung gestoßen seien. Es sei eine Sache, dass die tansanische Politik „die ,kapitalistische“ Motivation, d.h. das Gewinnstreben des Einzelnen“ nicht anerkenne, aber gleichzeitig sei es weder Tansania noch irgendeinem anderen Land gelungen, diese durch eine „andersgeartete Motivation [...], die einen ausreichenden Anreiz darstellen würde“, zu ersetzen. ${ }^{338}$ Diese Diskussion war ein frühes Anzeichen des neuentbrannten Streits um die entwicklungspolitische Gretchenfrage: Markt oder Staat, laissez-faire oder Interventionismus.

335 Nyerere an Modrow, Butiama, 23.1.1990; Nyerere an Gysi, Butiama, 24.1.1990. Kopien beider Briefe im Besitz des Verfassers. Ich danke Ulrich van der Heyden für die Bereitstellung der Dokumente.

336 Ziai, Globale Strukturpolitik, 99-100.

337 BArch Koblenz, B 213/33065, Hildenbrand (GTZ), Arbeitspapier: Beurteilung der politischen Situation in Tansania und ihre Auswirkungen auf die durch die BRD geförderten Projekte, o.O., 27.1.1977.

338 BArch Koblenz, B 213/33065, Rosenthal (BMZ), Vermerk, Bonn, 29.3.1977, S. 4. 
Als sich die Beziehung zwischen Tansania und den internationalen Finanzinstitutionen verschlechterte, ließ die BRD Gelder vorerst weiter fließen. 1979, nur einige Monate, nachdem Nyerere die IWF-Delegation aus dem Land geworfen hatte, sagte die BRD die Finanzierung weiterer großer Projekte $\mathrm{zu}^{339}$ Tansania blieb für das Auswärtige Amt ein bedeutender Mittler in der Region, „dem bei unseren Bemühungen um friedliche Konfliktlösungen im südlichen Afrika eine Schlüsselrolle zukommt", womit auch Entschuldungsmaßnahmen sowie technische und finanzielle Hilfe legitimiert wurden, um das Verhältnis nicht zu belasten. ${ }^{340}$ Innerhalb der GTZ diskutierten zwei Fraktionen - die „Entwicklungspolitiker“ und die „Ökonomen“ - während der 1980er Jahre, ob Entwicklungshilfe und Unternehmertum kompatibel waren oder nicht. Die GTZ machte den BMZSchwenk zur Exportförderung 1982 unter der Devise, Entwicklungshilfe „im Interesse des deutschen Volkes“ zu gestalten, vorerst nicht mit. Die „Entwicklungspolitiker“ wehrten sich, als „Lobbyisten der deutschen Industrie“ instrumentalisiert zu werden. ${ }^{341}$

Im Zuge des Wechsels zur schwarz-gelben Regierung unter Helmut Kohl 1982 setzten sich die kritischen Einschätzungen zu Ujamaa jedoch mehr und mehr durch. Tansanias Entwicklungsmodell galt nun als Irrweg. ${ }^{342}$ Die bundesdeutsche Regierung fuhr die Zusagen für finanzielle Zusammenarbeit zwischen 1982 und 1984 von DM 100 Mio. auf DM 30 Mio. mit Verweisen auf die fehlgeleitete Währungs-, Wirtschafts- und Genossenschaftspolitik zurück, ohne dabei auf entschiedenen Gegenwind aus der parlamentarischen Opposition oder den Tansania traditionell freundlich gesinnten Kirchen $\mathrm{zu}$ stoßen. ${ }^{343}$ Auch in geopolitischer Hinsicht war Tansania nunmehr marginal. Nyereres politischer Einfluss in der Region sank, als sich der Schwerpunkt des Befreiungskampfes in den Süden nach Sambia, Angola und Mosambik verlagerte. ${ }^{344}$ Frühere politische Argumente für die Unterstützung Tansanias verloren ihre Zugkraft, ökonomische Motive hatten ohnehin nie eine ernst zu nehmende Rolle gespielt. Als CSU-Politiker Jürgen

339 Edwards, Toxic Aid, 105-106. Dazu gehörten ein Wasserkraftwerk in Arusha, Straßenbau in Usambara und Lokomotiven für die TAZARA.

340 PAAA, ZW 125228, Schreiben des AA betr. Finanzielle Zusammenarbeit mit Tansania vom 4.7. 1979, S. 1.

341 Köhler, Mittler zwischen den Welten, S. 104, 134.

342 Köhler, Stellenwert Tanzanias, S. 26.

343 Engel, Die Afrikapolitik, S. 71.

344 Das Nkomati-Friedensabkommen zwischen den Regierungen von Mosambik und der Republik Südafrika sowie eine generell konziliantere Haltung der (v. a. westlichen) internationalen Gemeinschaft gegenüber dem Apartheidregime, das so seine Macht stabilisieren konnte. Siehe PAAA, AV Neues Amt 13470, Vermerk BRD-Botschafter Kremer über Abschiedsbesuch bei Präsident Nyerere am 26.5.1984, Dar es Salaam, 28.5.1984. 
Warnke das Amt des Entwicklungsministers (1982-1987 und nochmals 1989-91) übernahm, schlug das Pendel entwicklungspolitischer Konjunktur, zumindest rhetorisch, deutlich in Richtung wirtschaftlicher Eigeninteressen aus. ${ }^{345}$ Im Kontext der größten weltwirtschaftlichen Rezession seit 1945 und steigender Arbeitslosenzahlen setzte Warnke die „Beschäftigungswirksamkeit“ der Entwicklungspolitik - womit er die Wirksamkeit in der BRD, nicht in den ebenfalls von Arbeitslosigkeitsproblemen geplagten Ländern wie Tansania meinte - ganz oben auf die Agenda. ${ }^{346}$ Als neues Prinzip für die Beziehungen mit den „Entwicklungsländern“ diente neben der Beschäftigungswirksamkeit der euphemistisch betitelte „Politikdialog“, der eine „Entideologisierung“ anstrebte. Warnke verstand unter seinem Programm der „Entideologisierung“, links orientierten Regierungen wie den Sandinisten in Nicaragua die Unterstützung zu entziehen, aber sowohl die Durchsetzung sozial kostspieliger Strukturanpassungsprogramme als auch die Kooperation mit rechten Diktatoren als unideologisch und moralisch vertretbar darzustellen. ${ }^{347}$ An Tansania sollte diese „Entideologisierung“ exemplarisch durchexerziert werden. Wie Warnke 1986 in einem Interview mit dem Spiegel darlegte, habe die BRD ,der [tansanischen] Regierung klargemacht, dass das mit innertansanischen Fehlentwicklungen zu tun hatte“; die Bundesregierung sei dann infolge der wirtschafspolitischen Neuorientierung mit Zusagen von DM 100 Mio. „an die Spitze getreten“ und habe so auch „die anderen Geber zu größeren Leistungen gebracht“. Für Warnke war Tansania damit „ein Musterbeispiel für jenes politische Gespräch, den Politikdialog, den wir mit unseren Partnerländern führen. Nicht darüber, wie sie sich ideologisch auszurichten haben, sondern über die Rahmenbedingungen wirksamer Entwicklungshilfe“. 348

„Rahmenbedingungen“ bezogen sich in dieser Lesart immer auf die nationale Politik; die ungleichen Nord-Süd-Beziehungen, die die Diskussionen der 1970erJahre dominiert hatten, wurden ausgeblendet. Der „Politikdialog“ fand unter denkbar ungleichen Bedingungen statt. 1983 teilte ein Vertreter des BMZ dem tansanischen Außenminister Salim A. Salim unmissverständlich mit, dass die Bundesregierung beschlossen habe, die jährlichen Mittel für Tansania um ein Drittel zu kürzen, bis auf die Reformforderungen eingegangen werde. ${ }^{349}$ Die „Freisetzung der Marktkräfte“ galt nunmehr als Grundvoraussetzung für die

345 Siegfried Pater, Stichwort: Wende. Konservative Entwicklungspolitik seit den Achtzigern, 2., vollst. überarb. Aufl., Bad Honnef 1990.

346 BArch Koblenz, B 102/216260, Steeg an Minister für Wirtschaft, 1.5.1978, S. 111-113.

347 Ziai, Globale Strukturpolitik, S. 100-101.

348 So Entwicklungsminister Jürgen Warnke in einem Interview in Der Spiegel 46/1986, S. 63. 349 Köhler, Zum Stellenwert Tanzanias, S. 27-28. Siehe zum Konflikt zwischen Malima und dem IWF auch Edwards, Toxic Aid, S. 97-101, 120, 135-140. 
„Zusammenarbeit“ mit Tansania. ${ }^{350}$ Hierbei handelte es sich keinesfalls nur um Rhetorik, sondern um die Legitimierung von Interventionen, die die Souveränität Tansanias infrage stellten. Derartige Eingriffe in die politische Entscheidungshoheit Tansanias hatte die BRD zuletzt 1965 vorgenommen und war auf unerwarteten Widerstand gestoßen. Im April 1984 demonstrierte Minister Warnke die Macht der BRD und ließ die planmäßigen zweijährlichen Verhandlungen kurzfristig platzen. ${ }^{351}$ Ein halbes Jahr später reiste Planungsminister Kighoma Malima für die neu angesetzten Verhandlungen nach Bonn, war aber - in der retrospektiven Betrachtung eines BMZ-Beamten - „ideologisch so stark fixiert, dass sich keine Verhandlungsspielräume ergaben“. ${ }^{352}$

1985, als auch die skandinavischen Länder die Daumenschrauben angezogen hatten und Nyerere das Präsidentenamt für den reformwilligen Ali Hassan Mwinyi geräumt hatte, war die BRD dann unter den ersten Gebern, die den Reformkurs materiell unterstützen (und sich so profilieren) wollten. Seit der Unabhängigkeit war die BRD von allen DAC-Gebern schon immer unter den wichtigsten gewesen, aber 1985 trat sie in der geradezu heroisierenden Formulierung Warnkes ,an die Spitze“ und erleichterte anderen Gebern die Entscheidung, in ihrem Windschatten $\mathrm{zu}$ folgen. Obwohl die tansanische Regierung den Reformvorgaben keineswegs schnurstracks folgte, blieben weitere groß angelegte Disziplinierungsmaßnahmen der Geber aus. Gerade im Fall der konservativen BRD-Regierung, die sich immer wieder für ihre Unterstützung rechter Regime rechtfertigen musste, scheint Tansanias Rolle hier einmal mehr gewesen zu sein, neben Mosambik und Äthiopien ein „linkes“ Gegengewicht im Portfolio darzustellen, zumal Warnke sich von seinem naiven Schrecken vor dem „Afrikanischen Sozialismus“ schrittweise emanzipierte. ${ }^{353}$ Warnkes Nachfolger Hans Klein (CSU, 1987-1989), der Tansania in einem Atemzug mit dem marxistisch-leninistischen Äthiopien nannte, läutete jedoch eine neue Runde antikommunistischer Rhetorik ein. Genauso ahnungslos oder desinformiert wie Warnke einige Jahre zuvor besuchte Klein Tansania als eins der vermeintlich ,ideologisch nach dem Ostblock orientierte[n]“ Länder Afrikas, um zu begutachten, wie weit der Prozess, das „marxistische Strukturgerüst ihrer Wirtschaft, aber auch ihrer Politik aufzulockern“,

350 BMZ, B 213/63790, Tansania Allgemeines Heft 5, BRD-Botschaft Tansania, Koordinierung der Entwicklungs- und Außenwirtschaftspolitik in Tansania, o.D. [1987].

351 Rolf Hofmeier, Aid from the Federal Republic of Germany to Africa, in: The Journal of Modern African Studies 24/4 (1986), S. 577-601, hier: S. 591.

352 Köhler, Zum Stellenwert Tanzanias, 28

353 Hofmeier, Aid, S. 592. 
gediehen war. ${ }^{354}$ Die BRD-Botschaft kam 1987 zum Schluss, dass die westliche Entwicklungshilfe insgesamt einen großen Unterschied gemacht habe, nahm dabei allerdings nicht die Auswirkungen von „Hilfe“ auf die „Entwicklung“, sondern auf die Politik Tansanias zum Maßstab:

Die in Tansania engagierten westlichen Geber haben im Laufe der vergangenen 20 Jahre erheblichen Einfluss auf die Durchführung und auch auf die Formulierung der tansanischen Entwicklungspolitik genommen. Teilweise haben sie das tansanische Entwicklungsmodell höher stilisiert als die tansanische Regierung selbst. So haben die Empfehlungen von Weltbank und Währungsfonds die Wirtschaftspolitik spürbar beeinflusst. Die Entscheidung über die Durchführung der zahlreichen Projekte in den ersten beiden Entwicklungsdekaden ist wesentlich von den Gebern beeinflußt worden. Daraus folgt, daß, wenn man die Ansicht vertritt, das tansanische Entwicklungsmodell sei gescheitert, dem Westen eine Mitverantwortung zuzuschreiben ist. Dieser Mitverantwortung entsprechen die meisten westlichen Länder mit großzügigen Hilfezusagen nach der Einigung Tansanias mit dem IWF. ${ }^{355}$

Der Ton in den bilateralen Beziehungen änderte sich spürbar, da die tansanischen Reformkräfte auf externe Unterstützung für ihren intern immer wieder angefochtenen Kurs angewiesen waren. Erstmals schlug ein tansanischer Präsident sogar in aller Öffentlichkeit kolonialnostalgische Töne an. Auf einem BRD-Besuch 1988 äußerte Mwinyi sein Bedauern, dass „die guten Deutschen“ den Ersten Weltkrieg (und damit Deutsch-Ostafrika) verloren hatten; die Kolonialherrschaft stellte er als Ursprung der „Freundschaft“ mit Deutschland dar, die nun in einen neuen Marshallplan für Tansania münden solle. ${ }^{356}$ DDR-Berater im Planungsministerium berichteten, dass diese Anbiederung des neuen Präsidenten an die BRD unter seinen tansanischen KollegInnen für Irritationen sorgte und sehnsuchtsvolle Erinnerungen an Nyerere weckte, wie dieser 1965 bundesdeutschen Erpressungsversuchen die Stirn geboten und so die Souveränität des Landes verteidigt hatte. ${ }^{357}$ Diese Nostalgie war ein deutliches Anzeichen für die bereits Dekaden anhaltende Bedeutung der Entwicklungspolitik, aber auch für ihre Dynamik.

354 Privatarchiv S. R., [ohne Ordner], Deltgen, Interview mit Bundesminister Hans Klein, o.O., o.D. [1988], S. 4.

355 BMZ, B 213/63790, BRD-Botschaft, Entwicklungspolitischer Zweijahresbericht Tansania, Dar es Salaam, August 1987, S. 25.

356 SAPMO BArch Berlin, DY 30/15207, Leitung der GO der SED in der VRT an Leiter der Abt. Int. Verbindungen im ZK der SED, Dar es Salaam, 20.9.1988.

357 BArch Berlin, DE 1/57846, H. R., Halbjahresbericht für den Zeitraum Juni - November 1988, 15.11.1988. 


\section{Fazit}

In der Phase der Emergenz ab 1958 hatten sich Kontakte zwischen Tanganjika bzw. Sansibar und den beiden deutschen Staaten langsam verdichtetet. In den folgenden Jahren bildeten sich nicht nur persönliche Verbindungen heraus, sondern auch entwicklungspolitische Institutionen und Instrumente in DDR und BRD, die Transfers von Ressourcen in Form von Kapital (im Falle der DDR äußerst selten), Ausrüstung, Waren, Personal und Ausbildungsplätzen zu politisch ausgehandelten Bedingungen bewerkstelligten und kontrollierten. In dieser Ähnlichkeit spiegelt sich das geteilte Verständnis für Modernisierungsprozesse sowie der Konkurrenzcharakter: Auf beiden Seiten galten diese Instrumente zugleich als probate Mittel in der Systemauseinandersetzung. Ebenso wie „Entwicklungshilfe“ der kommunistischen Expansion Einhalt gebieten sollte, war auch die „sozialistische Hilfe“ Mittel zur Bekämpfung des westlichen Imperialismus. Dabei lässt sich nicht davon ausgehen, dass Akteure in kommunistischen Staaten wie der DDR in entwicklungspolitischer Hinsicht nur reagierten und sich bereits entstehenden Normen und Spielregeln der „neokolonialen Entwicklungshilfe“ anpassten. ${ }^{358}$ Es handelte sich um ein mehr- und wechselseitiges Verhältnis, in dem Forderungen aus Ostafrika einerseits sowie gegenseitige Wahrnehmungen von Ost und West andererseits Konkurrenzeffekte erzeugten. Für Akteure in Tansania war es damit in den Folgejahren möglich, sich die bipolare Weltsicht im globalen Norden zunutze zu machen, ohne sie zu teilen.

Von 1964 bis 1970 trugen die deutschen Staaten ihre Rivalität mit erheblichem Mittelaufwand auch in Ostafrika aus, nachdem sansibarische Politiker den Kontakt zur DDR gesucht hatten. Die Erfahrungen, die verschiedene Gruppen in beteiligten Staaten in der Zeit der Konkurrenz sammelten, führten zu Neubewertungen und Neuorientierungen. Die Anwendung der Hallstein-Doktrin durch die BRD trug fraglos zu Nyereres Betonung nationaler self-reliance bei und stärkte ihn in seiner Strategie, die äußeren Beziehungen $\mathrm{zu}$ diversifizieren. ${ }^{359}$ Als Nyerere demonstrativ den Abzug aller Hilfe forderte, lernte man im Auswärtigen Amt nicht nur, dass ein direkter Eingriff in die Entscheidungshoheit souveräner Staaten, unintendierte Gegenreaktionen hervorrufen konnte, sondern auch, dass die eigene Macht beschränkt war. Einzig der eigenen wirtschaftlichen Muskelkraft, gepaart mit den den Fehlschlägen der DDR in Sansibar war es geschuldet, dass die

358 So etwa Sara Lorenzini, The Dilemmas of Solidarity - East German Policies in Africa in the Age of Modernization, in: Berthold Unfried/Eva Himmelstoss, Hg., Die eine Welt schaffen: Praktiken von „Internationaler Solidarität“ und „Internationaler Entwicklung“, Leipzig 2012, S. 57-71, hier: S. $70-71$.

359 Engel/Schleicher, Die beiden deutschen Staaten, S. 174. 
BRD in Tansania nicht noch mehr an Boden verlor. In der DDR realisierten Diplomaten und FunktionärInnen verschiedener Institutionen durch das Intermezzo in Sansibar eigene Schwächen und die Abhängigkeit von den Interessenslagen im Partnerland. Nach den postrevolutionären Flitterwochen verkam die „Freundschaft“ mit Karume, der keinerlei Nähe zum wissenschaftlichen (oder Afrikanischen) Sozialismus bewiesen hatte, zu einer Zweckbeziehung, die schon sechs Jahre nach der Revolution in die Brüche ging. Auffällig sind dabei die Parallelen zwischen dem DDR-Sansibar-Intermezzo und den Beziehungen zwischen der Sowjetunion und Ghana und Guinea Anfang der 1960er-Jahre. Wie die DDR in Sansibar war die UdSSR nicht den „klassisch“ marxistisch-leninistischen Weg über den Aufbau einer Kaderpartei gegangen, sondern hatte - in Übereinstimmung mit den Intentionen Sekou Tourés und Kwame Nkrumahs - eine primär wirtschaftliche Modernisierungsstrategie verfolgt. Wie in Sansibar führten gescheiterte Projekte in diesen Ländern zu einer Desillusionierung auf afrikanischer Seite. Wie DDR-Akteure legten auch sowjetische Entscheidungsträger nach diesen „Fehlinvestitionen“ in Westafrika größeres Augenmerk auf die ideologische Positionierung der unterstützten Regierungen. ${ }^{360}$ Ein ähnlich umfangreiches Engagement auf dem afrikanischen Kontinent wagte die DDR erst wieder ab 1977, allerdings nicht in Tansania, sondern in Staaten, deren Regierungen eindeutige Nähebekenntnisse zum sowjetischen Lager abgaben.

In Tansania folgte zuerst die Phase einer friedlichen Koexistenz der beiden deutschen Staaten. Zwar bestand die deutsch-deutsche Rivalität fort, aber sie wirkte sich nach dem Ende der Hallstein-Doktrin kaum noch auf die Entwicklungspolitik in Tansania aus. Die BRD verfolgte nun nicht mehr die Verdrängung „Pankows“, die Leitlinie ab 1970 lautete, mit der DDR in den „Wettbewerb“ zu treten. ${ }^{361}$ Mit den 1970er-Jahren hatten sich auch die entwicklungspolitischen Institutionen und Instrumente in den deutschen Staaten verfestigt - die Dynamik der 1960er Jahre, in der Organisationen und Initiativen aus dem Boden sprossen und um Kompetenzen rangelten, war nunmehr erlahmt, die bundesdeutsche Entwicklungsbürokratie verknöcherte zusehends. Entgegen der ständigen Reformulierung und scheinbaren Innovation westlicher Entwicklungskonzepte blieb organisatorisch das meiste beim „business as usual“.

360 Alessandro Iandolo, The Rise and Fall of the 'Soviet Model of Development' in West Africa, 1957-64, in: Cold War History 12/4 (2012), S. 683-704, hier: S. 703-704.

361 Diese Linie hatte eine Sansibar-Delegation dem Auswärtigen Amt schon 1966 in Bezug auf das DDR-Engagement in Sansibar vorgeschlagen, war aber an der Ansicht des AA gescheitert, dass Nyerere die Konsequenzen für sein Fehlverhalten spüren solle. Kilian, Die Hallstein-Doktrin, S. 216-217. 
Die Phase der Konvergenz war durch zwei Trends geprägt. Die Öl- und Konjunkturkrise führte in allen beteiligten Staaten zu einer stärkeren Ökonomisierung ihrer Entwicklungspolitik. Gleichzeitig lässt sich aber auch eine Politisierung der Entwicklungspolitik ausmachen, die vom wieder aufflammenden Ost-West-Konflikt ausging. Dass es sich trotzdem um eine Ära der Konvergenz handelt, zeigt nicht nur die Kooperation west- und ostdeutscher Unternehmen in Tansanias Textilindustrie, sondern auch die Tatsache, dass es in allen Ländern zu ähnlich gelagerten Debatten über die Entwicklungspolitik kam. In Tansania, der BRD und der DDR gab es Konflikte zwischen „ÖkonomInnen“ oder „AußenhändlerInnen“, die in erster Linie auf volkswirtschaftliche Nutzeffekte abzielten und den Solidaritäts- und EntwicklungspolitikerInnen, die sozialen und politischen Zielstellungen Vorrang einräumten. In allen Ländern sollten die wirtschaftlich orientierten Kräfte schließlich die Oberhand gewinnen. Ihre GegnerInnen stemmten sich gegen den Trend und versuchten einmal mehr, globale Rivalitäten und transnationale Netzwerke zur Ressourcenmobilisierung zu nutzen. Der Ujamaa weiterhin verteidigende Flügel in Tansania versuchte durch eine Revitalisierung der Beziehungen zu den RGW-Ländern das Wegbrechen der westlichen Unterstützung zu kompensieren. Aufgrund der stärker ökonomisierten Vergabepraxis (und später auch dem „Neuen Denken“ in diesen Ländern, das jedem Prestigebedürfnis eine Absage erteilte), verzeichnete dieses Vorgehen kaum Erfolge. ${ }^{362}$ Das entscheidende Problem zwischen der DDR und Tansania war ihre strukturelle, in mancher Hinsicht ähnliche Position vis-a-vis dem kapitalistischen Zentrum. Beide Länder hatten mit einem chronischen - und zunehmend systemgefährdenden Devisenmangel zu kämpfen. Während es der DDR gelang, dieses währungspolitische Problem im Falle von Beziehungen mit Staaten wie Äthiopien (Kaffee) oder Angola (Kaffee, Erdöl) durch außenwirtschaftspolitische Instrumente wie den Tauschhandel ohne Einsatz harter Währung zumindest zeitweilig zu umgehen, ${ }^{363}$ konnte Tansania aufgrund der eigenen Verschuldung keine vergleichbaren Vereinbarungen abschließen. Die Krise und anschließende Implosion des Staatssozialismus in Osteuropa bedeutete für die Regierung in Tansania, wie in anderen Ländern des globalen Südens, eine verringerte Manövrierfähigkeit. ${ }^{364}$ In der BRD

362 Zum „Neuen Denken“ siehe Schleicher, Afrika, S. 27-28.

363 Anne Dietrich, Zwischen solidarischem Handel und ungleichem Tausch. Zum Südhandel der DDR am Beispiel des Imports kubanischen Zuckers und äthiopischen Kaffees, in: Journal für Entwicklungspolitik 30/3 (2014), S. 48-67; dies., Kaffee in der DDR - „Ein Politikum ersten Ranges“, in: Christiane Berth u.a., Hg., Kaffeewelten: Historische Perspektiven auf eine globale Ware im 20. Jahrhundert, Göttingen 2015, S. 225-248.

364 Jude Howell, The End of an Era: The Rise and Fall of G.D.R. Aid, in: Journal of Modern African Studies 32/2 (1994), S. 305-328, hier: S. 328. 
wie in der DDR gab es nun kaum noch Akteure, die eine Konvergenz von Lebensstandards zwischen dem globalen Süden und dem industrialisierten Norden erwarteten: Länder wie Tansania wurden zwar immer noch durch das Paradigma aufholender Entwicklung betrachtet, aber galten als weit abgeschlagen. In dieser Hinsicht war die Phase der Konvergenz gleichzeitig auch ein Zeitalter der ReDistanzierung.

Diese Geschichte von Emergenz, Konkurrenz, Koexistenz und Konvergenz auf dem entwicklungspolitischen Feld, die im Zeitalter des Imperialismus wurzelt, ist insbesondere durch die personellen Verflechtungen eine geteilte Geschichte. Die Personen, die zwischen Tansania, der BRD und der DDR zirkulierten - Studierende, FreundschaftsbrigadistInnen, Regierungsberater, EntwicklungsexpertInnen und KooperantInnen - sind Teil dieser Geschichte und haben sie mit hervorgebracht. Die strukturellen Bedingungen und Heterogenität ihrer Motive, Handlungsspielräume und Erfahrungen stehen im Zentrum der folgenden zwei Kapitel. 